\title{
The Grrrls are All Write: The Role of Zines in Third-Wave Feminism
}

\author{
by \\ Tara Westover \\ A thesis submitted to the Faculty of \\ Graduate Studies and Research in partial fulfilment \\ of the requirements for the degree of \\ Master of Arts \\ in Canadian Studies
}

The School of Canadian Studies

Carleton University

Ottawa, Ontario

I4 May 2008

(cc) 2008 Tara Westover, Some Rights Reserved

Except where otherwise noted, this work is licensed under Creative Commons

Attribution ShareAlike 3.0 


$\begin{array}{ll}\begin{array}{l}\text { Library and } \\ \text { Archives Canada }\end{array} & \begin{array}{l}\text { Bibliothèque et } \\ \text { Archives Canada }\end{array} \\ \begin{array}{l}\text { Published Heritage } \\ \text { Branch }\end{array} & \begin{array}{l}\text { Direction du } \\ \text { Patrimoine de l'édition }\end{array} \\ \begin{array}{l}\text { 395 Wellington Street } \\ \text { Ottawa ON K1A 0N4 } \\ \text { Canada }\end{array} & \begin{array}{l}\text { 395, rue Wellington } \\ \text { Ottawa ON K1A 0N4 } \\ \text { Canada }\end{array}\end{array}$

Your file Votre référence ISBN: 978-0-494-40618-2 Ourfile Notre référence ISBN: 978-0-494-40618-2

NOTICE:

The author has granted a nonexclusive license allowing Library and Archives Canada to reproduce, publish, archive, preserve, conserve, communicate to the public by telecommunication or on the Internet, loan, distribute and sell theses worldwide, for commercial or noncommercial purposes, in microform, paper, electronic and/or any other formats.

The author retains copyright ownership and moral rights in this thesis. Neither the thesis nor substantial extracts from it may be printed or otherwise reproduced without the author's permission.
AVIS:

L'auteur a accordé une licence non exclusive permettant à la Bibliothèque et Archives Canada de reproduire, publier, archiver, sauvegarder, conserver, transmettre au public par télécommunication ou par l'Internet, prêter, distribuer et vendre des thèses partout dans le monde, à des fins commerciales ou autres, sur support microforme, papier, électronique et/ou autres formats.

L'auteur conserve la propriété du droit d'auteur et des droits moraux qui protège cette thèse. $\mathrm{Ni}$ la thèse ni des extraits substantiels de celle-ci ne doivent être imprimés ou autrement reproduits sans son autorisation.
In compliance with the Canadian Privacy Act some supporting forms may have been removed from this thesis.

While these forms may be included in the document page count, their removal does not represent any loss of content from the thesis.
Conformément à la loi canadienne sur la protection de la vie privée, quelques formulaires secondaires ont été enlevés de cette thèse.

Bien que ces formulaires aient inclus dans la pagination, il n'y aura aucun contenu manquant.

\section{Canada}




\section{Abstract}

Zines are important but under-documented sites of resistance for third-wave feminists and other activists. Zines are effective in countering contemporary oppressions because they avoid suppressive tactics, such as the commodification of resistance that occurs in late capitalism. Though zines are a novel form of feminist publishing, they draw on a history of second-wave feminist publishing. While the second and third waves may seem disparate, by considering the environments in which these movements functioned, I contend that these differences are superficial and reflect changed contexts of oppression, rather than changed aspirations. By considering zines within the framework of Bhabha's theory of cultural resistance, I show how zines upset social hierarchies that marginalise some groups by allowing for counter narratives; zines create non-physical space for marginalised people to gather and develop resistance according to third-wave principles of inclusiveness, accessibility and non-hierarchy. To support this idea, I rely on a sample of zines from the Ottawa area and a sample of second-wave feminist newspapers from the Canadian Women's Movement Archives, as well as a questionnaire distributed to zine makers. 


\section{Acknowledgements}

Thank you to all of the zine makers who participated in this research - your enthusiasm and insights were invaluable and inspiring.

Thank you to my supervisor, Patrizia Gentile, for all of your patience and perseverance - your willingness to listen to my crazy ideas and energy to direct them into something coherent made this whole thing work.

Thank you to my second reader, Pauline Rankin, for your dedication, work and mad proofreading skills.

Thank you to the following people for your care, support and encouragement. There were many times when I thought I might not get this done; you convinced me otherwise: Sara Young, Hillary Westover, Oren Howlett, Phil Winch, Sean Zio, Mary Casaubon and my family. A special thank you to my partner, Tristan Winch, for all of your support - emotional, academic and house-work related. 


\section{Table of Contents}

List of Illustrations

$\mathbf{v}$

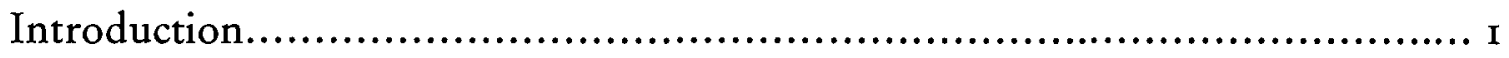

Chapter I:

Conspicuous Production: The Origins and Context of Third-Wave Publishing....

I4

Chapter 2:

Grrrls Just Wanna Have Printruns: Feminist Publishing Across the Waves..........

47

Chapter 3:

Resisting Commodification: Zine Tactics for Avoiding the Commodification of

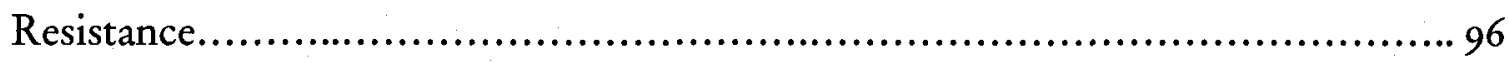

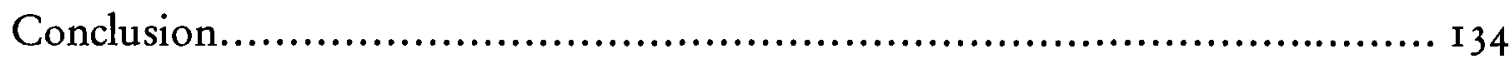

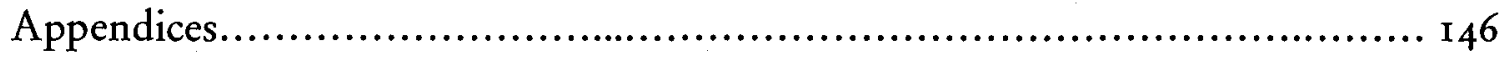

Works Cited.................................................................. 149 


\section{List of Illustrations}

Figure ra: Recommended publications in a second-wave newspaper

Figure $\mathrm{Ib}$ : Recommended publications in zines

Figure 2: Author acting as an expert in a zine

Figure 3: Geographic imagery in a zine

Figure 4: Women-only space being challenged in an second-wave newspaper

Figure s: An introductory piece in a zine

Figure 6: A "soundtrack" in a zine

Figure 7a: Calls for submissions in second-wave newspapers

Figure $7 \mathrm{~b}$ : Calls for submissions in zines

Figure 8a: Sexual health article in a second-wave newspaper

Figure 8b: Sexual health article in a third-wave zine

Figure 9a: Article countering violence against women in a second-wave newspaper

Figure 9b: Comic countering violence against women in a zine

Figure Io: Response to anti-feminist backlash in a third-wave zine

Figure I I: Anti-consumerism comic in a zine

Figure I 2: A survey of different zine styles

Figure I 3 : Collage work in zines

Figure I4: Critique of mainstream media in a zine

Figure I 5 : Instructions for making a zine, in a zine

Figure I6: Drawing connections to historic resistance in a zine

Figure 17: The Why Cheap Art? Manifesto

Figure I 8: Unconventional writing style in a zine 


\section{Introduction}

Fredric Wertham defines fanzines as "uncommercial, nonprofessional, smallcirculation magazines which their editors produce, publish, and distribute" (33). He cites the 1930 publication of The Comet as the first amateur fan magazine, a genre which focused on fantasy, adventure, science fiction and comic books $(38,44) .{ }^{\mathrm{I}}$ The term fanzine (later shortened to 'zine, and then zine), was a contraction of "fan magazine," and was used to describe such science fiction publications, in contrast to "prozines," which paid their writers (Gunderloy \& Goldberg 2). This first wave of zines was followed by a second surge in zine making by comic fans in the early I960s. Comic fans produced underground comix on the type of printing equipment used for newsletters (Robbins I 26). These zines are notable in that they contained original material, along with fan pieces that commented on professional work.

Those looking to find the origins of today's zines turn to the early I 980 , when punks started generating publications. ${ }^{2}$ These zines focused mostly on music, and were again created by fans (Gunderloy \& Goldberg 2). The zines that I analyse in this thesis evolved from this tradition of punk music zines. Zine makers, especially girl and women zine makers, started writing less about punk music and more about their own lives and other topics. Generally, these zines focus on topics that are excluded from, or only narrowly represented in, mainstream media. Such zines are a space for alternative perspectives. Consequently, they have drawn people whose experiences and voices are marginalised, including third-wave feminists. ${ }^{3}$

Trina Robbins defines zines as self-published, photocopied "minimagazines." Stephen Duncombe adds that they are "non-commercial," and "nonprofessional," and distributed by selling, gifting or swapping, usually through mail.' These do-it-yourself (DIY) tactics allow zines to function outside of consumer and 
capitalist models, extending their reach to less privileged people. ${ }^{6}$ Because they are self-produced, they also are able to circumvent the censoring aspects of commercial media - zine makers don't need to take profits into consideration when deciding on their content. All of these factors work to encourage both the creation and distribution of zines by less privileged people.

While Duncombe notes that zines have limited reach (with an average 250 copies per issue; Robbins claims print runs range from 30 to 5000 copies), he believes the reach of zines to be more significant than this number implies, due to the number of individual zines, which varies from I0,000 to 50,000 at any given time in the United States (Duncombe, “Alienated Together" 427; Robbins I 26). Mike Gunderloy and Janice Cari Goldberg estimate the total audience of zines to be in the millions (I). As such, while any one zine may reach only a small number of people, collectively they are a significant phenomenon.

Because of the ease with which zines can be created and distributed (as opposed to publishing in mainstream media), many marginalised groups and individuals find them a useful method for distributing information. Third-wave feminists, in particular, make use of zines for a number of activist projects. But because many of these projects, including zine making itself, occur outside of mainstream structures, third-wave activisms are not as visible, or easily understandable as a cohesive strategy of resistance, as are the activisms of previous waves of feminism in retrospect.

Robin Kelley, in his discussion of unorganised worker resistance against McDonald's restaurants in the late I970s, calls for a redefining of what is considered political and what are considered "authentic" movements or strategies of resistance. Kelley questions the assumption that only certain types of resistance, organisations 
and ideologies can represent marginalised groups (98). In his case, he submits that the assumption that workers' struggles must be located within labour organisations "disregards diversity and conflict within groups" while presuming that "the only struggles that count take place through institutions" (98-99). Kelley claims that "the so-called margins of struggle," including unorganised resistance, are "a fundamental part of the larger story waiting to be told" (99). This proposition - that resistant movements themselves have margins, and that the resistance that takes place at these margins is valuable - acknowledges non-institutional and unorganised resistance, such as that in which many third-wave feminists participate.

\section{Goals and scope of this thesis}

This thesis examines how zines work as an element of resistance and activism in third-wave feminism. Third wavers find themselves in a unique situation: they have the histories and products of first and second-wave publications on which to draw, yet they must also confront evolving contexts, such as increased social emphasis on consumerism and the ubiquity and narrowness of mainstream media. As such, they create novel means and strategies for resistance and activism, such as zines.

In this thesis, I highlight the spirited, determined and dedicated third-wave feminists whose work is often hidden, and thereby discounted. Third-wave strategies and tactics for fighting oppression and creating non-hierarchical space differ from those of previous movements, feminist and otherwise. It is easy to see contemporary feminists and activists, therefore, as passive and apathetic. By analysing their activism, and considering how the different contexts in which they work and resist result in altered strategies, I draw connections between the second 
and third waves of feminism and show continuities between their work. I argue that third wavers adapt strategies of resistance to meet new contexts of oppression, and choose novel and effective ways to counter those oppressions. They make use of what Homi Bhabha refers to as third space - a space outside of mainstream structures and dominant group hierarchies - to gather, form resistance and create strategies and tactics for action. When third-wave zines are viewed through the lens of Bhabha's theory on cultural resistance, their potential as a resistant tool is revealed.

This thesis focuses on the impact of mainstream media and culture on marginalised groups and people, and their resistance to this media and culture. While dominant groups and individuals also are negatively affected, and even damaged by dominant social standards and mainstream media, I have taken marginalised people and groups, particularly those marginalised by gender, race and sexuality, as my focus because it is these groups whom mainstream discourses frequently exclude, and mainstream media fail to represent.

I do not address the impact that the internet has had on zine makers and their products. While many still hold out hope that the internet will provide a democratised medium for marginalised voices, this goal remains largely unaccomplished. ${ }^{7}$ The internet exists as a space of mainly privileged access. ${ }^{8}$ What the internet can do is lower the costs of small publications, facilitate recruitment of readers, and circumvent censorship. ${ }^{9}$ In this, the internet is as much a tool as it is a medium. ${ }^{\text {to }}$ While I consider briefly how zine makers use this tool, a full examination of this, as well as of online zines and blogs, is beyond the scope of this thesis. 
Methodology

My analysis of zines employs what Shulamit Reinharz and Lynn Davidman refer to as multimethod research. In the case of zines, where I both collected and analysed zines and then circulated a questionnaire to zine makers, my goal was to combine "found" information with information that was "produced" specifically for this research (I48). By drawing on both types of information, I tested my conclusions about the "found" information by consulting with its authors (199). For my research on first- and second-wave newspapers and pamphlets, I drew on a wider range of secondary resources, in the form of articles and books, to supplement my analysis of the primary sources. Reinharz and Davidman assert that a multimethod approach "work[s] to enhance understanding both by adding layers of information and by using one type of data to validate or refine another" (201). By combining these various methods - synthesis and analysis of articles and books on first- and second-wave publications, consideration of second-wave newspapers and third-wave zines and a limited survey of zine makers - I was able to draw connections between marginalised people from different time periods, and be as thorough as possible in gathering information according to what suited that information, rather than what suited any one method of gathering it (197, 202, 21 3).

My thesis carefully examines the contemporary contexts that feminists face, drawing on theorists who critique mainstream media and consumerism, and the effects of these environments. To ground this work further in feminist histories, I consider the histories of first- and second-wave publishing. To explore the similarities and differences between second- and third-wave publications, I selected a geographically diverse assortment of second-wave newspapers from the Canadian Women's Movement Archives (CWMA), located at the University of Ottawa, and a 
selection of zines available in the Ottawa area through local distribution networks. My second-wave sample includes forty-four issues of thirteen second-wave newspapers published between the fall of 1969 and the fall of 1993 (see appendix for full list). My intent with this sample was to include a newspaper from each region of Canada, and to attempt to include newspapers by groups that identified around issues in addition to gender, such as race or sexuality. Once I had selected the thirteen newspapers, I looked at the earliest and most recent issues available through the CWMA - in cases where the earlier and later issues differed significantly, I looked at additional issues, in order to again a more comprehensive understanding of the differences in goal and format during the timeline of the publication. In this, however, I was limited by what was available through these archives; I was unable to get all of the newspapers I wanted, and the archives did not always have full sets of each newspaper. ${ }^{\text {II }}$ As well, in the period under review, three other publications merged with the publications I documented.

My sample of zines draws from forty-four issues of thirty-six zines produced by twenty-two authors, some of who collaborated on the zines sampled in addition to making their own zines (see appendix for full list). I limited my zine selection to those that could be considered perzines, or zines that contain personal writing. I found these zines at a number of fairs held in Ottawa, including the 2006 and 2007 Ravenswing Craft and Zine Fairs, Ladyfest Ottawa 2006 and the Ottawa Small Press Book Fair 2006. Additionally, I found zines at the Ottawa stores Venus Envy and Mother Tongue. By comparing the form and content of publications from these different waves of feminism, I compare their similarities and differences, and suggest some reasons for these trends. I contend that differences I found between the form, approach and distribution of second-wave newspapers and 
third-wave zines actually demonstrate continuities between the waves in terms of aspirations and goals, when the context in which they exist and resist are taken into account.

While the newspapers I selected were necessarily feminist (due to the source from which they were drawn), the zines did not identify themselves as such necessarily. While there are some third wavers who proudly identify themselves as feminist, one aspect of the backlash against second-wave feminism remains a reluctance of subsequent generations to identify themselves with the stereotype of feminist that the backlash perpetuates. As such, I posit that there are a lot of engaged and active people, both women and men, whose activist and resistant work is very much in line with third-wave feminist ideals, though they may not identify as feminist.

In order to substantiate further my analysis of third-wave goals and how zine makers see themselves within this movement, I distributed a questionnaire to the addresses and email addresses printed in the zines in my sample. ${ }^{12}$ Additionally, I handed out the questionnaire at the second Ravenswing fair that I attended. I took particular care with my method of interviewing third-wave zine makers, as this was the only instance in which I was interacting with individuals. I asked broad, openended questions, in order to allow participants the latitude to answer with whatever information and in whatever style they felt best suited the information they wished to share (Kim 99). My goal with this technique was to acquire as complete information as possible, while also empowering participants to give, or not give, information about themselves (Kim 99; Reinharz \& Davidman I8). As Reinharz and Davidman found in their study of feminist research methods, this resulted in significant variations in the length of responses, but also highlighted the differences 
among participants' responses (18-19, 25). ${ }^{13}$ Reinharz and Davidman also add that by making space for participants, in their case women, to give information in their own words, researchers can counter "centuries of ignoring women's ideas altogether or having men speak for women" - a statement which can be generalised to include marginalised groups (19).

I also chose to collect this information in written form for a number of reasons. While I initially sent the questionnaire to the addresses and email addresses provided by the zines in my sample, I also attended zine fairs. My intention was both to find zine makers and to meet them in order to give them the opportunity to ask me questions about the questionnaire in person. I then offered them the questionnaire in both paper and emailed versions. Additionally, some zine makers passed copies of the questionnaire on to other zine makers. By offering zine makers the questionnaire in written form, I gave them a way of answering confidentially (Letherby \& Zdrodowski 578,585 ). While many zine makers chose to identify themselves and to allow me to identify them by their real names or their published pseudonyms, others chose to remain anonymous, or to request that their name not be associated with either their answers or their zines. Because of the confidential nature of many topics discussed in zines, this anonymity was likely crucial in some zine makers' decisions to participate or not. I also felt that a written questionnaire would be the least intimidating form for zine makers - since zine making generally is a written form of cultural expression. The written form also shifts the balance of power away from the researcher, as the respondent can choose when and where to do the questionnaire, and at what pace and with what length they prefer to answer (Reinharz \& Davidman 22). They can also back out of the process at any time without any perceived pressure from the researcher to continue. A drawback to this 
method, however, is that I did not have the opportunity to clarify questions, or to ask for additional information. For example, I found question $\mathrm{r}_{4}$, "Where do you read zines from?" to be too vague. While I'd hoped to have participants share the geographical locations of the zines they read, many people instead told me about how they acquired zines - mostly from friends, through independent bookstores, or at fairs. Because I limited myself to sending out only one questionnaire, I was not able to get particularly consistent information from participants for this question (though, of course, the information they gave was revealing - just not in the way I originally intended).

I quote directly from these responses, in addition to paraphrasing and using the information provided..$^{14}$ I have also included quotations from, and images of, the newspapers and zines in my sample. In these quotations, I have reproduced the style and choices made by the original authors, rather than making stylistic and grammatical changes that would conform to academic writing norms. In doing so, I hope to reproduce more honestly the intentions of the participants and publications, and to convey what participants wrote without altering it to suit my needs (Reinharz \& Davidman 9, 39).

\section{Chapter summaries}

I begin with a discussion of my understanding of third-wave feminism and the contemporary environments within which third-wave feminists work. I argue that mainstream media and their emphasis on consumerism not only dictate the parameters within which third-wave feminists act, but also potentially co-opt their resistance to oppression. I rely on Bhabha's insights on alternative space and cultural products as my theoretical framework. These cultural products upset the 
social hierarchies that marginalised some groups, and allow marginalised people to present narratives that counter their oppressions. I consider how third wavers in particular make use of this potential in later chapters.

Chapter two surveys the historical roots of feminist publishing in North America, and Canada in particular. The histories and goals of first-, second- and third-wave feminist publishing seem disparate in many areas. A closer examination of the environments in which these waves functioned, however, reveals a number of parallels in their aspirations, despite their differing tactics. In this chapter, I illustrate how these continuities reveal feminist publishing's rich history and successes in Canada, and create a space for third-wave feminism to build on these experiences and generate new styles of publications that can resist oppression in contemporary contexts.

In chapter three, I examine how the contemporary environments of mainstream media and consumerism, along with the legacy of second-wave feminism and the backlash that followed it, impose specific challenges for third-wave feminists. In particular, I argue that the commodification of resistance poses difficulties for those creating resistant culture. I argue that third wavers fight these oppressive environments by creating community and using other methods and strategies that effectively resist the commodifying and oppressive forces of late capitalism. An emphasis on DIY projects, such as publishing zines, enables third wavers to circumvent oppressive factors and create acts and products of resistance.

In the conclusion, I reflect on the evolution of feminist publishing and the contemporary contexts that feminists face. I then assess the challenges facing thirdwave feminists, and the creative methods they use to meet these challenges. I conclude that while marginalised people are inundated with messages that their 
voices are not valuable, third wavers celebrate these voices. Misogynist mainstream media set marginalised people up against one another; third wavers build community around difference. Consumerism implies that the only way to create identity or social change is through purchasing products; third wavers assume control of the productive process, and then distribute their cultural products for little or no cost. Late capitalism suppresses resistance to privileged and powerful groups by commodifying that resistance; third wavers refuse to work within the boundaries of capitalist systems.

My thesis demonstrates that while the work that third wavers do, both in publishing and other forms of activism, sometimes seems entirely distinctive from that of the second wave, their roots in second-wave feminist goals and priorities are undeniable. Third wavers have taken this heritage and developed new forms of activism, like zines, to battle the contemporary oppressions they face. I begin this discussion in the following chapter by first examining these evolving forms of oppression and then framing feminist publishing within Bhabha's theory of cultural resistance. 
${ }^{1}$ The Comet was a collection of short articles on science and science fiction (Wertham 38; see also Bailey \& Michel; Duncombe, "DIY").

${ }^{2}$ See Austin \& Gregg 82; Duncombe, "DIY"; Schilt, "A Little" 6.

${ }^{3}$ Feminism in North America is commonly referred to as occurring in waves. This model situates first-wave feminism as occurring in the late $19^{\text {th }}$ and early $20^{\text {th }}$ centuries and focusing mainly on official inequalities, such as laws preventing women from voting. Second-wave feminism occurred from the late I960s to late I970s and focusing mainly on challenging unofficial inequalities, such as sexist stereotypes and how they prevented women from obtaining high-status jobs. Third-wave feminism began in the early I 990 s in response to the backlash against second-wave feminism, and the perceived failings of the second wave. The concept of waves of feminism, however, is contested due to its focus on feminism engaged in by white, middle-class women to the exclusion of other feminists. It also implies an ebb in feminism in between these movements, which emphasises activities that happened during these specific time periods, and minimises activity that happened in between them. Despite these shortfalls, I will be using this terminology for the sake of convenience.

${ }^{4}$ Robbins I 26; see also Austin \& Gregg 8 r; Bailey \& Michel; Harris, "Riding” 29; Pinterics I7.

${ }^{5}$ Duncombe, "Alienated Together" 427; see also Bacon-Smith 309; Bell, "Riding"; Gunderloy \& Goldberg I; Pinterics I 7 .

${ }^{6}$ DIY stands for do-it-yourself, a philosophy wherein individuals take on projects normally done by professionals. In this case, zine makers take on cultural production, rather than leaving it to mainstream media companies. Amy Spencer calls this "the urge to create a new cultural form and transmit it to others on your own terms," emphasising the freedom and control DIYers find in producing their own work (I2). Kathy Bail adds that DIY can involve not only self-produced content, but can also refer to the buying and exchanging of products within one's community (82). An additional aspect of DIY is making complex social processes and theory accessible to non-professionals.

${ }^{7}$ For more on hopes that the internet would bring about positive social change, see Curran 227; Ganley 2, 8-10, 59-67; Kramer I 19, I 2 I, I 27; McChesney 70;

McCullough 9-Io, I3.

${ }^{8}$ The internet is limited to those who can afford computers and internet access (McChesney 70-71; McCullough i 5 ; Oliphant). These economic factors, however, mean that internet access is also strongly correlated to race, age and gender (Sinha \& Stone 275). In her study on global internet access, Pippa Norris adds other factors that affect access, such as education level, whether one comes from a single or dual parent family, and whether one has disabilities (IO-I I). She also notes that lack of internet access entrenches poverty, as those without access are unable to access free online services and job listings (17). James Curran also notes that as $85 \%$ of web content is in English, despite the fact that less than I0\% of the world's population speaks English as a first language, access to what is on the web is limited by language abilities (238). Additionally, much web content is commercialised, and must be paid for through memberships or per-piece fees (McCullough I 2).

${ }^{9}$ Curran 233; see also Downey \& Fenton 198; Norris 19. 
${ }^{10}$ See Downing et al 8; McCullough I I-I 2; Sinha \& Stone 276.

${ }^{11}$ The collection of these newspapers is complicated by the fragility of the newsprint on which they are printed and also by the inability of under-funded women's groups to maintain archives.

${ }^{12}$ Overall, I emailed twenty-two zine makers, mailed a questionnaire to one, and gave it in person to five. Two others emailed me requesting a questionnaire after hearing about it from other participants. Of those emailed, I heard back from thirteen, eleven of whom decided to participate. Due to the nature of email, I am unable to say how many of the eleven individuals I emailed and who did not respond actually received the questionnaire, and how many went to defunct email addresses, or were otherwise filtered or discarded due to an unfamiliar sending address. Of the five that I handed out in person, all were returned to me. In total, I sent out thirty questionnaires; sixteen were completed; two people declined to participate due to other commitments; one was definitely not received; and eleven were either lost or received by people who decided not to respond.

${ }^{13}$ The responses to the questionnaire ranged between just over 250 words from participant 13 to over 2000 words from participant 16 .

${ }^{14}$ Unless otherwise indicated, information and quotations from the participants are drawn from these questionnaires. 


\section{Chapter I}

\section{Conspicuous Production:}

\section{The Origins and Context of Third-Wave Publishing}

\section{Introduction}

An element of third wave feminism, feminist zines, originated with riot grrrl, an American punk feminist movement. Riot grrrls took music-based fanzines and adapted them to explore and confront sexism and oppression. Third wavers continue to use zines, given their usefulness as a tool of resistance. A key focus of third-wave critique in zines is mainstream media's portrayal of women and other marginalised people. Third wavers argue that mainstream media producers take advantage of the power of mainstream media, and use it to reinforce existing social power imbalances.

First, I outline my understanding of what third wave feminism is, and its origins in the riot grrrl movement. While other origins for third wave are suggested, riot grrrl introduced zines to feminism, so they are my focus. Next, I turn to a central aspect of riot grrrl - their critique of mainstream media, and the damaging stereotypes these media present, especially of marginalised people and resistant movements, like feminism. I then consider the emphasis on consumerism in mainstream media. While mainstream media pushes consumerism as a key site of identity-formation, third wavers challenge this assumption by taking on producer roles and creating media, such as zines. When these resistant publications are framed within Bhabha's theory on cultural production, their potential as activist tools becomes evident.

I use Bhabha's theory, which proposes that the production of culture in 
marginal spaces enhances non-oppressive society, to consider the activist nature of third wave zines. Bhabha contends that no one culture is better than another, and that through cultural negotiation and acceptance of cultural difference, a balance can be achieved. In spaces of open cultural negotiation, the dominant culture can be challenged. I argue that zines act within these marginal spaces to challenge oppression, and to resist hierarchies. Third wave feminists in particular, make use of this space to highlight injustice and to demand that their voices be included in mainstream society.

\section{Defining third-wave feminism}

Current feminisms differ from those of second-wave feminism to the extent that they label themselves a third wave (Ferree \& Hess viii-ix; Steenbergen, "Feminism" 8-9). Since third-wave feminists do not necessarily "share the same political motivations, priorities, or dreams," or follow the same agenda, their ideology and activism is difficult to define. In fact, many activists reject the term feminist to define themselves and their actions (Steenbergen, "Feminism" I 2). ${ }^{\mathrm{I}}$ Many writers refer to third-wave feminists as young feminists, and even cite an age range that defines this group. Ednie Kaeh Garrison, however, refuses to define third-wave feminists as restricted to a specific age cohort. ${ }^{2}$ Instead, she considers third-wave feminism a historically situated feminism that exists "in the late-capitalist and postmodern world but still references a longer movement history" (I44). If one were to limit third-wave feminists to an age group, Garrison states, that would erase the "significant presence and contributions of many overlapping and multiple cohorts who count as feminists, and more particularly, of those who can count as Third Wave feminists" (145). Most importantly, to limit third-wave feminism to an 
age group would reserve third-wave politics for a limited group of feminists - a move that would counter the expansive definition of third-wave feminism, and its coalition-building emphasis.

Much of third-wave feminists' activism differs from that of previous feminists. ${ }^{3}$ As such, they are less easily identified. Myra Marx Ferree and Beth Hess note that the "significant transformations in feminist political practices" includes a burgeoning of spaces in which feminists act (xvi). These spaces include nontraditional activist sites, such as zines and networks created over the internet (viii-ix). Because of the new locations in which feminist activism occurs, they can be more difficult to identify as feminist or activist. In addition, Candis Steenbergen notes that there are "few organizational structures surrounding them as a 'wave,", making it also difficult to see third-wave feminism as a cohesive movement (“Talking”" 263). Others note that despite the hidden and unorganised nature of third-wave feminism, there is "nonorganizational" communication and activism at work in these third-wave groups. ${ }^{4}$

Another factor that makes third-wave feminism more difficult to identify is that a number of their practices are less evident than those of previous feminisms. Steenbergen asserts that many third-wave voices speak through "independentlyproduced zines, in book reviews hidden in the backs of journals, on walls and across public advertisements, in non-mainstream publications, and in other, lessconspicuous (and less financially rewarding), spaces" ("Feminism" 9; italics in original). The "nonorganizational" forms of communication that Ferree and Hess cite above are also less formal and less visible. Zines, internet sites and listservs may be effective places for third wavers to meet, form ideas and organise activism, but they are not as noticeable to outsiders as a group of people meeting in a physical 
place. Still, Steenbergen and Ferree and Hess assert that these less visible methods of third-wave feminism do not indicate that third wavers are not active (Ferree \& Hess viii; Steenbergen, “Talkin”” 26 I, 263-64). Rather, third wavers are "resisting, resisting, resisting in their own innumerable private and public ways" (Steenbergen, “Talkin”" 263-64). In her zine, Jigsaw, Tobi Vail states:

Resistance is everywhere, it always has been and always will be. Just because someone is not resisting in the same way you are (being a vegan, an out lesbian, a political organizer) does not mean they are not resisting. Being told you are a worthless piece of shit and not believing it is a form of resistance. (qtd. in Brasile 65)

Many writers contend that third-wave feminism rose out of racialised women's critiques of second-wave feminism's universalisation of the category woman.' Other writers choose to highlight the continuities between the second and third waves (Garrison I44-45). For example, Steenbergen, in explaining the diverse forms of third-wave feminism, notes that multiplicity is not unique to third-wave feminism, but rather is a characteristic of previous feminisms as well ("Feminism" I 2). Ferree and Hess draw a similar parallel, calling the third-wave emphasis on coalition building as a strategy for dealing with differences within the movement a "classic response" in American women's movements (viii-ix). While third-wave feminism may engage in different activisms than previous feminisms, it cannot be defined solely in opposition to those feminisms.

There is a strong emphasis on the examination, acceptance and celebration of difference within the third wave. ${ }^{6}$ This has meant the "redefinition and renaming of women's disparate conditions" in order to more accurately and widely define woman and feminism in a way that encompasses difference (Steenbergen, "Talkin" 265). Allyson Mitchell and Lara Karaian describe this as complicating the category of woman, in which third wavers recognise that power relations exist between different 
groups of women (72). In addition, third-wave feminism leaves room for fluidity between identities and for changing roles (Klein 224-25). Third wavers do not interrogate these differences without acknowledging the power and privilege imbalances caused by membership in different categories of oppression, examining both how they are oppressed and privileged. ${ }^{8}$ The third wave's take on feminism on who qualifies as oppressed or as resisting oppression - is expansive and flexible.

Doreen Piano asserts that anti-exclusionary practices are developed through conscious engagement with "self-reflexivity, political intervention, and antiessentialist practices." These practices have demanded a "greater acceptance of complexities, ambiguities, and multiple locations," as well as wariness of dichotomous thinking in general. ${ }^{9}$ One way that third wavers enact these values is through creating anthology publications, encouraging contributions to expand the demographics of feminists being published, and as a way to "recogniz[e] and celebrat [e] that diversity" (J. Armstrong, "Web Grrrls" I02). Natasha Pinterics confirms that the use of "divergent personal narratives" in anthologies, zines, the internet and other third-wave publications indicates the "theoretical basis" of equally-valued multiple perspectives (I6). Third wavers have thoughtfully put into practice their beliefs about intersections of oppressions by ensuring that those who are marginalised are welcomed to shape and define feminism by participating in its publications.

\section{Riot grrrl: Origins of the third wave}

While third-wave feminism can be difficult to locate and to define, its origins are often cited as the riot grrrl movement (Robbins I 24). ${ }^{10}$ Certainly, riot grrrl introduced DIY theory and the production of zines to feminist practice. The 
origins of riot grrrl, though, are disputed. There is consensus that girls and women in Olympia, Washington and Washington D.C. met in August of r99r to discuss sexism in the punk music scene. ${ }^{11}$ Kristen Schilt adds that the women found inspiration in the antiracist riots that had just occurred in D.C., and decided to start a "girl riot" against a society that "offered no validation of women's experiences" ("A Little" 6). Piano agrees with the locations, but insists on an earlier timeline, asserting that in the late 1980 , these same women initiated "a series of feminist interventions" into local hardcore punk scenes. Melissa Klein and Stacy Thompson point to the International Pop Underground (IPU) Convention, held in Olympia, also in the August of 1991. ${ }^{\mathrm{I2}}$ The five-day-long IPU convention, organised by Calvin Johnson, began with an event titled "Love Rock Revolution Girl Style Now." ${ }^{13}$ At this event, which Alison Jacques refers to as riot grrrl's "coming out party," four all-female bands played, and the audience's enthusiasm for the event "led audience and band members to recognize in themselves a nascent collectivity" (Jacques 47; S. Thompson 59). ${ }^{14}$ Then, in July of 1992, these women organised the weekend-long Riot Grrrl Convention in D.C., featuring workshops on "fat oppression, sexuality, rape, unlearning racism, domestic violence and self-defense," female bands and spoken-word performers, and the "All-Girl All-Night Dance Party." 's While the initial stirrings of riot grrrl remain debatable, the conferences in 1991 and 1992 signal a concerted effort to bring girls and women together for the purpose of challenging sexism.

While women had been a part of punk since its inception, they usually were limited to "feminine" roles and subjected to physical and verbal harassment (Piano). The North American punk variant called "hardcore" was particularly notorious for its hostility toward girls and women (Jacques 48 ; Piano). Women involved with 
punk felt that a "macho violence" dominated the scene and kept women out, sometimes with threats of physical violence. ${ }^{16}$ Riot grrrls protested the enforced maleness of punk, and then extended their critique to patriarchy in mainstream society as well (Jacques 47$).^{\mathrm{I}}$

Mainstream media quickly noticed riot grrrl. Nicole Arthur asserts that they were "titillated by the notion of a teenage girl army," explaining the wide coverage of girl culture by media usually disinterested in girls (209). In repackaging riot grrrl for mass consumption, however, mainstream media misrepresented and trivialised the riot grrrl movement. ${ }^{18}$ Schilt asserts that stories about riot grrrls "often were misinformed, antagonistic, or banal" and that writers took riot grrrl out of context, "making them appear immature and ridiculous." Robbins adds that riot grrrls, like feminists in the second wave, often were stereotyped as lesbians and "violent manhaters" (I 26). These representations of riot grrrl worked to de-politicise and delegitimise riot grrrl, making the movement appear to be trivial and a passing fashion.

Some grrrls objected to how mainstream media used riot grrrl, and felt that the manipulation of riot grrrl in the press attempted to neutralise the movement (Garrison I53; Klein 223). Consequently, some grrrls began to refuse the label, while others fought back (Reynolds \& Press 323-24). Because of condescending and dismissive treatment at the hands of mainstream media, the proponents of riot grrrl established a nationwide mainstream media blackout in 1992, while continuing to work with alternative media, and creating their own media products..$^{20}$ Mitchell and Karaian point to this period as crucial in the evolution of riot grrrl into other forms of third-wave feminism. Riot grrrl, they state, "has since gone underground" and evolved and changed "in order to slip from the hands of mainstream media" (67). Mainstream media proved to be a hostile environment for riot grrrl, but riot grrrls 
resisted, removing themselves from the objectification they faced, and changing their strategies and activisms to subvert this oppression.

Riot grrrls advanced a number of goals pivotal to contemporary third-wave feminism. I discuss the emergence of these ideals in third-wave publications in chapters two and three, but here I briefly consider these riot grrrl values and activities in their general context, to explain the foundation of what third wavers now publish in zines. Riot grrrls participated in a number of activities, with the goal of building networks with each other, and "building a feminist and political consciousness" (Schilt, "A Little" I4). In order to create a feminist space, riot grrrls held weekly meetings and workshops, created and distributed zines, and had girlonly mosh pits at band concerts (Gillis \& Munford I70). ${ }^{21}$ These chapter meetings, along with band tours, zines and other social networks, spread riot grrrl ideas throughout North America (Gillis \& Munford I70; Klein 213-I 5). Monica Brasile and Stacy Gillis and Rebecca Munford note that these activities paralleled secondwave feminist consciousness-raising groups and networks (Brasile 64; Gillis \& Munford I70). Claire Villacorta points out another similarity - these activities focused on creating safer spaces for grrrls to communicate with one another to challenge the oppressions they identified.

Robbins notes that many of the girls and women involved in riot grrrl grew up in non-sexist households with mothers who participated in 1970 s second-wave feminism (I 25 ; see also Jacques 48 ). Jacques adds that many riot grrrls were students or graduates of women's studies programs. Robbins and Jacques argue that these women understood the concept of sexism and feminist activism, and took for granted gains made by second-wave feminism. ${ }^{22}$ Robbins notes too that when the backlash to feminism began, bringing "a new wave of sexism and homophobia," 
these women found their security threatened (125). Forming riot grrrl and engaging in anti-sexist activism was their response to this threat on gender equity that they understood as their birthright.

While most riot grrrls were white, they represented a variety of economic and educational backgrounds (Brasile 65; see also Jacques 47). In the case of race, as well as categories of oppression that more riot girls experienced personally, riot grrrls were "committed to helping each other identify [their] own prejudices" and privileges. As such, their meetings, conventions and zines included a focus on issues of race, class and sexuality in relation to sexism (Brasile 65). Simon Reynolds and Joy Press also point to the strong "lesbian element" in riot grrrl, which exhibited historical links to the gay punk movement, also called homocore or queercore. ${ }^{23}$ The feminism that riot grrrls practiced attended to the different oppressions that girls and women face based on categories of identification other than gender, and did not limit them to categories with which they personally identified.

Riot grrrls also positioned themselves in opposition to consumerism and capitalism. ${ }^{24}$ This stance manifested in their work as "creators of ideas and culture."2s Riot grrrls made their own music, produced zines and musical recordings, and started their own record labels (Brasile 63; Schilt, "A Little" ${ }_{4}$ ). ${ }^{26}$ By embracing DIY practices, grrrls could avoid conflicts with culture gatekeepers, while demonstrating to other girls and women that they didn't need to be passive consumers of culture, but could define and shape culture as producers of culture and knowledge through media like zines.

While S. Thompson notes that riot grrrl, as a movement, largely has died out, many of its goals and values exert substantial influence on subsequent manifestations of third-wave feminism ( 59 ). Their expansive concept of what 
qualified as feminist issues, their insistence on celebrating individual and group differences within the movement, their realisation of mainstream media as a hostile environment and their enthusiasm for DIY practices all exert a strong presence in third-wave feminisms. Their use of DIY practices, in particular, allowed them to pursue many of their goals, and continues to aid third-wave feminists in pursuing and achieving their own goals. In chapter three, I examine how third wavers combine riot grrrl theories and practices with their own anti-oppression values and their understanding of second-wave tactics to confront contemporary oppressions.

\section{Scary butches and "girl power": How mainstream media present feminism}

Riot grrrls and the third wavers who followed emphasise the power of media representations in their analyses, and critique how mainstream media wield this power to reinforce existing oppressions. Third wavers expose mainstream media's tactic of portraying feminism in limited ways as a means of discrediting feminist action and also note the emphasis in mainstream media on consumerism; they argue that the consumption of mass-produced commercial products is framed as a key method of identity creation, to the exclusion of activities such as production or activism. While consumption is a problematic method of identity formation, the ownership of mainstream media explains their encouragement of consumption, in addition to their unsympathetic portrayal of marginalised people and resistance movements. Mainstream media are owned almost entirely by conglomerates that benefit from consumerism, and are therefore threatened by resistance. ${ }^{27}$ Third wavers, however, refuse the assumption that consumption is the only acceptable behaviour, and take on production roles in order to counter the oppressions that mainstream media create and support. 
Gaye Tuchman notes that as early as 1967 , feminists commented on mainstream media's use of stereotypes in reinforcing gender roles and gender hierarchies. Consciousness-raising groups sought to counter these media images in their own understandings, and also critiqued sexism in media aimed at children and young people ( 530 ). Shari Graydon adds that these critiques also included concern about the under-representation of women in mainstream media (I43). The preamble to the first issue of Aphra, a feminist newspaper, suggests that the "biased and commercially oriented material" found in mainstream media, which is dominated by "male stereotypes, male fantasies, male wish fulfilment, and male power structure," led to the popularity of key forms of second-wave feminism, wherein women met in groups "with individuals bearing witness" giving women an "opportunity for community and identification" that they were unable to find in mainstream culture and media (rpt. in Garvey 374; see also Garvey ${ }^{368}$ ). This sentiment is echoed in third-wave feminist materials such as "Riot Grrrl is..." where the authors explain their desire to publish, saying "us girls crave records and books and fanzines that speak to US, that WE feel included in and can understand in our own ways" (Riot Grrrl 178 ; emphasis in original). ${ }^{28}$ Modern research demonstrates that the concerns of second and third-wave feminists regarding sexist media have not yet been addressed, and that the use of stereotypes, along with under-representation of girls and women, continues in today's mainstream media.

Stereotypes work to limit positive or acceptable expressions, behaviours and characteristics for marginalised people by creating a pervasive media environment where only stereotypical expressions are presented, thus implying that nonstereotypical behaviour is aberrant. These stereotypes are limiting and damaging, as they reinforce existing power structures in society, including sexist, racist, sexuality- 
based and economic oppression. ${ }^{29}$ This environment influences the behaviour of marginalised people and how individuals who belong to dominant groups view them.

Mainstream media also present skewed representations of feminism, further reducing marginalised people's ability to counter oppressions. Karen Green and Tristan Taormino assert that "there are fewer mainstream avenues for women to articulate the injustices and the inequalities" that affect them. They claim that when mainstream media "process" activism, they dilute it, portraying "only a semblance" of the activism that occurs (xii). Andrea Dworkin argues that mainstream media limit discussion to liberal feminism, despite a "deepening understanding of radical feminist ideas and more grassroots, radical activity now probably than there has ever been." She suggests that radical feminism is under-represented in mainstream media because many of the "very brilliant, very resourceful feminists all over the country who are doing direct action" are also "very poor," and as such have little influence over mainstream media (205-06). With mainstream media presenting only certain types of feminism, and minimizing any discussion of activist work, the "feminism" that exists in this environment is limited and inaccurate.

In Democracy's Oxygen, James Winter identifies fifty-four “Media Think Truisms" or underlying assumptions under-pinning mainstream media, including: "A small group of radical feminists is constantly whining about problems which either don't exist, or which are relatively small problems that we are already doing our best to solve," and "Since society "judges" people based on their merits, those who don't succeed, including women, are just not capable enough" (I I8). As such, feminists are frequently portrayed as "anti-men, anti-sex and obsessed with notions of women as hapless victims." ${ }^{30}$ These assumptions rely on the premise that 
previous feminisms achieved equality for women, and that people who continue to push for equity are either misinformed about their current access to equality, or are looking for more power than is fair. These sentiments underlie most mainstream reporting on feminism, contextualising feminism as ignorant, aggressive and unjust.

Additionally, when mainstream media publicise the advances of the women's movement, they are framed as if all feminist goals have been reached (Ahn I I9). At the same time, they neglect to identify these achievements as feminist. Jennifer Baumgardner and Amy Richards observe that by refusing to attribute gains in areas such as day care, micro-enterprise and anti-violence organising to feminist organising and activism, mainstream media give readers "the impression that feminism is about something else - usually something they can't relate to" (95). The separation of feminism from solid feminist successes creates confusion about feminist goals and deflects credit for these achievements away from those who worked for them.

Mainstream media frame third-wave feminism in very specific ways. Rose Glickman calls mainstream media images of young women a "collective Big Chill of feminism," noting that like most media generalisations, it is, for the most part, inaccurate (xii). Steenbergen adds that media representations of feminism focus on a very specific group of young women who have received a lot of media space and time for their views on the lack of necessity for feminist activism - women who are “[h]eterosexual, white, able-bodied, well-educated, financially successful, aggressive and overtly sexual" ("Talkin'” 259). Steenbergen goes on to note that content on the decline of feminism, "makes far better copy than accurate representations of burgeoning activism among young women" ("Talkin”" 262). Such mainstream media presentations of young feminists perpetuate the impression that young feminists do 
not exist, and present those that do as anathema to the media-presented version of young women's vision of feminism.

Alternately, mainstream media portray modern feminism as commercialised "Girl Power" culture. Christina Ahn calls this "trendy 'in-your-face' culture” superficial and unrealistic (I I9). This reduction of feminism to a sound bite or cultural artefact was something that riot grrrls feared. While the founding women of riot grrrl refused to define the movement or its participants, leaving it open for participants to define as suited their needs, mainstream media's "short, catchy articles" on the topic defined and moulded the movement into an easy-tounderstand form for their readers (S. Thompson 60). In doing so, they both misrepresented and alienated riot grrrls. By ignoring the nuances and politics of riot grrrl, and by emphasising the commercialised "Girl Power" that quickly followed, mainstream media reduce third-wave feminism to consumer products.

In her article on women in music, Jacques considers the wide mainstream media coverage of riot grrrl, but the lack of coverage of riot grrrl music, a key component of the riot grrrl movement. She comments: "it seems the media thought riot grrrls were better seen and not heard." Jacques also notes that shortly after the media blitz about riot grrrl, media attention turned to other women "whose anger was more palatable" (48). After initially reporting on riot grrrl, Jacques asserts that mainstream media de-contextualised the term $\mathrm{grrrl}$, using it to refer to "any independent, noisy (white) female rock musicians." This redefined a term "with which a subculture had named its defiance" into a word that "encompass[es] mass public femaleness" (49). Mainstream media trivialised the origins of riot grrrl and minimised its political and cultural impact.

Mainstream media treatment of feminism is in line with the message they 
convey about women and other marginalised people. As people who do not adhere to the media-enforced stereotypes of what women and marginalised people should act like, feminists are treated as if they are inadequate or unacceptable individuals. Like marginalised people in general, when they don't adhere to mainstream media's strict stereotypes, they are misrepresented or ignored. Feminists are a particular threat to mainstream media, as their behaviour challenges stereotypes, and their work challenges the foundations on which practices of sexism, racism and other oppressions thrive. As such, mainstream media work to silence those, such as feminists, who speak out about the oppression that mainstream media perpetuate. The effect of the mis- and non-representation of women in mainstream media is that women increasingly are disinterested in consuming this media. Gertrude Robinson and Armande Saint-Jean assert that newspaper readership by women decreased by 25 percent between 1985 and 1995 as a result of the "overwhelmingly white, male, middle-class view of the world" represented in mainstream media (34). This is supported by the earlier-mentioned preamble in Aphra and "Riot Grrrl is..." which both describe feminist production of alternative media in the face of inadequate mainstream media. As women and girls find representations of themselves in mainstream media increasingly inaccurate, they find mainstream media alienating and uninteresting. In chapters two and three, I examine more closely the alternatives that marginalised people are turning to, rather than continuing to consume mainstream media.

You are what you buy: Understanding the relationship between consumption and identity

In addition to perpetuating stereotypes about gender- and race-appropriate 
behaviour, mainstream media also reinforce ideas about consumption as a key method of identity formation. Mainstream media both explicitly advertise consumer products and implicitly promote consumerism over participation in production. Additionally, mainstream media frame themselves in the same way - as products for purchase that only professionals can create. By associating this consumerism with identity-formation, mainstream media tap into a social need, but fill this need in a problematic manner.

Individuals rely on consumption to create and express their identities. ${ }^{31}$ In this system, individuals judge one another's identities based on their consumption patterns - consumption becomes the measure of individuals' worth or status. ${ }^{32}$ This system of identity creation situates consumption as the activity by which "all possible selves can be created with the support of the products provided" (Friese 89). This emphasis on consumption structures an environment in which the value and importance of consumption itself far surpasses any use- or identity-formation value of the goods consumed, as consumption becomes key for judging people.

Yiannis Gabriel and Tim Lang note that individuals also may develop identity through negative consumption, or non-consumption practices. Alternative forms of consumption, including boycotts, consciously consuming less, consuming local products, avoiding products produced by corporations, and avoiding the use of cash and use of alternative economies, can play a part in creating an identity that includes resistance to consumerism $(146,94){ }^{33}$ These anti-consumption behaviours, however, still have consumption as their central factor, and this alternative- or nonconsumption forms identity.

One of the key issues with relying on consumption to form identity is that goods available for consumption are limited in selection. ${ }^{34}$ Mass-production, while 
providing an abundance of goods, is limited to goods that appeal to a wide selection of individuals. In Explorations in the Sociology of Consumption, George Ritzer describes this as the McDonaldization of culture. McDonaldization, he states, has led to the homogenisation of cultural products. In the case of fast food, "the food has been rationalized and compromised so that it is acceptable to the tastes of virtually all diners" $(43,63)$. Benjamin Barber describes this lack of consumer choice as a consequence of inelastic markets and economies of scale - "the quest for a single product that can be owned by a single proprietor and sold to every living soul on the planet" ( $137-38)$. Ritzer concludes that these limitations on available goods further deaden any desire for variety that individuals possess, replacing it with apathy, acceptance of uniformity, and even desire for predictability. ${ }^{35}$ Consequently, individuals frequently make identical or similar consumption choices from a limited selection of goods, which can only be used to create not-so-unique identities. ${ }^{36}$ In “The System of Objects," Jean Baudrillard echoes Ritzer and Susanne Friese, noting that limited consumer products forces consumers to fit their systems of meaning and identity creation to what is convenient and profitable for the production system, at the expense of consumers (I4; see also "Consumer Society" $38,43)$. Because of the strict meanings ascribed to these objects, asserts Baudrillard, products "tyrannically induce categories of persons" ("System of Objects" I6-17). Baudrillard looks beyond the restrictions created by limited products, and finds systems of power that privilege those in control of production.

The position of privilege held by producers, however, is masked. One way producers obscure their privilege is through the marketing of their products as transgressive. Contemporary consumerism, with its "taste for self-fulfilment and its intolerance for the confines of tradition," along with its continuous need for new 
products, has moved from regimes of taste and conformity to one of individuality and difference. Producers work to convince consumers that, with the right products, "we are rock ' $n$ ' roll rebels, each one of us as rule-breaking and hierarchydefying as our heroes of the 6os." Thomas Frank calls this marketing of similarity as difference "the genius at the heart of American capitalism" (3 I9). By marketing products as counter to dominant power systems, producers gloss over their own positions of power.

Consumerism is a problematic way to form and communicate identity, as perceived choices about what to consume are dictated by class position and availability of goods. Still, as other hierarchies erode, consumption is a key category by which others are judged. Zines counter this environment in a number of ways. In chapter three, I discuss how zines, as DIY products, are anti-consumerist. By encouraging production in the face of social pressures to engage only in consumption, zine makers challenge power structures that centre on the oppression and censorship inherent in a capitalist, profit-driven model of cultural production.

\section{Who produces mainstream media?}

Mainstream media present a hostile and unwelcoming environment to marginalised people. But these media are not a monolithic force - they are the product of a range of individuals and groups. The "realities" depicted in media products, therefore, are the results of many choices by those who own and manage mainstream media. The many choices that affect final mainstream media products reflect "the experience, knowledge and bias of the producers involved" ("Media Education"). The lack of marginalised people producing mainstream media allows for the perpetuation of negative stereotypes about marginalised people's abilities; the 
overwhelming presentation of negative stereotypes about marginalised people in mainstream media fosters a social environment in which they are framed as inadequate for powerful jobs, such as media production or other occupations with political or cultural influence. ${ }^{37}$

When mainstream media does portray marginalised people, it generally defines them as consumers. For example, in Amy Beer's study of Latina magazines, she found that while these magazines critique mainstream media's derogatory stereotypes of Latina women, they indicate that their readers can counter these stereotypes by "demonstrating their economic power" (164-65, 175). ${ }^{38}$ Lesbian and gay activists express similar concerns about emphasis on social justice through consumption. While many consumer products actively pursue a lesbian and gay market, Fred Fejes worries that "the acceptance of lesbians and gay males as sexual / political subjects is predicated on their acceptance and importance as consuming subjects" (197). By focusing on increased consumer choice, attention is drawn away from larger systemic oppressions. Baudrillard claims that these discourses on consumption "make of consumption the premise for 'human liberation', to be attained in lieu of, and despite the failures of, social and political liberation" ("Consumer Society" 56). These messages imply that marginalised people can overcome sexist, racist and sexuality-based oppression simply through consumption, placing the responsibility for these oppressions not on oppressive people and systems, but on marginalised people's lack of ability to fulfil consumer roles.

Robert Hackett, Richard Pinet and Myles Ruggles assert that advertisers are interested in two audiences: the wealthy, who have sufficient funds to purchase luxury goods; and the mass audience, which is large enough to offset individual 
consumers' lack of funds. Because advertisers concentrate on affluent audience members, media producers try to attract these wealthy audiences (265). As such, news media tend to frame stories from the perspective of the dominant groups who generally own this wealth to the exclusion of marginalised groups (266). When diversity of content is reduced, information about, and perspectives from, marginalised people are the first to be discarded. By relying on stereotypes and under-representing marginalised groups, in addition to denying marginalised individuals' employment in positions that would allow them to influence media content, mainstream media ensure that systems of power that privilege dominant groups, while oppressing marginalised groups, continue unchallenged.

A feature of mainstream media in Canada that makes these media even more powerful is the degree of concentrated ownership..$^{39}$ Many media corporations have merged, forming conglomerations that control vast media empires. As such, any failings with mainstream media are amplified by lack of alternatives and competition. The power that mainstream media wield is considerable, and difficult to challenge. Conglomeration increases this power, and makes challenging mainstream media that much more difficult.

Writing in 1951, Marshall McLuhan had high hopes for the media technologies of the $20^{\text {th }}$ century, stating that the mass audience they garnered could "be used as a creative, participating force." While McLuhan acknowledges that mainstream media is not yet being used in such a way, he nevertheless asserts that a "new form of 'politics' is emerging" with people participating via their television in activities such as "Freedom Marches, in war, revolution, pollution and other events" (22). This sharing of knowledge, theorized McLuhan, would mean that marginalised people could "no longer be contained [or] ignored" as "too many people know too 
much about each other." This knowledge of each other, asserts McLuhan, "compels commitment and participation," as the involvement with one another created by media such as television compels us to be responsible for each other (24). What McLuhan didn't consider was the effect that corporatisation would have on mainstream media, and the control that conglomerates would assert over media products, thus hindering the spread of information so crucial to McLuhan's predictions.

\section{Alternatives to the mainstream: Different practices and inclusive cultures}

The cultural environment that allows for the unchecked production and consumption of mainstream media is not, however, inevitable. There is space for the cultivation of alternative medias and alternative environments. Bhabha's theorising on this space indicates how alternative cultural products can emerge, and how they can present a significant challenge to mainstream media products. Bhabha proposes a model of cultural production that invites participation by marginalised groups. $\mathrm{He}$ critiques current models, which create hierarchies and conflict and permit only dominant groups to engage in production. His model allows for resistance to these hierarchies and for marginalised voices to be heard.

Bhabha asserts that practices of cultural diversity work to marginalise nondominant groups. Cultural diversity models rely on the objectification of nondominant groups, allowing for oppressions like racism to develop. Bhabha posits that a model of cultural difference, however, allows for non-hierarchical, different groups to coexist. Key to the understanding of his cultural difference model is the notion that culture is constructed in the space between objects and signifiers. Because all cultures are formed in this ambiguous way, no one culture is superior to 
another. Bhabha refers to this space of cultural construction as the third space. This third space, which follows cultural difference practices such as negotiation and the acceptance of non-unity, allows for agency within and outside of the third space itself. For example, Bhabha challenges the superiority of modern practices of consensus by interrogating accepted understandings of colonial practices. $\mathrm{He}$ challenges the modern demand for unity, which leads to cultural diversity practices, by arguing for a fuller understanding of its genealogy. Bhabha's critique of cultural diversity, and its foundation in modern demands for unity, creates space for alternative models, such as his suggestion of practices of cultural difference.

Bhabha draws a distinction between practices of cultural difference and cultural diversity. Practices of cultural diversity, he asserts, recognise specific "cultural contents and customs"; the dominant culture views other cultures as objects of knowledge. This construction of cultures as knowable entities doesn't allow for the separated cultures to relate to one another. Nor does it acknowledge any overlap or dialogue between cultures. Rather, each culture exists as a mythic identity category ("Commitment to Theory" 34 ). In a cultural diversity model, once a dominant culture recognises dissimilar cultures, it then finds a "mediator or metaphor of otherness" in order to contain the effects of the divergent aspects of the dissimilar cultures (3I).

Bhabha describes one method of othering as occurring textually, noting that while the other "is cited, quoted, framed, [and] illuminated," by cultural diversity practices, these practices take away the other's "power to signify, to negate, to initiate its historic desire, [and] to establish its own institutional and oppositional discourse." While these "other" cultures may be empirically well understood and "anti-ethnocentrically" represented, they are located outside of the norm and in a 
realm of knowable subjects. This produces "a relation of domination," allowing for oppressive practices ("Commitment to Theory" $3 \mathrm{I}$ ). Bhabha's description of textual othering theorises the aforementioned critiques of sexism and racism in mainstream media. When marginalised people are presented in mainstream media in stereotypical and limited ways, these representations not only reinforce negative stereotypes, but also frame marginalised people as knowable others.

Bhabha believes that in the United States, a strategy of cultural containment through diversity practices manifests as multiculturalism. Policies and practices of multiculturalism are an attempt to respond to, and control, articulations of cultural difference. These practices delineate a 'norm' constituted of the dominant culture and diverse 'others,' but don't recognise the fact of this construction ("Third Space" 208-09). Bhabha notes two problems created by multicultural practices. The first is the aforementioned construction of a norm, which acts to contain the cultural diversity it encourages within a norm-centred framework. This constitution of a norm creates a second problem, as it permits a universalism that "masks ethnocentric norms, values and interests," thus allowing for various forms of "rampant" racism to thrive (208). These multicultural practices of othering appear in mainstream media representations of racialised cultural events and celebrations. While these stories present racialised people in positive lights, they again reinforce otherness, and the notion that racialised cultures are not complex and nuanced, but simple, knowable topics.

A cultural difference model, however, doesn't create a central norm from which to differentiate other cultures, thus discouraging hierarchical valuations of cultures. ${ }^{40}$ Instead of a dominant culture objectifying other cultures, cultural difference models aim to rearticulate various cultures from the positions of these 
cultures' participants, acknowledging these groups as authoritative sources on their cultural practices ("Commitment to Theory" 34; "Dissemination". r62). What further distinguishes a cultural difference model from cultural diversity is that cultural difference allows separate and possibly conflicting cultures to exist without attempting to reconcile them ("Dissemination" I62). Bhabha states that attempting to "fit together" different cultures, and "pretend[ing] that they can easily coexist" is counterproductive, and even impossible ("Third Space" 209). At the same time, Bhabha claims that the changing nature of the public sphere demands "a notion of politics which is based on unequal, uneven, multiple and potentially antagonistic, political identities" (208, italics in original). The alternative to allowing conflicting identities is to gloss over these differences and deny the lived realities of people who belong to multiple identity groups. In order for Bhabha's model to work, institutions like mainstream media would have to be radically reformed. Not only would they have to cease presenting marginalised people as non-norm others, mainstream media would have to embrace self-representation by marginalised groups. In Bhabha's model, capitalist goals of media-as-business would be set aside and hierarchies of desirable audiences abandoned.

Additionally, Bhabha's idea of cultural difference assumes that political groups, like other objects, do not exist in a concrete sense. Nor do the labels used refer to a unitary or homogeneous group. These labels for groups are constructed by discourses, the priorities of which are in tension with the priorities of other discourses ("Commitment to Theory" 26). When these discourses insist on essentialising the groups they prioritise, they create tension with other constructions when reality interferes with the essentialised groups, as the effect of an essentialist group identity is to normalise and homogenise other forms of cultural 
difference. Bhabha asserts that people and groups with political and social goals should use a model of cultural difference, which doesn't call for this problematic assimilation ("Third Space" 213 ). He asserts that with a cultural difference model, universalisation is no longer necessary to legitimate political action and cultural practice ("Third Space" 213). Mainstream media demand essentialised categories of people in order to sell these audiences to their advertisers most effectively (Beer 177). But as Bhabha indicates, these essentialised groups are false, as they are not as homogeneous as indicated. Only media not constrained by profit motivation can consider the fluid and intersecting nature of these groups effectively.

\section{Problematising authority and making space for cultural resistance}

Bhabha argues that acceptance of the idea that multiple meanings, and therefore cultures, can be developed from the same objects and events problematises the authority of any dominant cultural representation. When cultural systems are understood as constructed in the "contradictory and ambivalent space" in between the signified and signifier, hierarchical claims about the originality or "purity" of cultures, and the power associated with these claims, are untenable ("Commitment to Theory" 37; "Third Space" 21 I). Cultural representations of the past are particularly at issue, because they are used to construct authority, based on a "pastness" that is not necessarily faithful to historical events, or which only represents one group's experiences of those events ("Commitment to Theory" 35 ). In particular, Bhabha is suspicious of cultures with "long and tyrannical histories of domination and misrecognition" as their purported cultural unity or totality may be a fiction enforced by the dominant culture. Bhabha's analysis is well suited to Canada, where violent colonial history is masked by official "It's a Small World 
After All"-type multiculturalism. By largely ignoring this colonial history, more subtle contemporary racism directed at Aboriginal people is not framed as colonial. As Bhabha's work suggests, the fiction of a unified multicultural Canada is enforced by a dominant culture.

When we understand that historical "truth" propping up dominant cultures is, in fact, only an interpretation, space is created for "translational moves of resistance" and the challenging of these dominant generalities ("Translator Translated" I 14). When non-dominant groups discuss history, their stories dislodge not just the histories they contradict, but the power structures built on those histories ("Dissemination" 162). For example, when a dominant group uses cultural differences as the "linchpin of a particular political edict or strategy," acknowledgement of alternative histories unsettles the ability of the dominant group to defend policies based purely on a (fabricated) cultural supremacy ("Commitment to Theory" 34; "Translator Translated" 82).

Bhabha calls the space of cultural creation in between a word and object a "third space," and calls the process of cultural negotiation that occurs there a process of "hybridity." ${ }^{4 \mathrm{I}}$ Third space displaces the histories derived from both dominant and marginalised cultures, and "sets up new structures of authority" ("Third Space" 2I I). The processes of hybridity allows for the combination of various meanings and discourses without giving any of them authority over another - including "original" discourses, which Bhabha labels "prior only in the sense of being anterior." The process of hybridity creates new spaces for negotiation of meanings and representations and systems and codes, while maintaining "traces of those feelings and practices which inform it," ("Third Space" 21 I; "Identity" 27). Third space provides a space for cultures, both marginal and dominant, to interact 
outside of the cultural diversity model. Third spaces exist outside mainstream media and consumerism, and their accompanying hierarchies. As such, cultural products produced by marginalised people are valued, as are their producers, not in relation to dominant cultures.

Third space, with its negotiations of culture and hybridity, works on a model of cultural difference. As such, third space processes do not require homogeneity or unity. Since third space both accepts and regulates antagonistic and conflicting elements "without rushing to produce a unity," it allows a tension and negotiation of that tension without demanding a "transcendent" story. When cultures conflict in third space, the goal is not to convince one side to the other, but to open up a space of hybridity where the construction of new ideas can remove expectations and change forms of recognition. Third space or hybrid sites "open up a cleavage in the language of culture" that constantly refers to the ambiguity of signs and the potential for multiple cultural meanings (Bhabha "Dissemination" I63). This allows for the destruction of the polarity "between knowledge and its objects" and also between groups ("Commitment to Theory" 25; 39).

Bhabha asserts that the tension in third space allows for the creation of ideas that cannot be contained in that third space, or by the elements that contributed to it. As such, these new ideas cannot be contextualised within the dominant culture, as cultural diversity models demand ("Dissemination" I63). Cultural products from a third space do not fit easily into models of cultural diversity - they do not necessarily accept the dominant norms or hierarchies that cultural diversity demands. Bhabha states that when these ideas focus on what he calls emergent "forms of historical agency" - when groups put forward histories that conflict with the dominant culture's interpretation of the same historical events or periods - there 
is potential for the negotiation of authority over society and stories ("Commitment to Theory" 33; "Translator Translated" I I4). These knowledges challenge not only the facts of history, but also the containment strategies of generalisation of knowledge and homogenisation of experience so crucial to cultural diversity (“Dissemination 163 ).

Bhabha asserts that individuals and groups with political and social goals should use a model of cultural difference, which does not call for problematic assimilation ("Third Space" 2I3). Here, Bhabha refers to the homogenising that can occur within a marginalised group as, for example, when feminist groups don't consider how race or sexuality might impact their members, but work from an essentialised definition of women. While this type of essentialising is damaging and inaccurate, it is often defended as necessary for effecting political change. Bhabha, however, believes that by demanding a unity from groups, we overburden our visions of political change ("Commitment to Theory" 38 ). He asserts that with a cultural difference model, universalisation is no longer necessary to legitimate political action and cultural practice ("Third Space" 213).

Zines are an example of the type of third-space cultural product that Bhabha theorises on. With third-wave community building especially, feminists have taken care to attempt community and coalition structures that allow for the "difference" that Bhabha discusses (as opposed to diversity) within their communities. In chapter three, I explore further how third wavers consider identity categories along the same lines as Bhabha - considering identity-based groups to be constructions that are sometimes useful, but also problematic. I also discuss how third wavers use zines to avoid the commodification that can threaten activist and resistant work. Here I examine how zines adhere to riot-grrrl inspired third-wave principles of 
inclusiveness, anti-capitalism and resistance to oppression. Third-wave feminists and other activists have incorporated zine making into their repertoire of resistance tools because zines allow them the freedom to build space and to share information.

\section{Conclusion}

Bhabha's proposal of a cultural environment of producers counters overwhelming environments of mainstream media and consumerism. Practices of cultural difference, rather than of cultural diversity, counter the oppressions that these environments amplify. Third-wave feminist practices of cultural production are an example of resistance to these environments through third space practices.

One way that third wavers build feminist space and coalitions and resist oppression is through the publishing of zines. In chapter two, I will examine how zine publishing is a community-building activity with roots in first- and secondwave feminism, with zine makers sharing information and ideas of accessibility in production and distribution that enhance this resistance. 
${ }^{I}$ Of the sixteen participants in this questionnaire, twelve consider themselves to be feminist, while four do not. Of those that do consider themselves feminist, seven defined feminism like participant 3, who stated: "I see it as my role to try and question all forms of oppression." While traditional feminist issues such as women's rights, gender roles and patriarchy were common examples of what participants consider feminism to be, so were concerns about issues of violence, health and queer issues. Participant I I describes her understanding of feminism as speaking up about the oppressions and privileges that she experiences and working as an ally to those who experience forms of oppression that she doesn't: "I believe in building bridges between marginalized groups and social justice movements, rather than succumbing to the old "divide and conquer" strategies that those in power use to keep the majority of people oppressed." These answers demonstrate an expansive understanding of feminism.

${ }^{2}$ See also Mitchell \& Karaian 62.

${ }^{3}$ Steenbergen, "Talkin"” 263-64; see also Harris, "Riding" 28, 3 I; Heywood \& Drake 4.

${ }^{4}$ Ferree \& Hess viii-ix; see also Garrison I64.

${ }^{5}$ See J. Armstrong, “Web Grrrls” I02; Garrison I 45; Heywood \& Drake I. When definitions of third-wave feminism centre on placing it in opposition to second wave, the focus tends to be on second-wave feminism's purported universalisation of the category woman as predominantly "middle-class, white, able-bodied, and heterosexual" (Diaz ıo; see also J. Armstrong, "Web Grrrls" IO2; Piano; Pinterics I6). This essentialising, states Pinterics, organised around women's “sameness" at the expense of their differences (I6). This explanation of third-wave feminism states that third-wave feminists work to build upon the changes brought about by second-wave feminists and continue to use "what works" from existing feminist theories. They combine this, however, with critiques of second-wave theory brought forward, for example, by racialised women and women arguing for nonessentialised forms of sexual expression (Garrison I45; see also Piano; Pinterics I7, I9).

"See J. Armstrong, "Web Grrrls" I02; Diaz Io, I 5; Garrison I 45, I49-50; Gillis \& Munford i68; Harris, "Not Waving"; Harris, "Riding" 28-29; Heywood \& Drake 3; Klein 207-8; Piano; Pinterics 16.

7 In considering gender, third wavers work to push "the boundaries and limitations of gender definition" (Pinterics I7; see also Mitchell \& Karaian 60). Mitchell and Karaian describe third-wave understandings of gender as such: "there is no correct way to be female, feminine, or a "woman"” (71; see also Davis 316, 320).

${ }^{8}$ Pinterics I7; see also Ferris 54; Garrison I 55, I6I; Heywood \& Drake 3.

9 Pinterics I6; see also Diaz I 5; Gillis \& Munford I7 I; Klein 207-8, 224-25; Mitchell \& Karaian 59-60.

10 Surfergrrrls attributes the term grrrl to activist and Bikini Kill singer Kathleen Hanna, who coined it as a reclamation of the word girl. Surfergrrrls states that "Grrrl' puts the growl back in our pussycat throats" (Surfergrrrls in Garrison I4I; see also Jacques 49; Schilt, "A Little" 6). Brasile expands on this, noting that the reclamation of derogatory identity labels is a common oppositional tactic. She adds that the term grrrl signalled a refusal to adhere to the stereotypes of girl; grrrls 
refuse to be "polite, silent, and subservient," and are ready to riot against injustices (63; see also Jacques 49). Schilt adds that the use of girl is a nod to childhood as a time when "girls have the strongest self-esteem and belief in themselves," "A Little" 6). Overall, the term signifies aggression and power, but directed toward injustice: it is a demand to be heard and considered.

" See Arthur 209; Bell, "Riding"; Gillis \& Munford I70; Klein 21 3-2 I 5; Reynolds \& Press 323-24; Schilt, "A Little" 6; Wald 594. While the two locations are distant, in the summer of 1991, Olympia-based bands Bratmobile and Bikini Kill went to D.C. for an "extended stay" (Klein 2 I 3). This visit bridged the two locations.

${ }_{12}$ The IPU was a record club organised in the late 1980 s by Calvin Johnson, founder of the independent record label K records. Members received 7"s (small records) with an Olympia-based band's song on one side, and an internationally known band's song on the other (S. Thompson 58 ).

${ }^{13}$ See Jacques 47; Klein 2 I 3-I s; S. Thompson 58-59.

${ }_{14}$ The bands that played were: Heavens to Betsy of Olympia, Washington; Jean Smith of Vancouver, British Columbia; Mecca Normal of British Columbia and Bratmobile of Eugene, Oregon (S. Thompson 58-9).

Is Klein 2 I3-I 5; see also Gillis \& Munford I70; Jacques 47.

${ }^{16}$ Robbins I 24; see also Ferris 52; Mitchell \& Karaian 67; Villacorta.

${ }^{17}$ One of the ways that riot grrrl bands challenged sexism, both within and outside of punk, was through the appropriation of "masculine" punk music (Davis 3 I 9; Klein 2 IO-I I; Schilt, “A Little” I I).

${ }^{18}$ See Jacques 48-49; Piano; Reynolds \& Press 323-24; S. Thompson 60.

${ }^{19}$ Schilt, "A Little" 9; see also Tucker qtd. in S. Thompson 70.

${ }^{20}$ See Jacques 48; Schilt, "A Little" 8; S. Thompson 60.

${ }^{21}$ At the weekly meetings, grrrls discussed political, emotional and sexual issues, held workshops on self-defence and other skills, engaged in collective creative endeavours and spent positive social time with other girls and women (See Brasile 64; Gillis \& Munford I70; Klein 2 I 3-I 5 ).

${ }^{22}$ Jacques 48; Robbins I 25 ; see also Reynolds \& Press 324.

${ }^{23}$ Reynolds \& Press 324; see also Jacques 47; Wald 594.

${ }^{24}$ See Driscoll i 84-85; Jacques 50; S. Thompson 60.

${ }^{25}$ Brasile 63; see also Garrison i 54, i 56. Riot grrrl's challenge to consumerism included a rejection of "traditional rockist ideas of "cool' and mystique," as well as the concept that "technical virtuosity" was a "prerequisite for creative endeavour" (Reynolds \& Press 324). Riot grrrl music instead emphasised other aspects of communal music experience over technical skill, including political messaging, enthusiasm and group participation.

${ }^{26}$ Schilt emphasises the importance of avoiding major record labels, noting that recording contracts could force bands to "tone down" their music and change their image ("A Little" IO). S. Thompson asserts that "most important" riot grrrl record label was Kill Rock Stars, founded by Slim Moon in r991 (59).

${ }^{27}$ Mainstream media are largely owned by conglomerates (see Auletta 3 I; Barber I 39-40; Hackett, Pinet and Ruggles 263-64; Taras, Power 7 I, 76, i I 5; Vipond, Mass Media $3^{\text {rd }}$ ed. $\left.63,72-74\right)$. As such, these conglomerates use their media to promote consumerism, in order to increase their profits (see Baumgardner \& Richards Io8I Io; Hackett, Pinet and Ruggles 260). Additionally, these conglomerates are motivated to reduce the presence of marginalised voices in their media to reduce the 
cost of producing this media (see Barber I 37-38; Friese 90; Hackett, Pinet \& Ruggles 260-62; McLuhan 21; Osler 300; Taras, Power 2 I 5; Vipond, Mass Media, $3^{\text {rd }}$ ed. 4-5, 62-69; Warde I7; Winter xiii), to maintain their positions of privilege (see M.

Andersen 55, 61; Hackett, Pinet and Ruggles 259; Ross I I 3-I 4; Winter I 40, I 6 6, I 19), and to undercut resistant movements that threaten this privilege (see M.

Andersen 55; Hackett, Pinet and Ruggles 258, 259; Ross I I 4).

${ }^{28}$ When referring to this piece, the author of which is cited as "Riot Grrrl," I will capitalise Riot Grrrl. When referring to the movement, I will not capitalise riot grrrl. ${ }_{29}$ Mainstream media rely heavily on the use of stereotypes (see M. Andersen $55-56$, 62; R. Andersen 224-25; Baumgardner \& Richards I02; Beer 164, I7I-73, I77; Ferris 52; Fleras 407, 4I 2-25; Graydon I 44-50; Robinson \& Saint-Jean 32; Ross I I 2, I 17 , I 25; Roth I75; Steenbergen, "Feminism" I 2; Tuchman, 530-3 I; Winter I I 8). These stereotypes are damaging to marginalised people, and reinforce power structures that privilege others (see M. Andersen 57; Graydon I 57; hooks, "Killing Rage" I09IO, I I 5-I7; Ross II 3; Tuchman 53 I, 539).

${ }^{30}$ Steenbergen "Talkin"” 259; see also Baumgardner \& Richards 79, 94; Pozner 35. ${ }^{31}$ See Arnould \& Price I I ; Driscoll i 76; Featherstone I7, 85; Firat \& Dholakia 2, I 28; Friese 27, 94-95, 98, 245; Gabriel \& Lang 44, 78, 83-87; Lunt 247, 249; Pooler 4, 45, 48; Ritzer 64; Solomon, Zaichkowsky \& Polegato I 54; C. Thompson I 3 I; Thompson \& Tambyah 59 .

${ }^{32}$ See Firat \& Dholakia 46, I 28; Friese I 5; Gabriel \& Lang 8; McLuhan 58; Pooler 3; Solomon, Zaichkowsky \& Polegato I 53-54; Veblen 74; Warde 13.

${ }^{33}$ For discussion of boycotting as an economically privileged form of protest, see Brasile 65.

${ }^{34}$ See Firat \& Dholakia 37; Riordan \& Meehan xiii; Warde 196.

${ }^{35}$ Ritzer 44, 64; see also Baudrillard, "System of Objects" I 3; Friese 90.

${ }^{36}$ This lack of choice imposed by mass-production, however, is masked. Ritzer, along with Fuat Firat and Nikhilesh Dholakia, asserts that when individuals make choices among the offered goods, their decisions get counted as authentic choices. Ritzer, however, adds that these choices are really made based on "the lack of available alternatives" (63; see also Firat \& Dholakia 37).

${ }^{37}$ While the lack of female involvement in the production of mainstream media is often cited as the reason for mis- and under-representation of women, this reasoning is rarely cited as a reason for the mis- and under-representation of racialised or queer people. Instead, the lack of portrayal of racialised and queer people is blamed on other factors. This allows media producers to excuse themselves from changing their products to better represent reality, while also avoiding the need to hire racially and sexuality diverse staff to create realistic products.

${ }^{38}$ Beer defines Latina magazines as American magazines made for American Latina women and produced in English with smatterings of Spanish (I65).

${ }^{39}$ Media ownership in Canada is concentrated in the hands of a few powerful individuals and corporations (see Hackett, Pinet and Ruggles 26I-62; Osler 296; Power 77, I I 5; Vipond, Mass Media $2^{\text {nd }}$ ed. 83-85; Vipond, Mass Media $3^{\text {rd }}$ ed. $74^{-}$ 76).

${ }_{4 \circ}$ Bhabha's model of cultural difference is dependent on his concept of culture. $\mathrm{He}$ asserts that while cultures have different features from one another, they are related because culture itself is a "signifying or symbolic activity" ("The Third Space" 210 ). The meaning necessary for culture is constructed in the separation between the 
word for an object or activity and the object or activity itself ("The Third Space" 210; "Commitment to Theory" 36, 38).

${ }^{41}$ Bhabha uses negotiation broadly, to describe any interaction of differing cultures and not to indicate compromise or consolidated meanings ("Dissemination 163 ). $\mathrm{He}$ asserts that these negotiations, which constitute the process of hybridity, are constant as "any situation of political opposition or antagonism" demands negotiation ("The Third Space" 216). Whenever relations of power or authority exist there is negotiation of "demands, of wills, of meanings" rather than the submission of the less powerful to the dominant ("Identity" 25, 27). In Bhabha's definition, practices of subversion and transgression are types of negotiation - they are how the marginalised claim power. 


\section{Chapter 2}

\section{Grrrls Just Wanna Have Printruns: \\ Feminist Publishing Across the Waves}

\section{Introduction: Publications of the women's movements}

Feminism boasts a long history of using cultural products, particularly publications, as a practice of resistance. From suffragist pamphlets to second-wave newspapers to third-wave zines, feminists create publications to address the issues for which they fight. While these publications may appear in vastly different forms and discuss dissimilar topics, their goals and intentions remain remarkably similar. While the environments in which feminists resist constantly evolve, and while the technologies available to them also evolve, a strong continuity of fighting for change via publishing runs through the different waves of feminism.

In this chapter, I describe how first-wave feminists in Canada and the United States used newspapers and pamphlets to disseminate information about the suffrage movement. Next, I turn to how second-wave feminists employed newspapers as a type of consciousness-raising tool to draw attention and membership to the women's movement. Thirdly, I consider how third-wave feminists use zines as a space to give marginalised people a voice. While the explicit aims of each movement appear disparate, each wave turned to the means of publication available to them to share information, build their movement, and challenge mainstream culture and society across the geographical and social barriers. Finally, I examine the content of a sample of Canadian second-wave newspapers and Canadian zines to draw out further similarities and differences between the two types of publications, and discuss the implications of these comparisons. The 
similarities between the different types of publications indicate the ongoing oppression, and resistance to oppression, that feminists fight. The differences in how each wave uses publications speaks to the specific environments, and resulting oppressions, they resist.

First-wave publishing: Disseminating information about women's suffrage The Canadian and American first-wave women's movements of the midnineteenth century published prolifically, though these activists preferred to meet in person rather than communicate on paper (Jerry $2 \mathrm{I}$; Kerr I I). The more radical branch of the woman's suffrage movement in the United States, the National Woman Suffrage Association, began publishing The Revolution in 1868 (Bloomberg 32; Solomon 9). This weekly newspaper discussed suffrage, as well as broader considerations of women's rights in areas such as marriage, law, land policy, abortion, sex education, cooperative housekeeping, organised religion and prostitution. ${ }^{1}$ In addition, The Revolution's authors wrote extensively about the social and sexual oppression of women in marriage and the differing standards and expectations for women and men in these relationships. ${ }^{2}$ The similarly named American Woman Suffrage Association, which focused solely on suffrage in order to reduce controversy, started the Woman's Journal in $1870 .{ }^{3}$ While these papers enjoyed a far reach in the United States, at least thirty-one other women's suffrage newspapers started between I 870 and I 890 , including The Woman's Era, which worked specifically to organise Black women (Flexner \& Fitzpatrick I 8 I; Jerry 24). By I920, however, women's suffrage was well covered in the mainstream press, and demand for, and publication of, these papers decreased significantly (Jerry 26-7).

These feminist newspapers played a number of roles in the first wave of the 
women's movement. Firstly, until the I920s, the women's suffrage movement in the United States was unable to get sympathetic coverage in the mainstream press, if they could get any coverage at all (Solomon 3, I 3). While mainstream newspapers were interested in increasing their female readership, they attempted to do so by increasing content in the areas of "home, fashion, and etiquette rather than women's rights" (Jerry 19). Newspapers sympathetic to the suffrage-promoting American Equal Rights Association emphasised Black male suffrage, and avoided publishing articles on women's suffrage for fear of ruining the chances of expanding male suffrage (22). By creating their own publications, feminists publicised their own goals, and countered antagonistic accounts of women's suffrage events.

In particular, feminist newspapers were necessary because of the complications imposed by geographic distances as well as the social and economic position of some women within society. ${ }^{4}$ Newspapers bridged these distances and often circulated among multiple readers.' Lois Waisbrooker's Foundation Principles, for example, boasted correspondents in at least twenty-four states. The majority of her readers, however, lived in rural Kansas, Illinois and Iowa, demonstrating that these papers reached geographically marginalised women (Passet 238). Publications also allowed the women's movement to reach wider demographics - including women from different economic classes, men, women reluctant or unable to attend a public meeting, women who didn't think of themselves as feminist, and women alienated by the "white-gloved, middle-class suffragists". ${ }^{6}$ Feminist newspapers "were able to bridge the gaps of time and distance, educating and uniting women across the country" building a community of women across distance and social barriers (Solomon I 5 ; see also Passet 239, 240). In some cases, feminist newspaper editors drew on the cultural traditions that frontier women developed to cope with 
isolation. In her newspaper, The Woman's Tribune, Clara Bewick Colby exploited the rich tradition of letter writing among frontier women, adding her publication to the existing social community created through writing. ${ }^{7}$ These women already had created a community; Colby simply added her feminist voice to that community and extended its reach.

The message that these publications disseminated to women was the same as the message they spread at their conventions: convincing women that they had issues and problems in common and that they had the right to seek solutions to those issues and problems, while also providing role models that countered the prevailing stereotypes of women (Solomon I3). Since women had few opportunities to meet other women's rights activists, publications played a key role in assuring women that activist was an acceptable role for women (Bloomberg 36). Colby, in an effort to show women that they did not have to give up "what it meant to be a turnof-the-century 'woman' in order to also be a 'feminist,'” included articles that discussed the daily lives of women alongside more radical feminist ideas (30; see also 57, 59). Kristin Mapel Bloomberg contends that by doing this, "Colby gives her readers permission to integrate a political analysis of women's roles into their daily routines" in a way that was non-confrontational for her readers (43; see also 28, 30). This type of publication fulfilled another aim of the women's movement - providing information and news that would sustain women's commitment to the cause, even if they were unable to attend women's movement events in person (Solomon I 5 ).

First-wave publications in Canada differed from those in the United States. In Catherine Cleverdon's comprehensive book, The Woman Suffrage Movement in Canada, she makes mention of only one feminist newspaper, Women's Sphere, which was published by L'Alliance Canadienne pour le Vote des Femmes du 
Québec (222, 232-33). Kandace Kerr adds The Champion, the newspaper of the British Columbian Political Equity League, which worked like its American counterparts to spread suffragist messages across a sparsely populated province (I I). 9 Canadian suffragists, however, generally produced other "literature" in the form of pamphlets. This consisted of opinion pieces written by suffrage supporters, reprinted letters to the editor written by suffrage associations and pieces written by literature committees of suffrage associations on topics like the legal status of women in different provinces..$^{\text {To }}$ These pamphlets were distributed in rural areas and at large urban events, such as the 1937 Canadian Manufacturers' Exhibit in Montreal, where 20,000 suffrage pamphlets were handed out (Cleverdon 192, 249). In particular, the Montreal Suffrage Association actively distributed and sold suffrage literature. Their Literature Bureau, headquartered at the Edinburgh Café, sold literature and otherwise spread the word daily from three to six pm (225). ${ }^{\mathrm{II}}$ While pamphlets tended to be issue-specific, they did much of the same work as suffragist newspapers, providing information and reaching out to potential supporters.

Canadian suffragists found wide support from other groups in Canada which advocated for suffrage in their organisational newsletters, or gave over print space to suffragists. Many of these groups supported suffrage not just in principle, but because it also aligned with their own interests. Labour unions avidly supported the cause, believing that women's suffrage would lead to protective legislation for women workers and gain equal wages for women. ${ }^{12}$ Other labour organisers maintained that if working women had the vote, the chances of electing (male) working-class representatives would increase (Bacchi I I 8 ). ${ }^{13}$ In most cases, these supportive organisations saw that women's suffrage would benefit their male 
members in addition to women. Consequently, they lobbied government, drew in new supporters, and published pro-suffrage information and opinions. The widespread support for women's suffrage from these organisations arguably decreased the need for suffragist newspapers, as these groups helped to spread prosuffrage information and advocated for suffrage - a service not available to American suffragists. With this degree of support from mainstream media, Canadian suffragists did not need to produce their own newspapers to secure fair reporting of their events or to disseminate their messages about suffrage.

Organisations demonstrated their support for suffrage by campaigning for women's suffrage in their own publications. The Winnipeg Voice first published articles in favour of women's suffrage in 1902 and the B.C. Federationist officially endorsed women's suffrage in 1913 and published a weekly suffrage page edited by Helena Gutteridge. ${ }^{14}$ In many cases, suffrage associations exercised direct influence over editorial content. For example, Sarah Curzon, a member of the Toronto Women's Literary Club, was associate editor of the Canadian Citizen, a Toronto weekly that promoted prohibition. ${ }^{\text {Is }}$ The Canadian Citizen made a column available to the Toronto Women's Literary Club, and was the first paper in Canada to officially support women's suffrage (Bacchi 26, 72; Cleverdon 20-2I). In I909, Flora MacDonald Denison, who later became president of the Canadian Suffrage Association, began writing a regular column in the Toronto World, which disseminated suffrage movement information (Ray 46, 87). In Halifax, E.M. Murray, a leader in Halifax's women's groups, was an influential member of the editorial staff of the Halifax Morning Chronicle and Echo (Cleverdon I $57 \mathrm{n}$ ). Francis M. Beynon, a “militant feminist," became the women's editor of the Grain Growers' Guide in 19 12. Like Colby in the United States, Beynon wrote about women's daily lives 
with articles on "washing sweaters, baking Christmas puddings [and] painless childbirth" alongside articles pushing for equal pay for equal work, challenging the idea of women's "natural" child-raising abilities, and criticising the concept of women as property (Mahood 27). As with Colby's publication, this mixing of politics with everyday life would allow women to encounter radical politics in a non-confrontational manner. The focus of Beynon's column, however, was suffrage, and she advocated, advertised gatherings, and gave advice to other organisations. ${ }^{16}$ Beynon, in contrast to eastern women's groups, challenged the disenfranchising of aliens during the war, and criticised Nellie McClung for excluding foreign-born Canadian women from her demand for women's franchise (Mahood 27). ${ }^{17}$ Both organisational and mainstream newspapers reflected support for women's rights by including women in their editorial staff. These women frequently took advantage of this control, using editorial space in these newspapers to lobby for suffrage.

In the case of The Provincial Freeman, Canada's first anti-slavery newspaper, editor Mary Ann Shadd Cary enjoyed complete control over content. ${ }^{18}$ While her focus was on the abolition movement and immigration of Black Americans to Canada, Shadd Cary was also a suffragist, and her paper's content reflected her politics (Sadlier 37). ${ }^{19}$ Issues discussed in The Provincial Freeman were sometimes picked up in more widely distributed papers, allowing Shadd Cary's work to spread beyond the readership of her abolitionist paper (43). The unusual degree of control that Shadd Cary had over the paper came at the cost of initially crediting a supporter of hers and the paper, Samuel Ward, as the editor, and later by editing under the gender-anonymous name, M.A. Shadd (Sadlier 33; Walcott 33). When Shadd Cary revealed her gender in October 1854 , public reaction was so negative that Shadd 
Cary moved the headquarters of the paper from Toronto to Chatham, where she believed that a larger Black population would be more supportive (Sadlier 46 ). Shadd Cary held more power at a newspaper than any other woman at the time, but her need to remain gender-anonymous demonstrates that while powerful Canadians accepted educated white women editing and writing women's pages, even when those pages contained suffragist articles, they did not accept a Black woman as chief editor of a newspaper. Racism and sexism combined to oppress Shadd Cary in ways that white women and Black men were exempt from.

Because the situation for suffragists in Canada differed from that in the United States, their publishing strategies also differed. Canadian suffragists faced less animosity from the mainstream press than their American counterparts. As a result, they did not have to focus as intently on countering negative messages in the mainstream press or in communicating information about their meetings. The Canadian mainstream press, in which first-wave feminists played a role, addressed the issues of isolating distance and social inequity that drove American feminists to publish. Because Canadian suffragists did not feel the same pressure to publish their own newspapers, they were largely able to focus their resources elsewhere. The difference between Canadian and American first-wave publishing tactics is an early example of how different contexts call for different resistance strategies.

\section{The history of second-wave publishing: Making the news(papers)}

Little research exists on second-wave feminist publications, and they are not well represented in library collections (Samek I $3 \mathrm{I}$ ). In her article on radical feminist publishing in the American South, Ashli Stokes comments that while the first wave of feminism was oratorical, the second wave presents a challenge to researchers 
because of its reliance on alternative ways of communicating, such as newsletters, pamphlets, postering and recorded songs. These forms of communication were available only recently, with the advent of inexpensive printing technologies (Piano). Artefacts of the second wave, as such, are often hard to locate. Consequently, information about their content and form is sparse and largely American-focused. The Canadian newspapers in my sample, however, did not contradict the research done on American publications; Canadian publications also were elements of second-wave initiatives to disseminate information, develop the movement and build community among feminists.

Rosalyn Baxandall and Linda Gordon, in the introduction to their anthology of women's liberation movement writings, call the printed publications produced by the radical feminists of the women's movement vital, and note that a “significant" proportion of women's groups' resources and time went into creating and distributing them. ${ }^{20}$ While, for the most part, each individual publication reached only a small number of readers, Ferree and Hess assert that "cumulatively they provided a vast network of common reference" $(78)$. This network allowed second-wave feminists to reach beyond their usual audience and introduce feminist ideas to new minds.

In making and distributing their own publications, the second wave drew heavily on the experiences of the student and civil rights movements, as well as the first wave of the women's movement. Ferree and Hess comment that the second wave of the women's movement, following the student and civil rights movements, required an inexpensive and effective way to communicate with its members, so like these movements, the women's movement turned to mimeographed newsletters (78). Judith Hole and Ellen Levine assert that this ability to draw on other 
movements' experiences allowed the women's movement to grow rapidly (270). While the student and civil rights movements first had to develop a network of underground papers, this structure and knowledge was in place for the women's movement.

In the United States, the I960s saw local organisations producing newsletters, and feminist newspapers in larger cities such as Milwaukee and Cleveland (Ferree \& Hess 78). The first independent radical feminist newsletter, Voice of the Women's Liberation Movement, appeared in Chicago in 1968 (Hole \& Levine 407). By the 1970s, publications emerged that spoke to women in specific demographics or situations, such as women of colour, working women, lesbian feminists, and women in various specific professions and academic disciplines (Ferree \& Hess 78). They also came from, and spoke to, the "moderate and conservative" branches of the movement, in addition to the radical element (Hole \& Levine 27I). The number of feminist publications in the United States grew to over soo by the mid I970s (D. Armstrong 229; Baxandall \& Gordon I 5). This rapid growth attests to Hole and Levine's assertion that feminists accessed communications systems already in place, but also indicates the popularity of the movement and its publications, and the dedication of its members.

In her study of southern American feminist publications, Stokes found that the format of these newspapers were "typical of Women's Liberation newspapers generally." ${ }^{\text {2x }}$ She describes these typical publications as averaging five pages, hand published and distributed quarterly. The content included articles on women's health, employment and other "regionally specific" content (93). Hole and Levine elaborate on this description, noting that the publications ranged from "the extremely amateur and local to the highly professional and nationally distributed" 
(27I). Baxandall and Gordon add that these publications were created and maintained without funding or paid staff. Articles were frequently published anonymously or under first names only, as "the movement was hostile to the idea of intellectual private property" (I s). Because of irregular financing, stemming from women's less-privileged economic status, most publications were short-lived (Baxandall \& Gordon I6). Their goals, however, were not to produce regular, mainstream papers; rather, the second wave of the women's movement saw publications as a means to further feminist goals, instead of an end in themselves.

\section{Goals of second-wave publishing: Raising consciousnesses; building a movement}

Ellen Willis credits the communication strategies of radical feminism with the movement's initial quick growth and influence, asserting that publications were a crucial tactic used by radical feminists to reach potential converts and spread their messages outside of the movement (9I). Ferree and Hess agree, noting that since mainstream methods of communication, such as sympathetic mainstream media coverage or expensive self-publications, generally were not accessible to feminist groups, as with most social movements, they had to find "inexpensive and effective" ways of initiating and maintaining contact with members and potential members (78). Newsletters and newspapers, as inexpensive and accessible media, allowed the movement to reach a broader audience.

Newsletters available to individuals beyond the women's movement were key, as much of the focus of the second-wave women's movement was on “institutional policy and political change" (Steenbergen "Feminism and Young Women" 6). Feminist newspapers presented mainstream media and policy makers with accessible feminist critique and information. My sample of second-wave 
newspapers includes critiques of specific government policies and services that failed women, of sexism and racism in education and of women's economic role. ${ }^{22}$ In order to influence those in power, second-wave feminists needed a presence in mainstream media (Ferree \& Hess 8I). This presence would allow them to reach out both to policy makers and women outside of their feminist circles (Ferree \& Hess $82-83,84)$.

Feminist publications also functioned to raise awareness about feminist issues with feminist readers. Stokes draws parallels between second-wave publications and the consciousness-raising groups that the movement held (97) ${ }^{23}$ She divides this role into "soft" and "hard" consciousness raising, using definitions suggested by Claudia Dreifus's study of consciousness-raising groups. Soft consciousness raising describes the work women did in sharing experiences and realising their common condition, while hard consciousness raising describes the activism that women then engaged in to change these conditions (Dreifus I6). In the case of feminist newspapers, Stokes maintains that playful and humorous articles describing the "arbitrary nature" of beauty standards, or expressing sadness at these standards, fulfil a soft consciousness-raising role in helping women feel less alone and fortifying them against the regional pressures they felt in the American South. ${ }^{24}$ Sharing experiences and examining what those experiences meant also helped women develop feminist identities and communities (Stokes 99, 100), or as Aphra phrased it, offered women the "shock of recognition" (rpt. in Garvey 374; see also Garvey 368). ${ }^{25}$ Stokes sees the publications of radical feminists as an extension of other work done in consciousness-raising groups, but in a form that was accessible to women unable to attend such sessions in person, a sentiment echoed by secondwave publishers themselves. ${ }^{26}$ 
In addition to outreach, feminist newspapers also shaped the movement itself. Toni Samek asserts that feminist publications provided "social spaces" that allowed for the development and growth of a feminist analysis of women's oppression and the sharing of ideas, actions and resources (139). For example, newspapers in my sample contained information about other publications and listings for women's groups and centres (see Figure ra on page 68). ${ }^{27}$ This type of information would allow readers to access further feminist resources and encouraged them to become more involved in the movement. Stokes also describes the hard consciousness-raising role of second-wave newspapers in instances where they included discussions on what actions should be taken, and what actions would most quickly induce the changes feminists wanted in society (IO2). Baxandall and Gordon add that in addition to discussions on action, feminist publications contained "the most creative and cutting-edge theory and commentary" of the movement (I6). Not all these critical writings were supportive of the dominant trends in second-wave publishing. In a special "black women's" issue of Conditions, a feminist magazine that highlighted lesbian writing, writers called attention to the lack of writing by Black feminists and lesbians in other publications - feminists who felt marginalised by the dominant trends of second-wave feminism spoke out in the space provided by publications against their marginalisation (Garvey 368 ).

Newspapers allowed for a movement that, to a degree, evolved through consultation and consensus among as diverse a readership as could be reached. ${ }^{28}$

In Controversy and Coalition, Ferree and Hess write that feminist publications demonstrated that "experiences were indeed shared," building a community among women who, in reading about other women's experiences, realised that their situations were not unique, and that a community could be 
formed (78). On a theoretical level, Nancy Adamson et al note that in sharing different perspectives, feminism acknowledges that different "categories of experience within feminism" exist, thereby challenging the idea that woman is an "overriding, unitary category of experience" (I7I). In my sample, examples of different perspectives include regional reports and French-language articles.

While these two views - that publications demonstrated to women their common identity, and that they showed that women experienced that common identity differently - are superficially contradictory, they are not incompatible. In reading about other women's experiences, women recognised the overarching phenomenon of patriarchal oppression, while understanding that, based on their unique circumstances, women would experience that oppression in different ways. In taking care to understand these differences, the women's movement more accurately represented more women's interests. This type of development led to a stronger, more cohesive community than would have evolved otherwise.

While the first- and second-wave movements in both Canada and the United States faced different challenges, parallels can be drawn. Certainly, geographic distance between women was a more pressing issue for the first wave, but with barriers to feminist discourses in mainstream media, second-wave feminists also faced the complex issue of reaching out to women. Both groups used printed publications to address the issue of outreach and to build community among existing members. In addition, printed publications enabled each movement to present its views to mainstream society, whether through sharing of reading material in the first wave or by attracting the attention of mainstream media in the second.

\section{The history of third-wave publishing: Radical xeroxing}


The third wave of the women's movement links both the traditions and experiences of previous feminisms' publications and punk and queer-girl manifestations of fanzines (Brasile 66, Klein 216). ${ }^{29}$ In I991, Allison Wolfe and Molly Neuman created what is regarded as the first third-wave feminist zine, Riot Grrrl (Robbins I25, see also Klein 213-15). The new type of publication was extremely popular - when Sassy, a teen magazine from the early I990s, published the addresses of several zine makers, many zine makers were so overwhelmed with the amount of mail they received that they were unable to continue publishing (Schilt, "A Little" 7). By the early I990s, over ten thousand zines were being published in the United States (Gunderloy \& Goldberg I). ${ }^{30}$ In effect, third-wave feminists took a popular form of publishing and exploited its potential to fulfil feminist goals, much in the same way that previous waves of feminism made use of publication forms available to them.

Inexorably linked to the sudden rise in zine making, and particularly feminist zine making, was the advent of modern photocopying technology. McLuhan and Quentin Fiore claim that xerography "herald[ed] the times of instant publishing" and allowed anyone to be an author or a publisher (McLuhan \& Fiore I23). Zine makers took advantage of this publishing technology, exploiting the wide and inexpensive access and ease-of-use that photocopying provided. ${ }^{31}$ Photocopying also allowed for more creativity with the final product (and required less technical know-how) than previous printing technologies (Garvey 397; Gunderloy \& Goldberg I 57). Because photocopying technology became so widespread and inexpensive, it extended available sites for resistance..$^{32}$ For example, Garrison asserts that Kathleen Hanna, a founder of riot grrrl, was not unique in her anger toward the sexism and violence in the American punk scene and wider society, but that her 
use of communications technologies, such as photocopying, allowed her to express her anger publicly, and to build a resistance movement (I 56 ).

Because the means of print production are so ubiquitous, Ellen Gruber Garvey claims that "print itself cannot be controlled - or even effectively regulated" by any regulatory body, profession or economic class of people (367). Xerography offers zine makers complete "editorial, political, and artistic control" (Piano). In addition, Matthew Smith notes that self-publishing "escape[s] the limitations imposed by the gatekeepers of mass media publications." ${ }^{33}$ Further, because zines are not created for financial profit, zine makers need not consider the commercial or advertising viability of their products, allowing them more freedom than most other cultural producers. ${ }^{34}$ This freedom means that individuals previously excluded from participation in cultural production due to an inability to meet mainstream standards now are able to produce their own products. These assertions are reflected in the responses of the zine makers in my sample: of the 16 people I questioned, 3 published in zines because of an inability to publish in mainstream periodicals and 2 additional participants turned to zines to avoid being edited. Four noted zines' ability to avoid censorship, with participant 9 stating that zines 'can't be dictated to by others, "publishers"; so you see the stuff that's as "rough as guts".” Adela Licona adds a feminist perspective to this claim, asserting that zines offer a site for "self and Other representation" without the "reductive, phallogocentrism required" in mainstream media (I09; see also Wald 594). Because zine writers are also zine producers, they need not adhere to frequently patriarchal mainstream conventions. Instead, their products can legitimise marginalised people's cultural products. Without these constraints, zine makers may consider topics, and perspectives on topics, that are not considered by the mainstream (Garvey 397; see 
also Green \& Taormino xi). Xerography offers zine makers the ability to produce these cultural products completely, with more individuals able to participate in this type of cultural production.

\section{Goals of third-wave publishing: Trying to build an inclusive movement}

Third-wave feminists make use of these publication opportunities to pursue many goals similar to those that second-wave feminists sought with their newspapers. With the homogenisation and corporatisation of mainstream media, zine makers create a space for perspectives and expressions currently excluded from mainstream culture and media, allowing marginalised people to reach out to one another and paralleling the way that second-wave newspapers worked to recruit women to the movement by disseminating information that illustrated the shared circumstances of women's oppression. While second-wave publications worked to attract the attention of mainstream media, in hopes of further sp reading their messages, third-wave feminists focus on critiquing mainstream media. Like secondwave publications, zines work to raise the consciousnesses of their readers by sharing unprofitable information that is excluded from mainstream media. Zines, like second-wave publications, also offer a space in which readers and writers can guide the development of feminist movements through reflection and critique of dominant strains within movements. While these goals may manifest in different ways, by considering the environments within which second and third-wave publishers resist, strong continuities between the movements become evident.

A central project of feminist zines is to model resistance. The mere presence of a feminist voice counters the backlash rhetoric that feminism has "petered out and failed" (Gillis \& Munford I70). Of the sixteen zine makers I questioned, twelve 
identified their zine as a type of activism, with five specifically calling them feminist activism, indicating that a high proportion of these zine makers produce their zines with a social impact in mind. Zines work to remind feminists that they are not alone in their resistance, and to encourage potential feminists to see their own issues and struggles as part of a larger system. ${ }^{35}$ Because zines are a DIY project, they also inherently encourage others to make their own products - the production of feminist zines encourages and inspires others to tell their own stories and perform their own activism, building a movement through demonstration. ${ }^{36}$ Participant 5 states that the greatest impact of zines is their "anyone can do it" aesthetic: zines "force you to get involved because there are no excuses not to." This goal of thirdwave publications - to create a presence for themselves, and to encourage participation - parallels the work of second-wave publications to disseminate information, and to recruit women to their cause.

Because Western culture marginalises the voices and experiences of women and girls, in addition to other oppressed groups, the act of speaking, or writing, is in itself an act of resistance. ${ }^{37}$ Green and Taormino note the link between women's historical exclusion from communication and their limited access to social powerby speaking, feminists are contesting this exclusion from both communication and power (xii). Frequently, these writings include what $\mathrm{S}$. Thompson calls "the secret history of girls and young women": the history of taboo subjects such as "rape, incest, and eating disorders" (S. Thompson 68-69; Schilt, “A Little” 6). By speaking these histories, girls and women overcome the isolation that these experiences encourage, and they are able to share their outrage and shame - expressions that are also discouraged by dominant culture (Duncombe, "Alienated Together" 44I; see also Licona I I4). Because these experiences generally aren't portrayed in mainstream 
culture, the act of describing them resists the mainstream culture that ignores these experiences, implying that they don't exist, and legitimates the experiences of these girls and women (Duncombe, "Alienated Together" 446; Garrison I 2). Many girls and women feel compelled to define their realities in this manner and to express themselves through zines, in the face of a society and culture that ignores them..$^{38}$ Five of my participants saw their zines as a venue in which to express themselves, while three of those same participants, along with two others, noted the capacity of zines to, as phrased by participant 2, give "voice to realities and passions which are absent in the dominant culture". These expressions work to create a reality in which the oppression of girls and women is acknowledged, and act as a call for feminist resistance.

In addition to limiting or excluding the histories of girls and women, homogenised mainstream culture and media also limit the expression of complex and contradictory perspectives. Licona suggests that zines offer a space "from which to speak ambiguity and contradiction," which are usually not present in mainstream culture (IO9). In particular, states Licona, mainstream cultural products ignore the intersections of different identities, especially if those identities are contradictory but zines give their producers the ability to discuss even the most complicated of identities (I 24).

Sabrina Margarita Alcantara-Tan's article, “The Herstory of Bamboo Girl Zine," describes the omission of complex identities from mainstream media, and her reaction to this absence. In explaining why she began to make a zine, Alcantara-Tan, a self-described queer, mixed-blood, Asian woman, explains that "growing up, I searched like crazy for publications that spoke to me... but decided that my unique voice was too specific - or worse - even wrong" (34I). Unable to see herself reflected 
in the cultural products around her, Alcantara-Tan created a zine that discussed her experiences and concerns. Alcantara-Tan's zine developed a print run of over 3000 copies, indicating that she was neither too specific nor wrong, but that her complex identity and interests were not easy to capitalise on (347).

Third-wave feminists critique the previously discussed media exclusion of women and other marginalised groups and the demands that media put on girls and women to meet mainstream media standards of how girls and women should look and act. ${ }^{39}$ An un-cited zine writer in Reynolds and Press's The Sex Revolts asserts that girls and women are caught between social expectations of femininity and social valuations that align "cool" with "male," resulting in a negative evaluation of girls and women as either feminine but un-cool or cool but unfeminine (325-26). As mainstream media and their impossible-to-meet standards evolve, third-wave feminists alter their strategies of resistance to confront these differences.

Third-wave feminists' cultural products are an implicit critique of media representations, and, in particular, a lack of representation. ${ }^{40}$ This sentiment echoed the results of my questionnaire in which participants spoke of a desire for "media and art that is more directly related to their life, or reflects their own community" (participant 2). ${ }^{4 \mathrm{~T}}$ Third wave products, in reflecting marginal perspectives, work to "demystify the power of the popular media" by claiming agency and authority (Steenbergen "Talkin' 'Bout” 264). Zine makers use their reclaimed authority to "create spaces where expert and authorized knowledges can be critically examined," allowing for the re-imagination of the practices and discourses of society and culture (Licona I I9).

In the absence of consciousness-raising groups, third-wave feminists turned to zines as a key method of raising individuals' consciousnesses. Two of the 
participants questioned considered their zines to be consciousness-raising tools, with participant I I answering question I9, "Do you try to fulfil any larger social goals through zine publishing? If so, what goals?" with "Oh you know, just ending oppression in all it's forms and helping add fuel to the fire of many worthwhile social justice movements, such as feminism." Zines work to share information not widely available through mainstream channels, work as a place to rewrite and reimagine histories and futures, and provide autobiographical content which allows writers to engage with topics considered personal. As such, they work like consciousness-raising groups in developing individuals' political consciousnesses.

A key role of zines is the sharing of information with readers. ${ }^{42}$ Frequently, this information centres on topics that are not discussed in mainstream media, or are otherwise unavailable. For example, grrrl zines include information that is not readily available to girls and young women, or is not available in an accessible or safe format, but which is of interest to girls and women to live healthy, safe, informed lives. Examples of this information include content that deals with birth control options, lesbian sex, coming out to parents and roommates, herbal remedies for gynaecological or menstrual issues, domestic rape, self-defence, masturbation and global female adolescent labour. ${ }^{43}$ Zines also contain information for developing critical consciousness such as quotations from feminist activists, lists of recommended texts, information about historical feminists (or riot grrrandmas), and recommended feminist music and fiction. ${ }^{44}$ Like newspapers, they also refer to other zines in order to help readers find similar material (see Figure $\mathrm{rb}$ on page 68). While in some cases, such as with menstruation or birth control, the information in zines may only clarify or make accessible information provided through authoritative sources such as health classes and doctors, in other cases, such as 


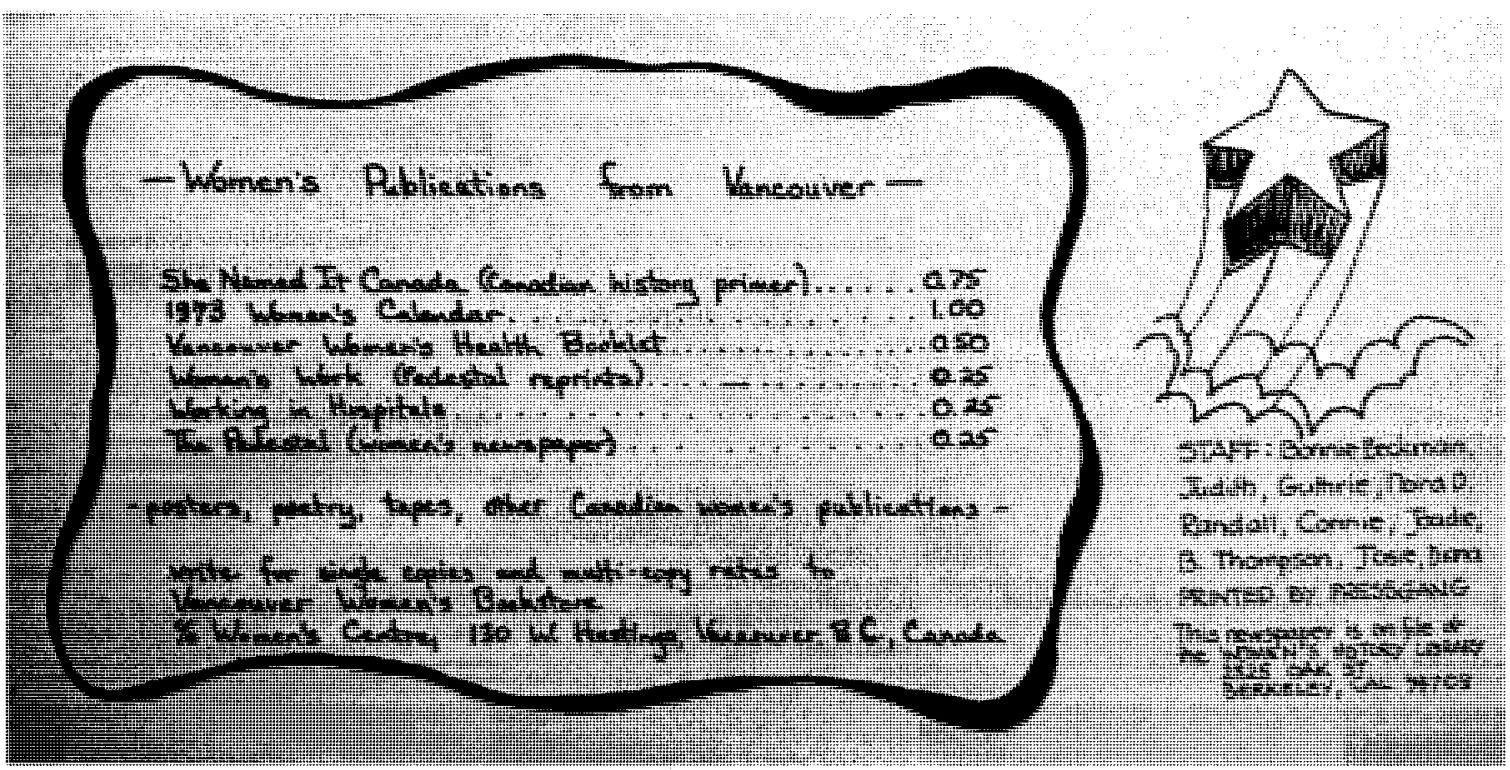

Figure 1a: List of recommended publications in The Pedestal: A Women's Liberation Newspaper 5.1, page 11. Published in Vancouver, BC.
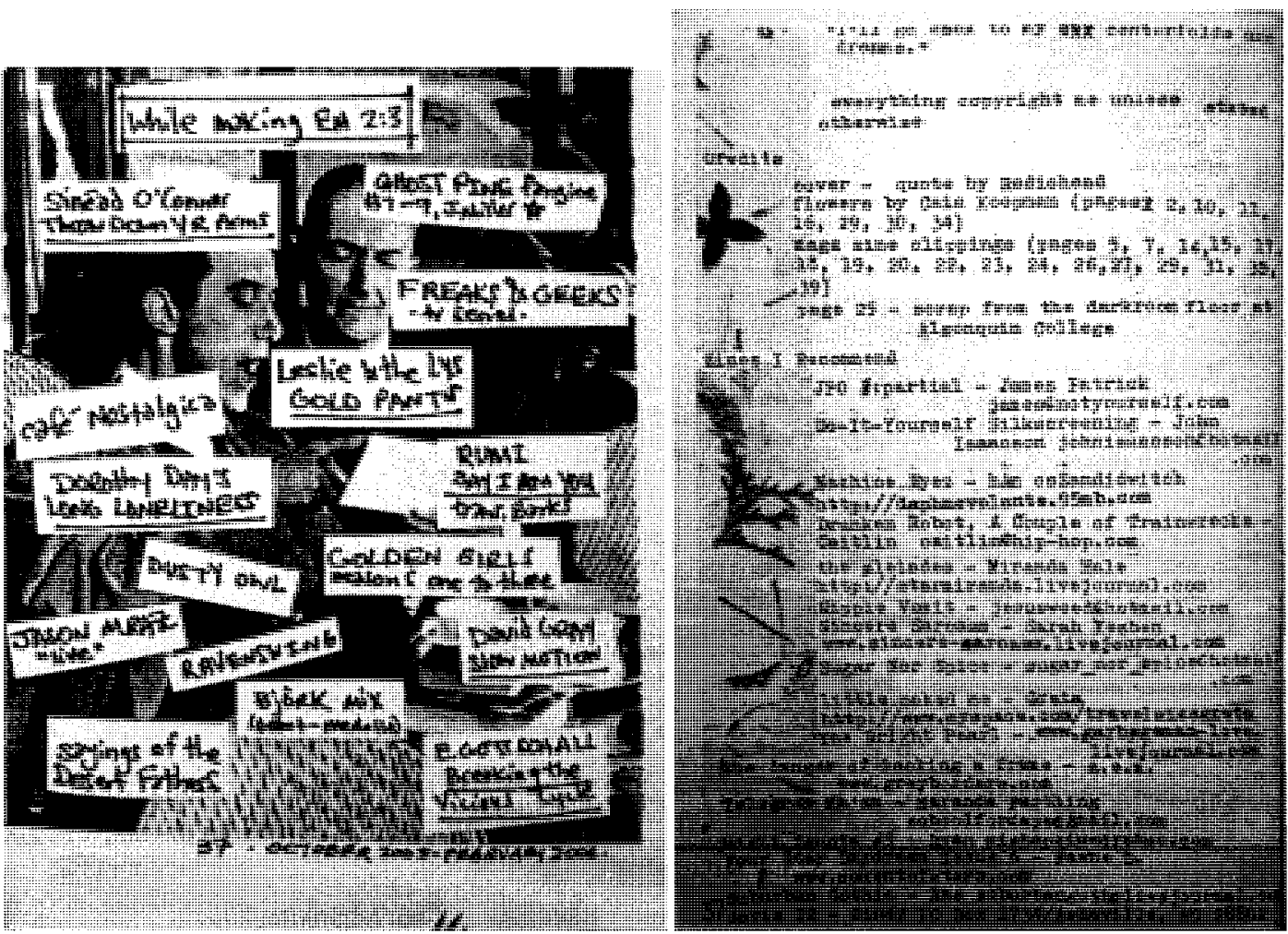

Figure 1 b: List of recommended publications in Sean Zio's Electric Mayhem 2.3, page 37 (February 2006) and Sarala B.'s Beautiful Mess 0, page 37. In the first example, note that there is no distinction made between books, television programs, and other zines. 
domestic rape and masturbation, this information may be the only information available to girls on these topics. Participant 6 speaks of her desire to "create a resource for girls young women that was not otherwise available" - a sentiment echoed by three other zine makers in my sample. In an environment where information that girls and women need is limited or obscured, girls and women have taken action to share this information amongst themselves, with zines providing a medium for this action.

The information available in zines differs from that in mainstream sources in that the writers and readers of this information often share similar identity categories. In the case of feminist zines, girls and women who rarely assume the role of "expert" in mainstream media, "act as experts on their own lives," providing information to other girls and women (see Figure 2 on page 70).45 Other marginalised groups use zines to share information that is either not deemed important enough to include in mainstream media, or which threatens the social power structures on which mainstream media producers rely. Examples of this include critical writing on race, sexuality, class and gender that many zine makers publish, in addition to zines dedicated to specific issues such as poverty and HIV/AIDS. ${ }^{46}$ Participant 16 describes the impact that access to such zines has, stating: "There is nothing like finding a queer manifesto or zine from the 70 and discovering that sense of history and solidarity with elders. That kind of history is not found in textbooks or in archives." As with grrrl zines, these zines makers resist an environment that considers them unimportant.

Zines are often autobiographical. ${ }^{47}$ In most cases, the autobiographical writing concentrates on daily life or ordinary experiences (Mitchell and Karaian 66; Sinor 252). Rebecca Hogan suggests that this type of writing is particularly 


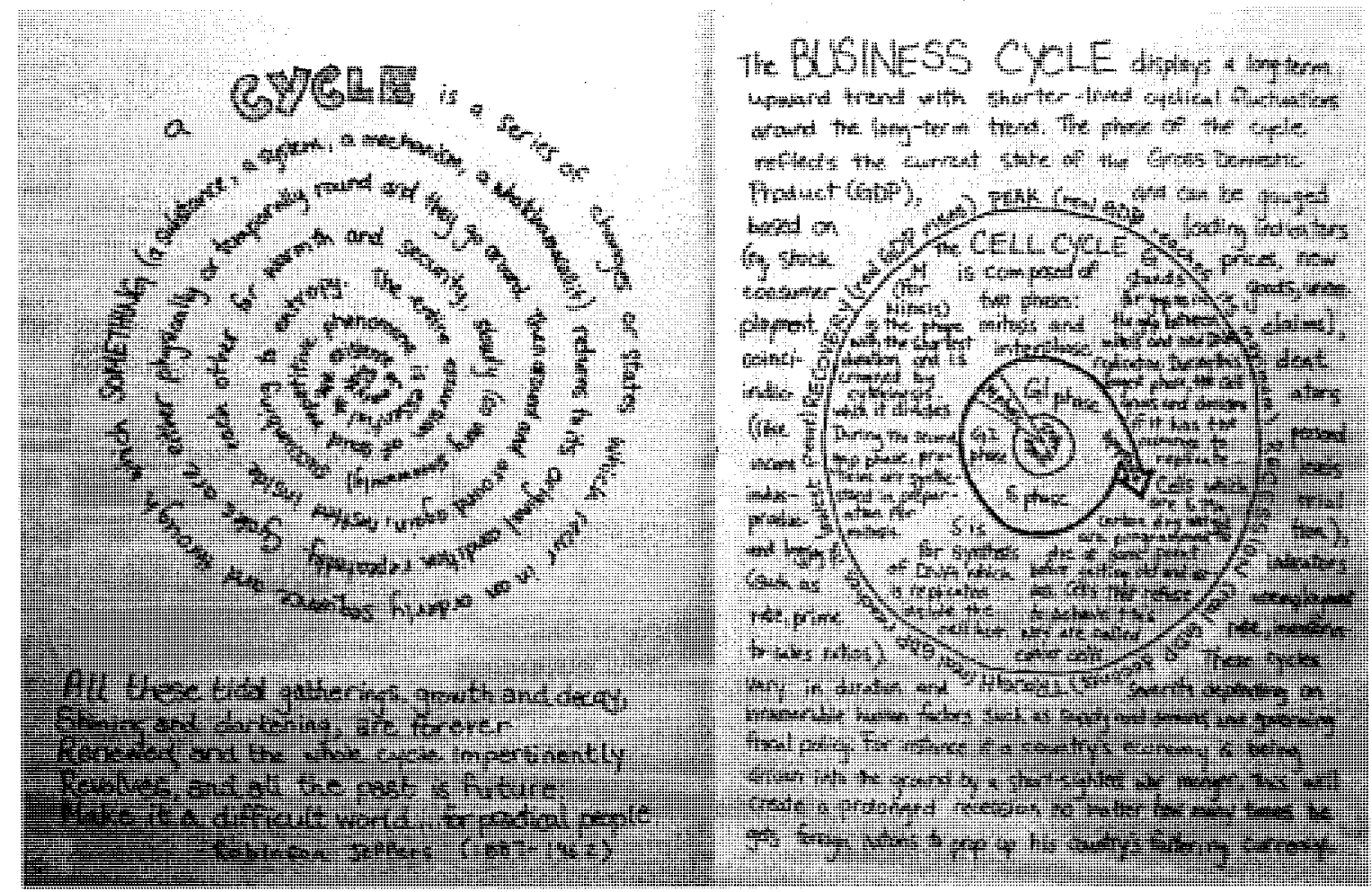

Figure 2: In Curses! 2, the author writes on business and science - two areas from which girls and women are discouraged from acting as experts. She also writes in an informal and accessible manner, with engaging formatting choices. These practices counter "expert" discourse in these fields, and encourage amateur participation. 
subversive because it "tends to cross and blur boundaries between things traditionally kept separate" (IO०). Hogan asserts that because autobiographical writing doesn't differently value "thoughts and feelings" of past and present selves, it blurs boundaries between self and others. In addition, because autobiographical writing attempts to preserve experiences, it crosses boundaries "between text and experience, art and life." Hogan concludes that autobiographical writing is an elastic form that combines many different types of writing to create a form that is "open to closer relations between world and text, author and text, reader and text" (I00). With this blurring of boundaries, zines are less focused on isolated topics, and more concerned with placing their discussions in a broader context, while maintaining a focus on widely held experiences.

Perhaps due to their autobiographical nature, the zines in my sample have a strong focus on interpersonal relationships, geography and self-conscious activism. Relationship topics include romantic relationships, ending relationships, not being over ended relationships, family relationships and the death of family members. Geography-based content includes the use of map imagery, information about where the zine was written, discussion of connection to certain places and travel (see Figure 3 on page 72). Discussions on activism include personal experiences, pieces on individual agency, fictional and historical pieces that positively portray activism, pieces that encourage others to engage in activism and zines that engage in activism themselves. All of these autobiographical elements work to place the writer within a greater context of their relationships to other people, their location and how they view their activist work.

This prevalence of autobiographical writing differs from the writing in first and second-wave texts, which were frequently journalistic, objective and focused on 

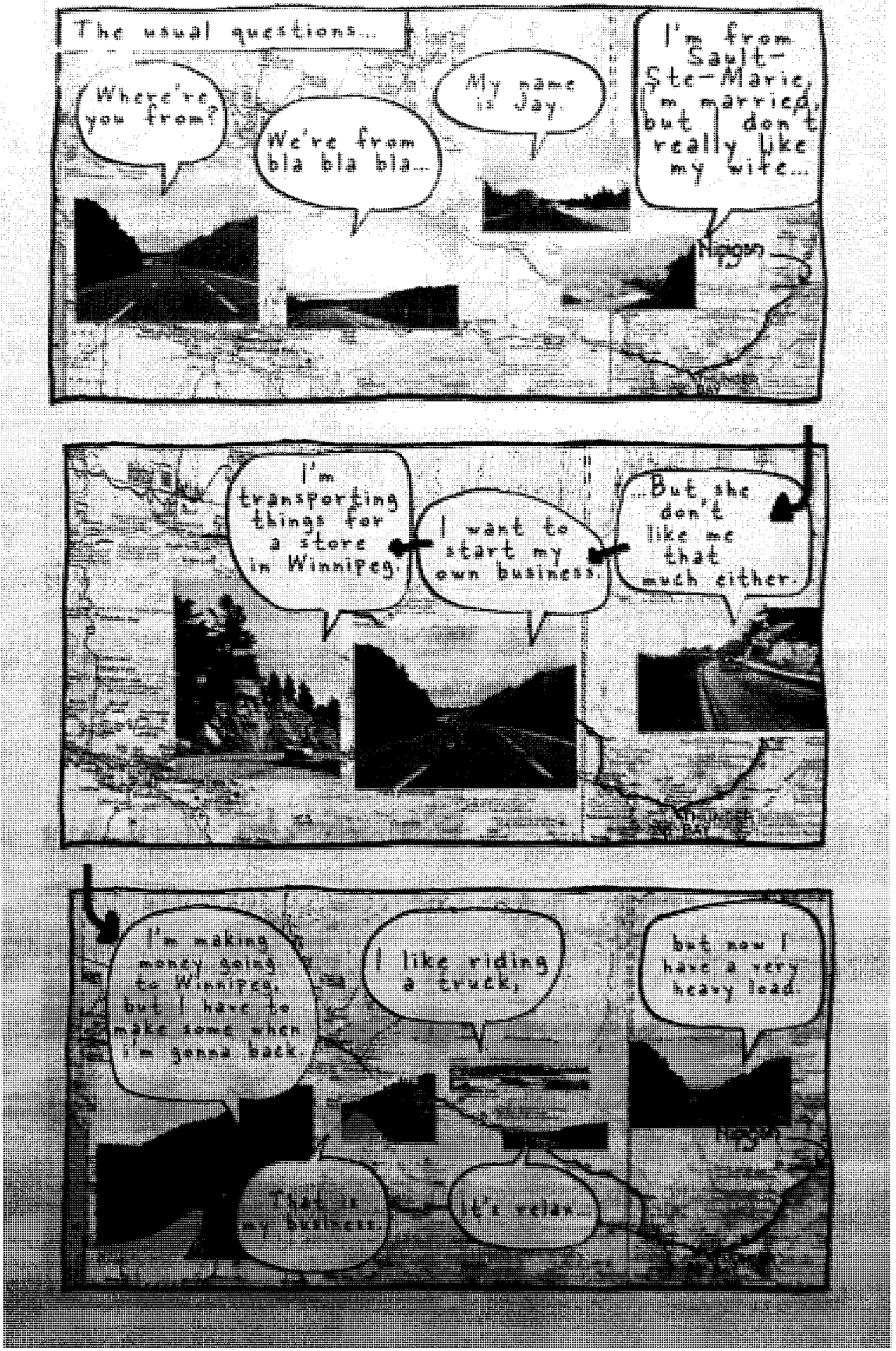

Figure 3: In this example of geographic imagery in Janaradan's "Hitch Lifts West," published in Gribeault 3, (Summer 2006), the background maps give a sense of location (Ontario) and a sense of movement, as the dialogue moves along the map with the characters. ${ }^{48}$ 
one topic. When second-wave feminists published, the existence of women-only spaces, such as newspapers produced solely by women, was a point of contention, as evidenced by many of the articles included in my sample of second-wave newspapers (see Figure 4 on page 74$).^{49}$ By writing in a journalistic manner, women showed that they were capable of objective and authoritative writing. This served as an example to women who read the papers that women were capable of this "men's work," and that women's issues deserved a place in mainstream-emulating media. In addition, these newspapers avoided features like recipes, which may have made their publications seem too feminine at a time when women were trying to break away from feminine stereotypes. By attempting to adhere to dominant journalistic norms, feminists challenged an environment that portrayed them as incapable of doing this type of work.

Conversely, the contemporary media environment is now over-run with authoritative individuals who claim to be objective. ${ }^{50}$ While women are rarely portrayed in mainstream media as authoritative experts, imitating these patriarchal figures, and trying to get the approval of mainstream media, is no longer the goal. Instead, feminists work to challenge the authority and assumed objectivity of mainstream media, through presenting alternative ways of sharing information, such as framing it through an autobiographical lens. The media landscape that feminists resist has changed substantially, so resistance has adapted in order to continue challenging mainstream media.

Even zines that are not explicitly autobiographical generally contain some information about their authors. Most zines have either an introductory or "outro" page (Chidgey 9; Sinor 257) (see Figure 5 on page 74)..$^{51}$ These personal pieces include information such as the author's reflections on the production of the zine, 


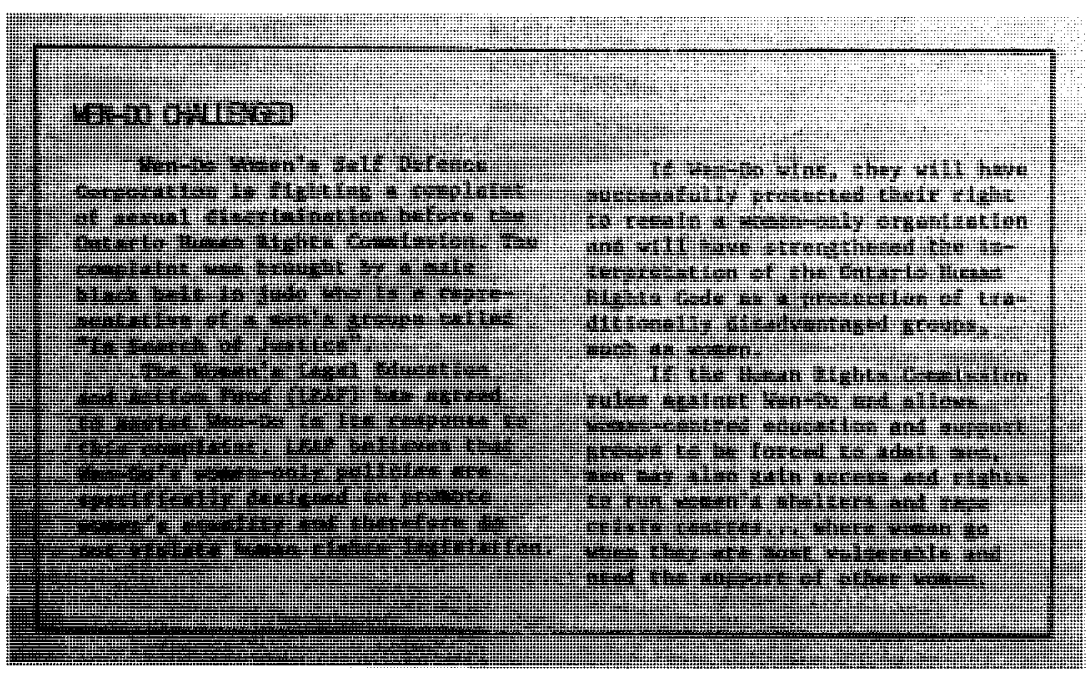

Figure 4: In this article from the second-wave newspaper, The Northern Woman 12.1, page 13 (July 1989), a women-only self-defence group has its women-only policy challenged. The article goes on to project implications to other women-only spaces if this challenge succeeds.

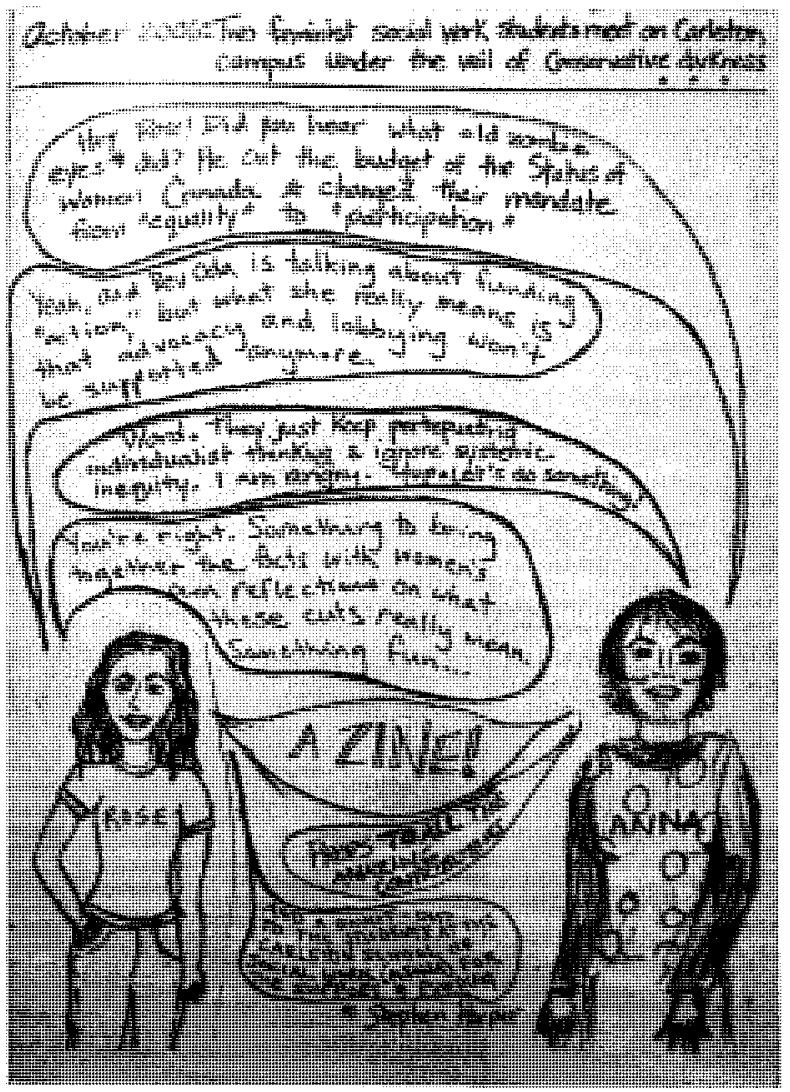

Figure 5: In the intro to Rose and Anna's Status Seekers, the zine makers describe their motivations for making their zine, thank contributors, and locate themselves geographically and politically. 
discussion of the theme of the zine, connections between the previous zine and the current one, autobiographical information such as geographic location and school or job occupation, acknowledgements for help or encouragement with the zine production, contact information and "soundtracks" or other cultural product recommendations (Sinor 257-58) (see Figure 6 on page 76 ). ${ }^{52}$ Red Chidgey asserts that these pieces are "signposting devices" that provide information that give context regarding the conditions of the production of the zine and "autobiographical imperative" $(9,10)$. In an environment in which information is passed on by often anonymous figures assumed to be objective, zines stand in contrast with authors who admit their biases and share personal information.

Because zine writers write from a localised standpoint, they allow themselves to delve into topics considered to be very personal. Zines frequently discuss issues absent from mainstream discussions, such as bodies, sexuality and abuse. Zines, as safe spaces to discuss these topics, work in similar ways to second-wave consciousness-raising groups, enabling marginalised people to see their personal experiences of oppression "as political issues rather than isolated personal incidents." ${ }^{33}$ In some cases, zine makers critique beauty standards imposed by mainstream media, while in others they focus on information and experiencesharing around issues like menarche and menstruation. ${ }^{54}$ These discussions contrast with the mainstream media environment, which adheres to strict body standards, implying that other bodies don't exist, and which portrays experiences like menstruation as shameful. In zines, girls and women can discuss their personal experiences of their bodies, and recognise that the oppression they feel from mainstream media is not personal, but rather an element of a sexist and oppressive system. 


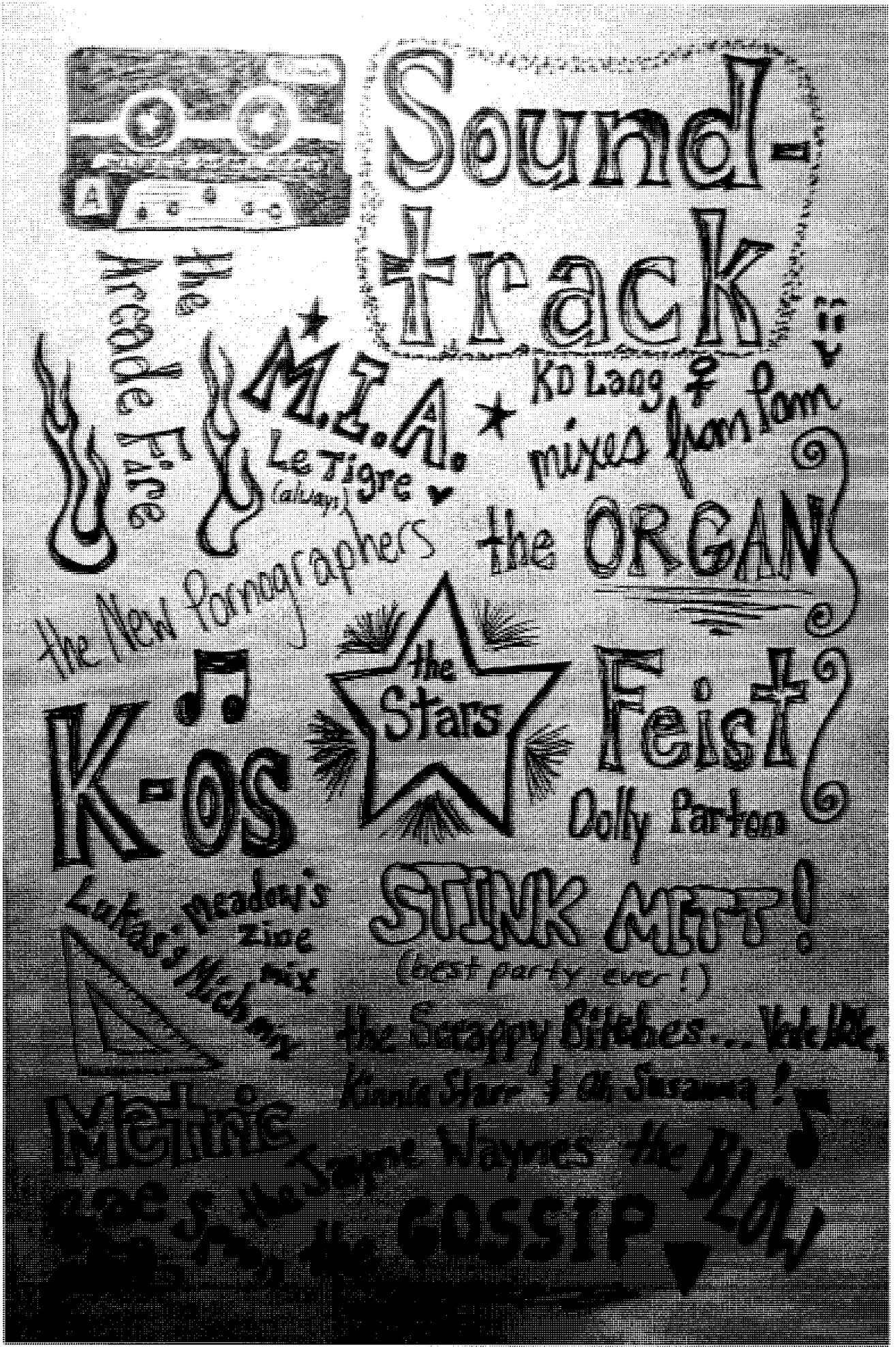

Figure 6: The inside back cover of Jess's Slightly More than Sound Bytes 4 (September 2005) features a graphically interesting soundtrack - music that the zine maker listened to while making the zine, and which she recommends. 
Female and queer sexualities are also represented narrowly in mainstream culture. In contrast, zine makers present varied perspectives on issues such as sexuality, desire, love, a sense of alienation from sexuality, sexual relationships, general information, problems and agency." The prevalence of discussions of sexuality indicates the conflict that feminists encounter when they attempt to reconcile mainstream media portrayals of acceptable sexuality and their own lived realities (Steenbergen, “Feminism" I2). In a media environment saturated with extremely limited versions of female sexuality, girls and women can use zines to discuss their contrary sexualities and the oppressiveness of mainstream portrayals.

Lesbians and gays also embrace zines as a medium to discuss sexuality. Catherine Orr notes a significant rise in "Gay, lesbian, bi, and queer-oriented zines," while zines not specific to queer issues also include discussions of queer topics. ${ }^{56}$ Schulman notes the lack of mainstream coverage of gay issues, and states that queer zines offer "one of the few unpackaged, uncensored published expressions of gay life now available" (qtd. in Long 402). Zines that discuss queer issues work much like those that discuss body, allowing individuals to express their reality and realise that their experiences are not as unusual as mainstream media imply.

Many zine makers also find zines a safe space to talk about physical, emotional and sexual abuse and self-mutilation, providing one of the few outlets where such discussions can occur (Schilt, "I'll Resist" 86). ${ }^{57}$ Zines also provide a space for victims to "speak out as survivors" and to "share success stories" to help other survivors of abuse (Klein 219). Since so many perceive abuse as an individual experience, zines play an especially crucial role in letting abused people know that their experiences are not unique, and in providing resources. While the 
consciousness-raising elements of zines differ from those of second-wave newspapers, their goals in sharing restricted information and leading readers to see personal oppressions as part of larger power systems are consistent. Zines work to raise consciousnesses and bring people into the feminist movement - once there, zines encourage feminists to actively critique and participate in the shaping and development of feminism itself.

Third-wave feminism, especially riot grrrl, is not without critics. Like the punk scene from which it arose, riot grrrl consisted largely of white girls and women and attracted few girls and women of colour. ${ }^{8}$ Riot grrrl, however, developed with a built-in critique mechanism - anyone critical of any element of the riot grrrl movement could publish and distribute a zine. Many writers took this opportunity to write about white privilege and racism within third-wave feminism, challenging riot grrrls to confront their racism. ${ }^{59}$ Zines produced by girls and women of colour interrupt the "often homogenizing voice of white, middle-class women zine editors who often tend to privilege gender issues, ignoring intersecting forms of oppression" and make their experiences of oppression visible and part of the discourse of third-wave feminism (Piano). By widening the definition of thirdwave feminism, these zine makers play a crucial role in creating a feminism that appeals to more people and draws more people to feminism.

In "A Freak Among Freaks," Bryn Austin and Pam Gregg examine how lesbian zine makers similarly challenge more mainstream lesbian and gay publications. While Austin and Gregg acknowledge the foundation of queer zines in both punk fanzines and the gay, lesbian and feminist presses, they assert that zines "deliberately situate themselves against this legacy" $\left(8_{3}\right) .{ }^{60}$ While many lesbians decry the "male content, perspective, and aesthetics" of more mainstream gay 
publications, Austin and Gregg assert that "for many lesbian 'zine makers, established feminist/lesbian publications are not much better" (83-4). For example, Austin and Gregg cite the habit of lesbian feminist publications of self-identifying as "women's publications," despite their volunteers, contributors and readership being largely lesbian $(85-86)$. Some lesbian zine makers respond to this by making sexuality a central theme of their zines, and by using explicit descriptions of sexuality (86). In response to the "exclusion by the lesbian community of identities deemed problematic or undesirable," Austin and Gregg assert that lesbian zine makers work to broaden the "parameters of what lesbians consider to be their issues" by calling on more mainstream lesbian media to consider issues such as AIDS and safer sex $(84,90)$.

These examples illustrate the critiques and negotiations that can be made in the space that zines offer (Duncombe, "Alienated Together" 447; Piano). This process of critique is more nuanced than feminist analyses of mainstream culture and media as it criticises from an insider perspective. This critique is vital, however, in ensuring that communities are as inclusive as they purport to be. In doing so, marginalised members of these groups participate in the formation of groups and movements, much like women in the second wave were able to guide the development of that movement through interaction through their publications.

A self-reflexive and cohesive community is key for groups looking to resist dominant environments. Smith asserts that such a community can more effectively affect mainstream texts (95-96). Using the example of a comic-book ezine community, Smith notes their ability both to garner mainstream media attention and to affect corporate decisions. Participant 16 refers to the zine community of which he feels a part as having "much, much challenge," which he contends is "the 
best sign of a healthy community." Communities that build a strong sense of cohesion through member interaction and member input to the dominant texts of that community are able to use that strength to organise easily around issues that threaten or affect their community. Licona asserts that zines have a further capacity: to "perform the difference they are trying to make" (Iog). By confronting and replacing exclusionary cultural and media practices, they "perform new representations of subjectivity," which act as "micro" practices of resistance and work to change society and media (IO9, I IO). The cultural space created by zines allows subjects to "explore alternatives to their fullest potential," and re-imagine historic presences and potential futures ( $\mathrm{I}_{3} 3$ ).

Zines intentionally work to build community through a number of practices. Zines themselves create networks among geographically distant individuals, and link people based on their interests.$^{65}$ Four questionnaire participants noted the community-building aspect of zines, with participant 2 describing them as such: "they are also little bonfires for people to gather around, become proactive and share." These networks then allow third-wave feminists to communicate with one another ${ }^{62}$ The community building aspects of zines also counter mainstream cultural elements that work to divide women and girls from one another. This "imposed separation" is a common topic of discussion in zines, as girls and women work to build coalitions despite cultural norms that require girls and women to compete with one another (Licona I 2I). These community-building practices explicitly counter these social expectations.

One of the more direct ways that zines create community is through the use of reviews and invitations to submit work for inclusion in the zine (see Figure $7 \mathrm{~b}$ on page $8 \mathrm{I}$ ). Austin and Gregg note a networking infrastructure created by zine makers 


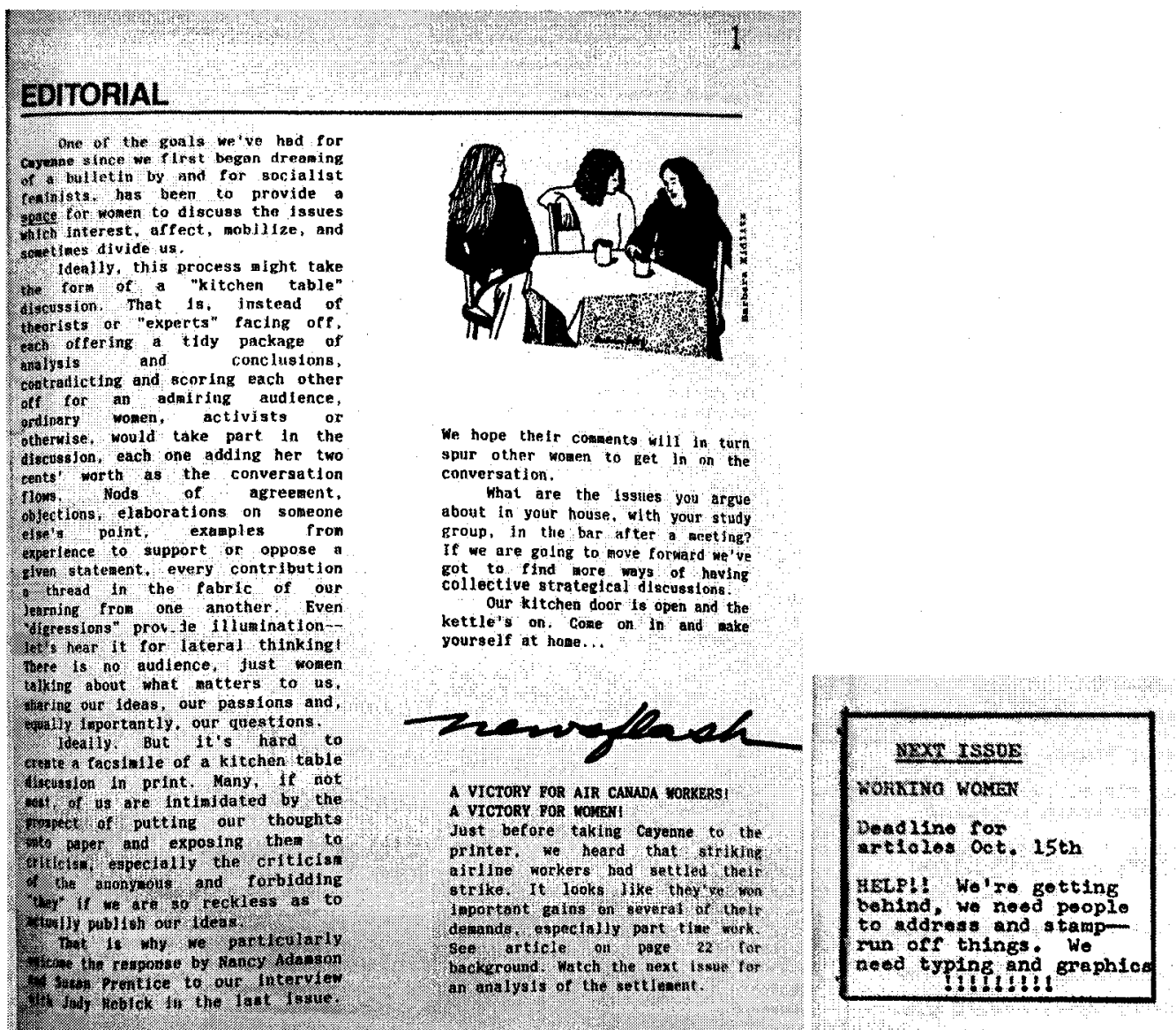

Figure 7a: Examples of calls for submissions in the second-wave newspapers Cayenne 3, page 1 (note how the writers describe their publication as a space) and The Northern Woman 13 (September 1974), page 26 (back cover).

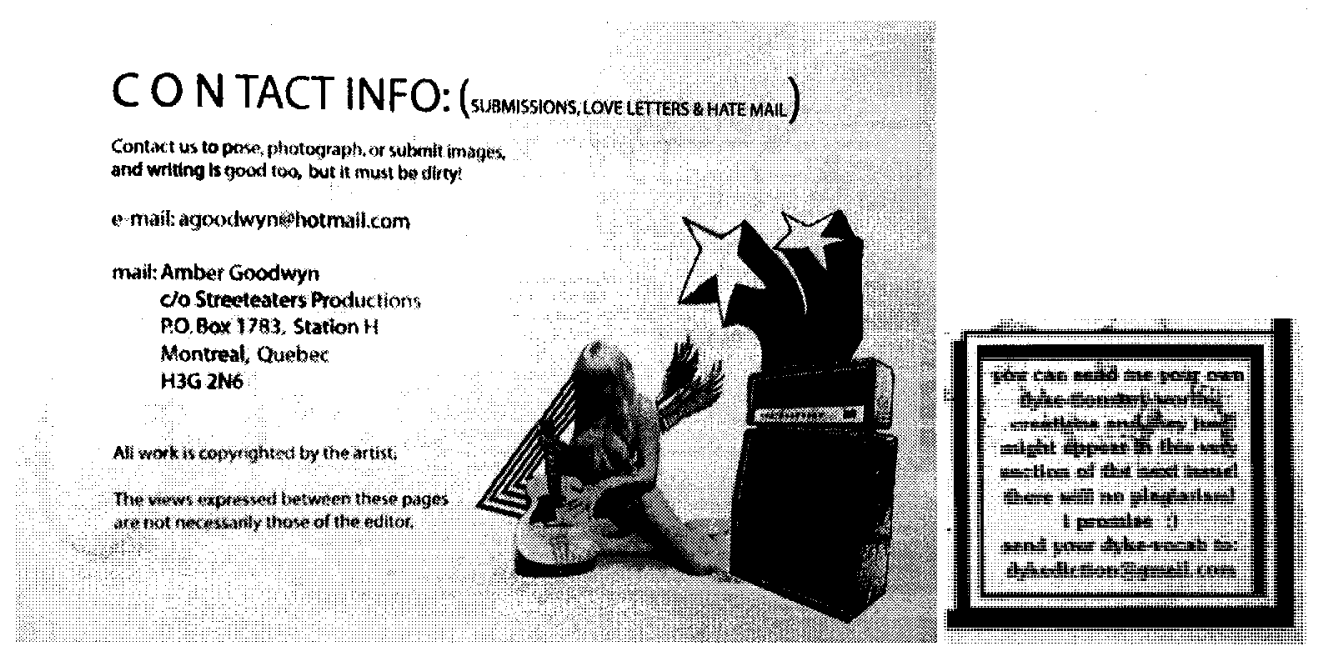

Figure 7b: Examples of calls for submissions in Amber Goodwyn's zine, Lickety Split 1 and Ina Julien's The Dyke-tionnary 1 (fall 2005), page 9. 
who review each other's work in their own zines. ${ }^{63}$ The value of these reviews is recognised in zines that are devoted entirely to reviewing other zines, such as Factsheet Five. Mike Gunderloy founded Factsheet Five in 1982 as a zine that reviewed over a thousand zines in each issue, along with reviews of other independent media products (Gunderloy \& Goldberg 4). Reviews allow zine readers to find other zines in which they might be interested, acting as advertisements for media which rarely enjoy distribution beyond direct mailings and trade fairs. ${ }^{64}$

Like newspapers, zines also explicitly encourage submissions and letters, though they rarely print those letters. ${ }^{65}$ Jayne Armstrong contends that invitations to participate in zine making or to communicate with zine makers recognises and celebrates the differences present in feminist groups, allowing those who don't have the resources to make their own zine the opportunity to participate nonetheless ("Web Grrrls" I02). J. Armstrong's assertion is complemented by participant 2 who states that her zine "promotes collaborative art making and encourages diverse contributions... in order to engage a variety of communities, including those that are traditionally disadvantaged." The invitation to participate thus encourages a "culture of inclusion and co-operation" and helps readers build an imagined community of which they are active members. ${ }^{66}$

Jennifer Rauch's study on the effects of the internet on zine publication found that the community fostered by the distribution of paper zines is central to how zine makers experience zine making and what motivates them to do this work (I60). Rauch quotes one of her subjects as saying: "The zine phenomenon is not a publishing phenomenon, which explains why no publishers were able to exploit it 
to make some coin. It's a social phenomenon instead" (I65). This statement shifts the focus of zine making from the cultural product (the zines) to the interactions that the product allows (community building between zine makers and readers through mailing distribution and face-to-face interactions at zine fairs and music shows) (I 54, I60). Rauch found that zine makers prefer paper distribution to electronic - the central point of zine making is to create and foster personal connections, not to "send or receive information" (I64).

The zine makers Rauch interviewed, however, acknowledged benefits of internet publishing, such as "utilitarian, economic and ecological advantages" (I57). They also find the internet a useful supplementary tool for helping them reach an audience for their paper zines through emailing, networking and researching. ${ }^{67}$ When asked, "Where are your zines available?" five of my sixteen participants volunteered a website address. Still, fourteen listed local distribution networks, again highlighting the preference for community-building contact found in Rauch's research. ${ }^{68}$ Again, this preference demonstrates that the main goal of zine makers is not the transfer of information, but the building of social ties among zine makers.

\section{Content of second- and third-wave publications: Different views of similar issues}

The content of second-and third-wave publications focuses on issues in a number of categories, including health, violence and poverty. While in some cases the focus within these topics shifted between waves, their continuing presence demonstrates continuities in women's oppression and in their resistance. The differences in how each wave approaches these topics indicate how the environments in which these oppressions occur have altered.

The second-wave feminist newspapers in my sample focused their 
discussions on health issues around topics related to reproductive rights and technologies. Most of these articles concentrated on issues such as abortion rights, political debate about abortion, $\mathrm{RU}_{4} 86$, the bombing of abortion clinics, and abortion availability worldwide. Others included those on reproductive technology, contraception, giving birth in hospitals, and forced sterilisation. ${ }^{69}$ Secondarily, issues of mental health were discussed in articles on feminist counselling services, the Canadian mental health care system's practices with lesbian patients, and electroshock therapy. These trends highlight the fact that second-wave feminists faced many legal barriers to health care.

In contrast, the health issue most discussed in zines is depression..$^{70}$ Articles include those that explore causes of depression, such as not having a job in a capitalist society, realising that powerful individuals value profits over other people's lives, living in a consumption-based society, and living in poverty, while others focus on the results of depression, such as self-mutilation and hospitalisation. These articles highlight the continued medicalisation of appropriate reactions to oppressive society, but interrogate the causes of mental health issues more than their treatment. Third-wave feminists, like many in wider society, seek to change the causes of health issues, rather than focusing on improving care during illness.

Secondarily, concerns about health in zines focused around food, with articles on fast-food habits, concern over the impacts of meat-eating, local and imported foods, government involvement in ensuring the safety of these foods, and recipes for healthy foods or the enjoyment of cooking and eating. Concerns about food sources reflect the globalisation of food supplies, and the transfer of food safety responsibilities from government to corporate sources. Third-wave articles on depression and food safety are less about explicit political and medical policies 
and are more about larger social structures, such as global capitalism and the stigmatisation of poverty, that prevent individuals from making healthy choices in their lives.

Some health-related topics surfaced in both media. For example, while the newspaper Upstream (2.3) includes a journalistic article on a women-only alcohol treatment centre, the zine I Miss You contains a first-person comic about the author's struggle with nicotine addiction, and how she overcame it. Various newspapers discussed sexual health issues, such as: Rebel Girls Rag (6.2), which contained an article on AIDS; Broadside (I0.5), with an article on sex education; Long Time Coming (2.6), which included an article on how to relieve menstrual pain; and The Other Woman (Winter 1972), which had an extensive section on sexually transmitted infections (see Figure 8a on page 86). The zine, Viva La Vulva, also discusses sexual health and education, but combines these articles with pieces on desire, female ejaculation and sex toys (see Figure $8 \mathrm{~b}$ on page 86). These examples demonstrate the shift from a journalistic writing style to more autobiographical writing that allows for the discussion of topics deemed too personal for mainstream cultural dialogue.

Both types of media also focus on violence. The second-wave newspapers in my sample exclusively discuss violence against women, with articles on rape, sexualassault legislation and service and advocacy groups, sexual harassment, self-defence, and violence within lesbian relationships. Some newspapers also include descriptions of local rapists and tactics these rapists use, in a bid to help women avoid these specific rapists (see Figure 9a on page 88). ${ }^{11}$ Again, these articles employ a journalistic style, with "objective," non-personalised and "serious" viewpoints, alongside the provision of information on resources for women. 


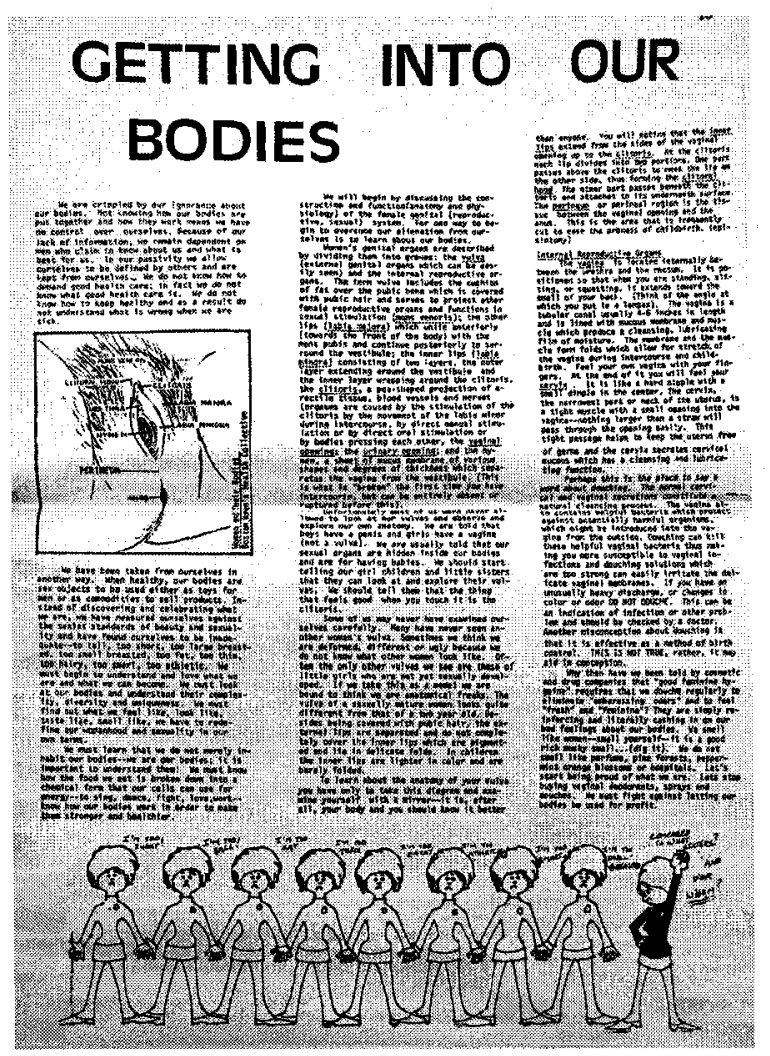

Figure 8a: Sexual health and knowledge in The Other Woman: $A$ Revolutionary Feminist Newspaper 1.1 (May-June 1972), page 15, published in Toronto, Ontario.
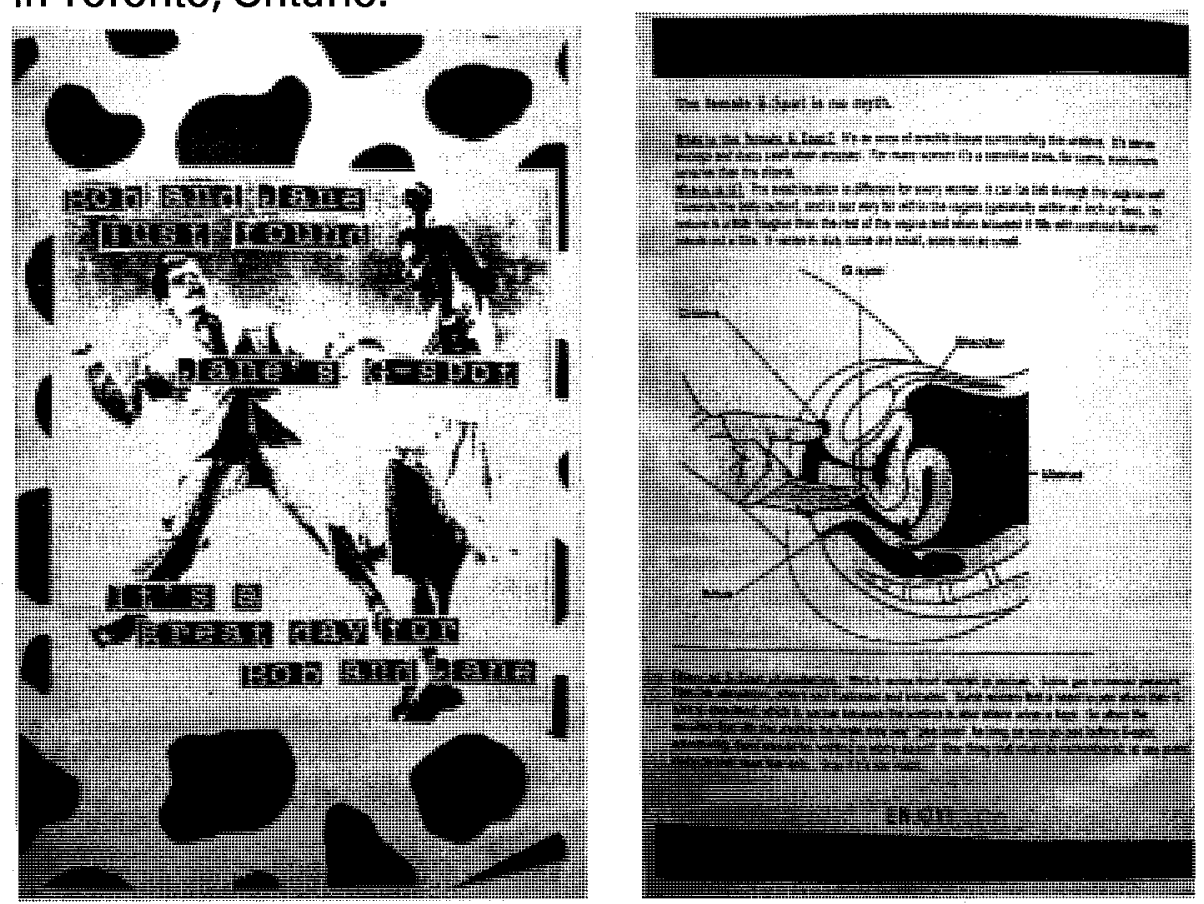

Figure 8b: Sexual health and knowledge in the third-wave zine, Viva la Vulva, by The Clit Liberation Front. 
While feminist zine writers also write about fear of men, rape and sexualassault centre services, their expanded definition of violence also includes other types of direct violence, such as queer bashing. Zine writers push this definition further, writing about the violence done by an economic system that imposes poverty on marginalised groups, and the ignored violence that occurs in day-to-day life..$^{72}$ Zine authors also write to normalise aggressive responses to violence, with fictional women disarming and, in some cases, killing their attackers (see Figure $9 \mathrm{~b}$ on page 88$)^{73}$

While in many cases, newspaper writers assert that many forms of violence against women should not be tolerated, zine writers take it for granted that their readers agree with this assertion. This assumption indicates a significant shift in what is considered socially acceptable. Still, zine writers continue to feel a need to create a discourse that includes fighting back - an extension and evolution of second-wave articles on how to protect oneself against violence. As with health issues, zine writers work toward understanding more what causes violence by looking at systemic violence. The gains made by second-wave feminists in raising awareness of, and revulsion against, violence against women produced an environment in which thirdwave feminists can now focus their attention on these larger systems of violence, while extending their analyses to other targeted groups.

Zines and newspapers also share a concern regarding poverty, with newspapers touching on the topic in a number of areas. ${ }^{74}$ They analyse systemic poverty, considering topics such as family benefits; single mothers and childcare; housing; differential wages for women; and how society works to impoverish certain groups, such as women who work as prostitutes, women domestic workers and rural women. 


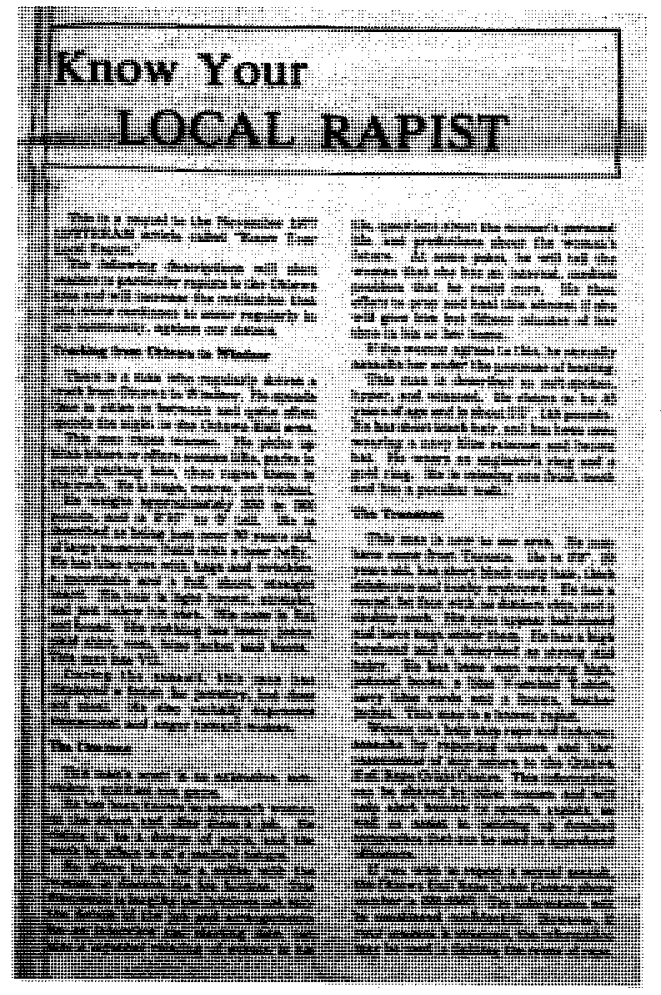

Figure 9a: The second-wave newspaper, Upstream: A Canadian Women's Publication 2.3 (April 1978), page 13, published in Ottawa, Ontario, describes local rapists, so that women might avoid contact with them.

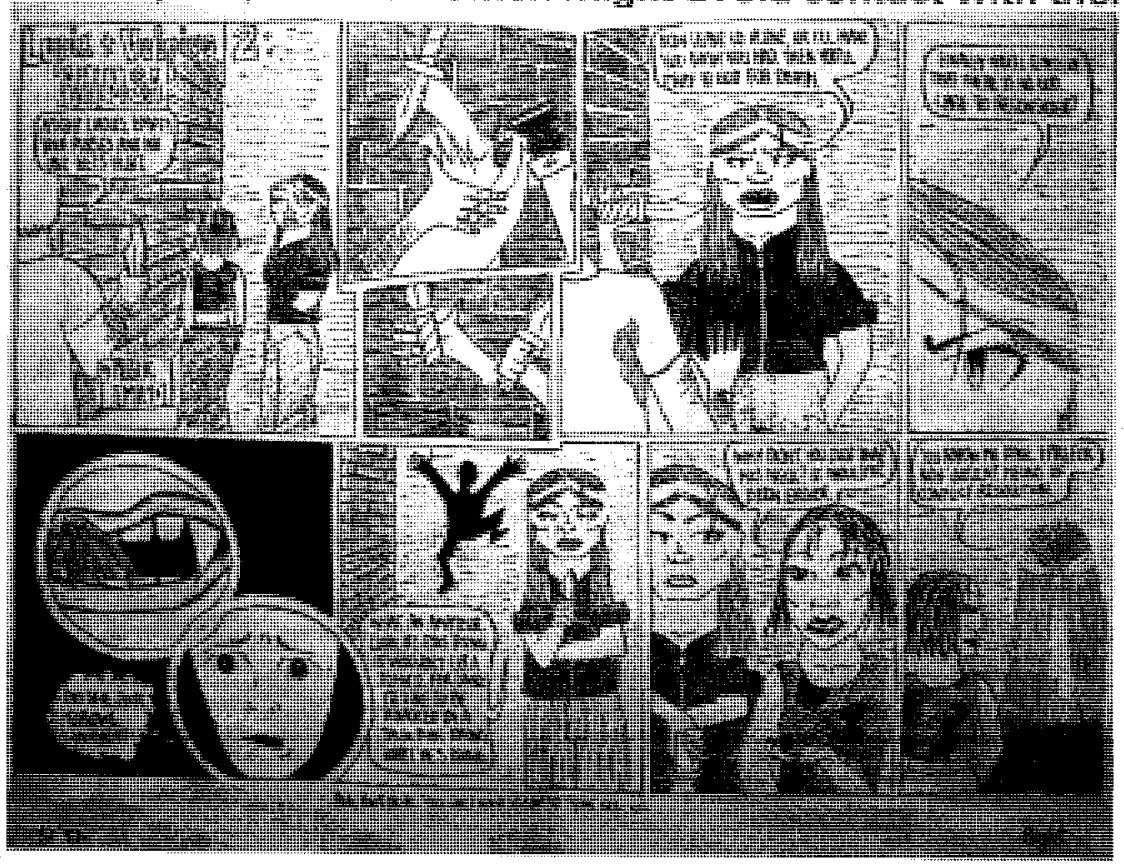

Figure 9b: Emily's zine, The Unfortunate Social Incidences that Have Now Been Attributed to Lupix \& Vulpius and Other Things 1 (2004), page 7-8 depicts a fictional encounter with a male attacker who is scared off by violent threats from the women he threatened. 
Zines also touch on a number of perspectives on poverty, with similar discussions on the systemic nature of impoverishment through social services and for groups like women who work as prostitutes and people in small towns. ${ }^{75}$ The sheer amount of writing on poverty is worth noting: of the 36 different zines in my sample, 18 consider poverty explicitly, with most writers taking poverty for granted as the backdrop for their writing. First-hand writing on joblessness and bad jobs and homelessness and bad homes is common, as are anecdotes about hitchhiking. In addition to these personal experiences, zine writers also describe their (generally marginalised) place in a consumer and capitalist society, and make connections between their poverty and these social structures.$^{76}$ While zines further feminist analyses of poverty, the topics they discuss are not only parallel - in many cases they are identical. This stasis indicates that environments causing poverty have not changed significantly.

While the differences between the two media are striking, a number of similarities also exist. Both media discuss health issues that were contentious at the time of publication. Both media consider these health issues in the context of social power structures. Both work to raise consciousness about violence, and to expand the definition of socially unacceptable violence. Both discuss poverty, and the demographics hardest hit. Both media also choose a style that appeals to the people they are trying to reach, and which best fights the oppressive environments of the day.

\section{Conclusion: Continuities between waves}

It is tempting to view zines at face value, and to highlight the ways in which they are a radical new type of feminist activism. Their roots in first- and second- 
wave feminisms, however, are deep. By considering changes and continuities in feminist publishing, changes in political, social and economic contexts, and how they are experienced as oppressive, come to light. The mainstream media and consumer environments highlighted in chapter one have altered the world that third-wave feminists face, the oppressions they encounter, and the resources with which they have to fight. Third-wave feminists draw on first and second-wave histories and resources to develop strategies and tactics to resist these contemporary environments.

Having considered the evolution of consumer and media environments and the location of third-wave publications within a history of feminist publishing, I next consider specifically how third-wave feminists use publications to resist contemporary oppressions. The following chapter demonstrates how the rise of consumerism and increasing media saturation of today's world create specific challenges for third-wave feminists, and how in many cases, feminists turn to zines as a vehicle through which to advance. 
${ }^{1}$ See DuBois 140, I44; Flexner and Fitzpatrick I 45; Hole and Levine 10.

${ }^{2}$ See DuBois I 44, I 45 . For more on first-wave newspapers' discussions of the sexual double standard, see Passet 234.

${ }^{3}$ See Bloomberg 32; Jerry 23; Solomon 9-Io.

${ }^{4}$ See Bloomberg 36; Jerry 28; Passet 230; Solomon I3, I 5.

${ }^{5}$ See Jerry 28; Kerr I I; Passet 246.

${ }^{6}$ Passet 230; see also Bloomberg 34; Jerry 27, 29; Solomon I3.

${ }^{7}$ See Bloomberg 38 . The Nebraska Woman Suffrage Association established the Woman's Tribune in 1883 , with Colby as editor. She soon took over independent operation of the newspaper (Bloomberg 33). For another example of community built through correspondence in a first-wave feminist newspaper, see Passet 246. ${ }^{8}$ Neither Carol Lee Bacchi in Liberation Deferred? nor Janet Ray in Towards Women's Rights make reference to this newspaper or any other suffrage newspapers published in Canada.

${ }^{9}$ Dorothy Davis and Maria Grant edited The Champion. In order to distribute their paper, they convinced the Canadian Pacific Railway to sell copies of The Champion on board during province-wide trips (Kerr I I).

${ }^{10}$ For opinion pieces, see Cleverdon 8. For letters to the editor, see Cleverdon 34 . For articles written by suffrage associations, see Cleverdon 56; Ray 33.

${ }^{11}$ For more examples of specific groups' activities, see Cleverdon 24-25, 56-57, 91 , I 89, 234 .

${ }^{12}$ At the time, labour unions saw that their male members' wages were being driven down by the lower wages of women who were not covered under protective worker legislation. The use of women as a cheap reserve labour force threatened general wage levels (see Bacchi i 8; Cleverdon I0; Mahood 23).

${ }^{13}$ In the prairies, the farmers' associations of Manitoba, Saskatchewan and Alberta endorsed suffrage in $191 \mathrm{I}$ and 1912 , and also offered women full membership in their own organisations (Cleverdon I 3; Ray 32). Protestant clergy outside of Quebec also supported the movement by approving of campaigns in their sermons and signing petitions, as some believed that women's suffrage would increase the chances of attaining prohibition (Bacchi 72; Cleverdon I4).

${ }^{14}$ See Bacchi I I 8; Kerr I I; Mahood 23.

${ }^{15}$ The Toronto Women's Literary Club, formed in 1876 , was the first Canadian suffrage association. Founded by Dr. Emily Howard Stowe, the club "functioned as an internal discussion and educational organization" until i 883 . At this point, the organisation renamed itself the Toronto Women's Suffrage Association, and began work to obtain the municipal franchise for women (Mahood 22-23).

${ }^{16}$ See Bacchi 35, I 25; Cleverdon 76-77; Mahood 25-27; Ray 33.

${ }^{17} \mathrm{McCl}$ ung was a Canadian feminist and social activist who pushed for women's suffrage. She was one of the "Famous Five" women who petitioned the Supreme Court of Canada for women to be declared persons under the British North America Act of i 867 . McClung called for the federal franchise to be extended to British women in Canada and Canadian women, excluding foreign-born women. She defined foreign-born women as those born outside of either the United Kingdom or Canada (Mahood 27). 
${ }^{18}$ Born in the United States, Shadd Cary moved to Canada in $185 \mathrm{I}$, when she started The Provincial Freeman, becoming the first Black woman editor and publisher in North America (Sadlier 33, 74; Walcott 3 I, 32).

${ }^{9}$ After moving back to the United States, Shadd Cary studied law at Howard University. Due to her gender, she was not permitted to graduate until well after she completed her studies, in $\mathrm{I} 88 \mathrm{I}$. Upon her graduation, Shadd Cary charged the university with sex discrimination; at this point, her energies transitioned further toward fighting for women's rights (Sadlier 33; see also Walcott 32).

${ }^{20}$ Baxandall \& Gordon I 5 . For more on the importance of publications to secondwave feminism, see also Ferree and Hess 78; Willis 9I.

${ }^{21}$ Stokes uses the terms newspaper and newsletter interchangeably. For an example, see Stokes 93 .

22 The newspapers in my sample included perspectives on how free trade, NAFTA, privatisation and the Meech Lake accord would affect women, as well as articles on nuclear power, the Canadian military, cuts to government programs, sexism and racism in education and women's role in the economy.

${ }^{23}$ Shana Calixte, Jennifer Johnson and Maki Motapanyane define consciousnessraising groups as gatherings of women who came together to "hear and share accounts of oppression across class and race lines" and to link those accounts to larger systems of oppression (19-20; see also Piercy \& Freeman).

${ }^{24}$ Stokes 98; see also Ferree \& Hess 83; "Preamble" reprinted in Garvey 374.

${ }^{25}$ Aphra was a feminist journal that began publishing in 1969. Its aim was to confront cultural and media stereotypes about women (Garvey 368 ).

${ }^{26}$ For an example of a second-wave publication describing itself as doing consciousness-raising work, see Garvey 374.

${ }^{27}$ Newspapers in my sample recommended other feminist newspapers, reviewed and recommended books and listed local women's groups and centres.

${ }^{28}$ Second-wave feminists also raised consciousnesses in the mainstream press. Their refusal to deal with male reporters forced mainstream media to send female

correspondents who had not previously been assigned to cover "hard news" such

as demonstrations and news conferences (Ferree \& Hess $8 \mathrm{I}-82$ ).

${ }^{29}$ Participant $\mathrm{I} 6$ refers to zines as "children of the 70 manifestos."

${ }^{30}$ Gunderloy and Goldberg do not note the genre of these zines, so it is not

possible to say what proportion were feminist in nature.

${ }^{31}$ See Austin \& Gregg 82; Garvey 367, 397; Gunderloy \& Goldberg 3, I 57.

${ }^{32}$ When asked question 19 , "Do you try to fulfil any larger social goals through zine publishing? If so, what goals?" participant I4 stated: "Accessibility is huge for me."

${ }^{33}$ Smith 88; see also J. Armstrong, "Internet Forms" i 85 ; Duncombe, "DIY"; Gunderloy \& Goldberg 28.

${ }^{34}$ See Duncombe, "DIY”; Garrison I62-63; Green \& Taormino xiii; Spencer 19.

${ }^{35}$ See Duncombe, "Alienated Together" 447; Schilt, "A Little" 7.

${ }^{36}$ See Green \& Taormino xiii; Gunderloy \& Goldberg 3; Pinterics 17.

37 See J. Armstrong, "Web Grrrls" 94; Harris, "Riding" 29; Klein 2 I 7.

${ }^{38}$ See Bell, "Women-Produced" 56; Green \& Taormino xii, xiv; Klein 2 17; Licona I I 4 . 
${ }^{39}$ See Duncombe, "Alienated Together" 444; see also J. Armstrong, "Internet Forms" I 86; J. Armstrong, "Web Grrrls" 98; Austin \& Gregg 8 I; Reynolds \& Press $32 \mathrm{I}$.

${ }_{40}^{\circ}$ See Duncombe, "Alienated Together" 428; Duncombe, Notes 3; Riot Grrrl 178. For examples of zines critical of mainstream media, see The Dyke-tionnary i; Ghost Pine Zine: Blood; Graceful Suicide s; "Marvellous World" in Gribeault 4; The Unfortunate Social Incidences that Have Now Been Attributed to Lupix and Vulpius and Other Things I.

${ }^{41}$ Two other participants directly addressed mainstream media's incapacity or unwillingness to address issues that they feel require attention.

${ }^{42}$ See J. Armstrong, "Internet Forms" I 86; Chidgey Io; Ferris 52; Garrison I 52;

Green \& Taormino xiv; Harris, "Riding" 29; Robbins I 26-27; Sinor 247.

${ }^{43}$ For documentation of these topics being covered in zines, see Kearny 300-0I; Klein 2 I7; Orr 38; Pinterics I 7; Schilt, "I'll Resist" 84 . Zines also frequently provide website addresses, which can provide further information or emergency resources. In my sample the following zines provided such website addresses: Beautiful Mess o; Block Traffic! Block Prints; Electric Mayhem 2.3; Fun is Free (Association); Graceful Suicide o; Graceful Suicide 5; The Last Thumbnail Picture Show; Matilda; Zines Will Change Your Life; Apt. 52.

${ }^{44}$ For examples of consciousness-raising information in zines, see Fun is Free (Association); Slightly More than Sound Bytes 2; Slightly More than Sound Bytes 3; Status Seekers. For discussion of this type of information in zines, see Garrison I44; Kearny 30I; Pinterics 17.

${ }^{45} \mathrm{~S}$. Thompson 70; see also Garrison I 52 ; Wald 594.

${ }^{46}$ For articles on zines that discuss marginalised groups, poverty, homelessness, human subjects for experiments, living with HIV/AIDS and drug users, see Brouwer; Gillett; Howley 280; Knobel \& Lankshear; Leonard I05; Long; de Moor; Orr 38; Weinstein; Wieloch.

${ }^{47}$ See J. Armstrong, "Web Grrrls" 93; Chidgey I, ro; Duncombe, "Alienated Together" 446; Garvey 397; Klein 2 17; Leonard ro5; Licona I 22; Mitchell and Karaian 66; Robbins I 26- I 27; Scott-Dixon, "Ezines"; Sinor 243, 246, 247, 252, 260. ${ }^{48}$ Gribeault is an anthology of comics written in French. A number of its issues have been translated into English.

${ }^{49}$ For examples of second-wave newspapers discussing the contention that arose around women-only spaces or publications, see The Other Woman May / June 1972 for an article on taking over the offices of Guerrilla to produce a women-only issue for international women's day; The Northern Woman I 2.I for an article on a women's only wen-do class that was fighting to remain women-only; Common Ground I I.I for an article on Pandora, a feminist newspaper in Halifax that was fighting to maintain a women-only editorial board.

${ }^{50} \mathrm{~A}$ common feature of, for example, television news programming, is the "expert commentator" (Ross i I 5 ). These roles, from quoted references to pundits, are almost invariably filled by white men (M. Andersen 57; "Male Authority"). In television and radio commercials, voiceovers provide a disembodied expert voice. These roles are also almost entirely filled by white men (M. Andersen 57; Graydon I 48 ).

"Chidgey uses the term outro to classify an introductory-type piece that is placed at the end of a zine. Many zines contain both an intro and an outro. 
s2 Soundtracks are lists of recommended albums or songs, usually consisting of music that the zine maker was listening to while making the zine.

"3 Schilt, "A Little" 7; see also Gillis \& Munford 170; Schilt, "A Little" 6.

${ }^{4}$ See Bell, "Riding"; Leonard io5; Schilt, "I'll Resist" 89; Sinor 246.

"See J. Armstrong, "Web Grrrls" I02; Austin \& Gregg 88; Green \& Taormino xi;

Orr 38; Schilt, "I'll Resist" 83, 84, 85; Sinor 246.

${ }^{36}$ For discussion on the rise of queer zines, see Orr 38 . For discussion on the inclusion of queer topics in non-queer focused zines, see Kearny 300; Leonard 105. "See Green \& Taormino xi; Jacques 47; Kearny 300; Reynolds \& Press 321, 32 5; Schilt, "I'll Resist" 83, 86; Schilt, "A Little" 6; Scott-Dixon, "Ezines"; Sinor 246.

${ }^{8}$ See Garvey 397; Piano; Schilt, "A Little” 7; Villacorta.

"See Piano; Schilt, "A Little 7; Villacorta.

${ }^{60}$ The first queer zine was a punk zine founded in Toronto in 1986 by G.B. Jones and Bruce LaBruce (Austin \& Gregg 82).

${ }^{61}$ For discussion of networks formed across geography, see Gunderloy \& Goldberg I; Klein 217; Smith 88. For discussions of networks formed based on interests, see Duncombe, "Alienated Together" 44I, 446; Ferris 55; Green \& Taormino xiv; Harris, "Riding" 29; Rauch I64; Schilt, "A Little" 6. ${ }^{62}$ See Bell, "Riding"; Brasile 66; Duncombe, "Alienated Together" 447; Green \& Taormino xiv; Licona I I0; Pinterics I7; Robbins I 26-I 27. In my sample, as with second-wave newspapers, I found zines to have information about activist opportunities for readers. See Slightly More than Sound Bytes 2; Slightly More than Sound Bytes 3; Status Seekers.

${ }^{63}$ Austin and Gregg 94; see also Bell, "Riding"; Duncombe, Notes Io; Harris, "Riding" 29; Piano; Romanesko.

${ }^{64}$ Of the sixteen participants, fourteen state that they distribute locally, seven province-wide, four across Canada and two to the United States. Five state that they make their zines available online, six use a distribution service, ten sell them through shops, three send them to zine libraries, five send them to ally organisations and three distribute at zine fairs. The participants' distribution methods indicate that contentions that zines are not easily available within normal consumer venues are accurate. Still, this same sample suggests that zines are widely distributed as the participants read zines from a variety of locations and distribution methods. Eight mention local sources for zines they read, eight read zines from across their province of residence, six from across Canada, four from the United States, three internationally, and two from "everywhere." Four find zines at fairs, four from friends, three through trades and two from zine archives or libraries. Despite the fact that zines are not well distributed, according to market valuations, their distribution methods appear effective.

6s See J. Armstrong, "Web Grrrls" 93; Smith 94.

${ }^{66} \mathrm{~J}$. Armstrong, "Internet Forms" I 86; see also Klein 217; Smith 95.

${ }_{67}$ Rauch I 57 ; see also J. Armstrong, "Internet Forms" 1 86; Bailey \& Michel.

${ }^{68}$ The remaining two participants replied that their zines were not available.

${ }^{69}$ For examples of newspapers that discuss reproduction issues, see Broadside I.I; Broadside I0.5; Common Ground I I.I; The Northern Woman I0; The Northern Woman I3; The Northern Woman I2.I; The Other Woman 4.4; The Pedestal 5.I; The Womanist September / October 1988. 
${ }^{70}$ See Apt 5 2; Beautiful Mess; Electric Mayhem 2.3; The Last Thumbnail Picture Show; This is What She Said.

${ }^{71}$ See The Other Woman I.2; Upstream 2.3.

${ }^{72}$ For examples of zines that discuss the violence of poverty, see Lickety Split; Sewing the Seeds of Life; Status Seekers. For an example a zine that discusses the violence that occurs in day-to-day life, see Electric Mayhem 2.3.

${ }^{73}$ See Lickety Split; The Trophy Wife; The Unfortunate Social Incidences that Have Now Been Attributed to Lupix and Vulpius and Other Things I; "What I Should Have Done."

${ }^{74}$ For general discussions of women living in poverty, see Broadside I.I; The Other Woman 4.4; The Pedestal 5.I; The Womanist September / October I 988; The Womanist December 1988 / January 1989; The Womanist February / March 1989. "For examples of zines that discuss different experiences of poverty, see Apt 5 2; Electric Mayhem 2.3; Five Days Ago West; Ghost Pine Zine: Blood; "Hitch Lifts West (A Year After) in Gribeault 4; Kissoff Zine; The Last Thumbnail Picture Show; Lickety Split; Matilda; Matilda Zine: The Special Neighbourhood Issue; The Miss G. Home for Wayward Jokes; Refuel; Status Seekers; Travelling the Republic of Heaven.

${ }^{76}$ See Five Days Ago West; "Hitch Lifts West" in Gribeault 3; "Marvellous World" in Gribeault 4; Sewing the Seeds of Life; Sex and Robots Monthly 4; Slightly More than Sound Bytes 2; Viva La Vulva. 


\section{Chapter 3}

\section{Resisting Commodification:}

\section{Zine Tactics for Avoiding the Commodification of Resistance}

\section{Introduction}

Building on the legacy of first and second wave, third-wave feminists find novel ways to resist new manifestations of patriarchy. With earlier waves identifying many aspects of patriarchy and creating a vocabulary for them, third wavers now apply this knowledge to the world they face, developing innovative tactics and strategies to counter the new types of oppression they identify. In particular, as third wavers exist in an environment where resistance is often commodified, they must ensure that their strategies and tactics take this risk into account. One way third wavers accomplish this is through the creation and use of alternative media, such as zines.

This chapter first considers how the environments dominated by rampant consumerism and mainstream media specifically affect third wave feminists. I then discuss the methods that third wavers use to counter these oppressive forces, with a focus on their publishing. I argue that zines makers use their products to accomplish feminist goals, while building community and circumventing late capitalist systems. They take advantage of third space ideals to formulate action in a manner consistent with third wave goals of inclusiveness, non-hierarchical systems and strategic uses of identity.

\section{Environments that specifically challenge third wave feminists}

Third-wave feminists participate in emerging forms of activism which 
frequently are less visible than previous forms of activism. Their tactics, such as DIY, and their topics, such as the examination of privilege and celebration of differences, are, if not unique to third-wave feminism, unique in their prominence. When considered in the context of the current contexts in which third wavers work, and are trying to change, the choice of these tactics and topics becomes clear.

Baudrillard explains that past practices of resistance were effective precisely because they matched the environments faced, and that these same practices, now that the environments have changed, are ineffective. He argues that, in fact, opposite practices best resist the environments that now exist. Previous systems of power worked through "oppression and repression," by excluding and repressing individuals. In response, individuals demanded that their voices be included, that they count as persons and citizens and that they enjoy the associated rights of what Baudrillard labels the "political subject". In contrast, contemporary systems of power, while still employing previous systems of oppression, now function mainly through maximising subject participation - the system justifies its existence through subject consent to the system, as exemplified by their participation in choosing the options presented to them by the system (which neglects to present alternative systems). Baudrillard suggests that the most effective way to fight contemporary systems of oppression is to refuse the position of the subject, and take on that of the object - to renounce the system itself. Baudrillard notes that people already engage in these practices, but are negated with terms such as "alienation" and "passivity" (Baudrillard, “The Masses" I 2 2, italics in original). Baudrillard notes that this form of resistance does not necessarily preclude previous practices of resistance, but is decidedly more effective as they are "most adapted to the present phase of the system" (I I3). He argues that practices of resistance must adapt to changing 
practices of oppression.

Similarly, feminists acknowledge that previous feminisms used different tactics and strategies in their resistance to the oppressive environments they faced and their distinct political conditions. ${ }^{\mathrm{I}}$ Diane Bell and Renate Klein note that "patriarchy assumes different forms under different conditions": these different forms present different challenges and issues for feminists. ${ }^{2}$ Klein suggests that these changing social contexts call for new forms of feminism in order to adequately resist them (207; see also Mitchell \& Karaian 59). In addition, Pinterics argues that these changing social contexts create different experiences drawing people to feminism, creating various motivations for resistance (i 5 ). Whereas women and other marginalised people were previously excluded from participation as political subjects, previous feminisms have focused on fighting for inclusion as with first wave feminists' fight for suffrage rights. But since contemporary systems of oppression work to legitimate themselves through subject participation in activities such as consumerism, feminists must ensure that their activism doesn't inadvertently support these systems. Third-wave feminists, in order to be effective, must recognise these systems of power and undermine them through refusal to participate. While Baudrillard notes that these anti-system actions are negated as passive, third wavers have developed a number of active ways to resist these systems.

Steenbergen argues that third wavers negotiate these new systems of power, addressing their experiences of contemporary systems and structures. ${ }^{3}$ They are "emerging, reacting, and acting within a particular moment in history." 4 And because this moment in history and the types of oppression that exist in it are "diverse, fluid, and complicated," so must their resistance be (Steenbergen, 
"Feminism" I2). Third-wave feminists face an environment that is inundated with mainstream media images that work to oppress them, and in which consumerism is positioned as a vital location of identity formation and democratic choice. Late capitalism, in particular, presents a number of unique challenges for third wave feminists, as it attempts to commodify their resistance. As such, third-wave strategies of resistance must work outside of consumer and mainstream media systems, and must undermine the ability of these systems to co-opt their resistance.

The victories of second-wave feminism have had a significant impact on the world that third-wave feminists face. Steenbergen notes that second-wave activists won access to "previously male-dominated realms and a broad spectrum of legal rights" for women ("Talkin"” 263 ; see also Pinterics I 5). Steenbergen posits that because changes to the environments of third-wave feminists have been so dramatic, third-wave feminists sometimes take these advantages for granted; herself "feel[s] a sense of entitlement as a result" of the gains made by second-wave feminists ("Talkin"” 263; see also Bell, "Riding”).

Advances made by the second wave, however, indirectly led to new issues that feminists must face (Ferree \& Hess viii; Pinterics I 5 ). These issues frequently appear in zines. Pinterics asserts that in response to social pressure, issues such as "sexism, racism, homophobia, and classism" have become more insidious and difficult to pinpoint (I 5 ). More specifically, Steenbergen points to date-rape drugs, neo-conservatism and post-feminism as emerging feminist issues. These issues are compounded by other evolving priorities, such as HIV/AIDS, advances in communication technology, increased commercialism and pop-cultural influences (Steenbergen, “Talkin”” 263).

The backlash to feminist success takes many forms, including fundamentalist 
and neoconservative movements (Garrison I42; Steenbergen, "Talkin"” 262-63). These movements, along with the mainstream media, work to present feminism as out-dated, and an ideology and label rejected by young women (Garrison I53; see also Gillis \& Munford I70). In doing so, they both portray women's equality as accomplished, and associate feminism with an imaginary stereotype which Ahn describes as "outspoken, bitchy, butchy, hairy-legged, men-bashing, bra-burning, PMS-ing, shit-disturbing lesbians" ( I 19; see also Crean 132). In Slightly More than Sound Bytes 2, the author addresses these stereotypes in her piece "Top Io answers to the question, "Are you a MAN-HATER?"” She adds that this question is frequently asked of "lesbians, feminist womyn who speak their minds, womyn who challenge the patriarchy, and anyone else who resist the male-dominated statusquo." The author draws attention to the fact that women who challenge male dominance, feminist or otherwise, are considered threatening to men, instead of to a system that oppresses them. (See figure Io on page I0I). To present women's equality as an accomplished task, mainstream media emphasises "post-feminism" (Garrison I42; Steenbergen, "Talkin”" 262-63, 264). Steenbergen defines postfeminism as an "analytically weak but, surprisingly, rhetorically persuasive" ideology that focuses on the "presumption that equal opportunities for all women are a reality." As such, they celebrate the triumphs of certain women while ignoring the continuing oppression of others. Steenbergen further suggests that despite its inaccuracies, post-feminism receives significant mainstream media attention because it has "chic, inoffensive, commercial qualities" and doesn't challenge dominant power structures (Steenbergen, “Talkin"” 260; see also Heywood \& Drake I). As such, post-feminism enjoys a significant platform from which to undermine the feminist movement. Ahn observes that media portrayals of post-feminism give the 


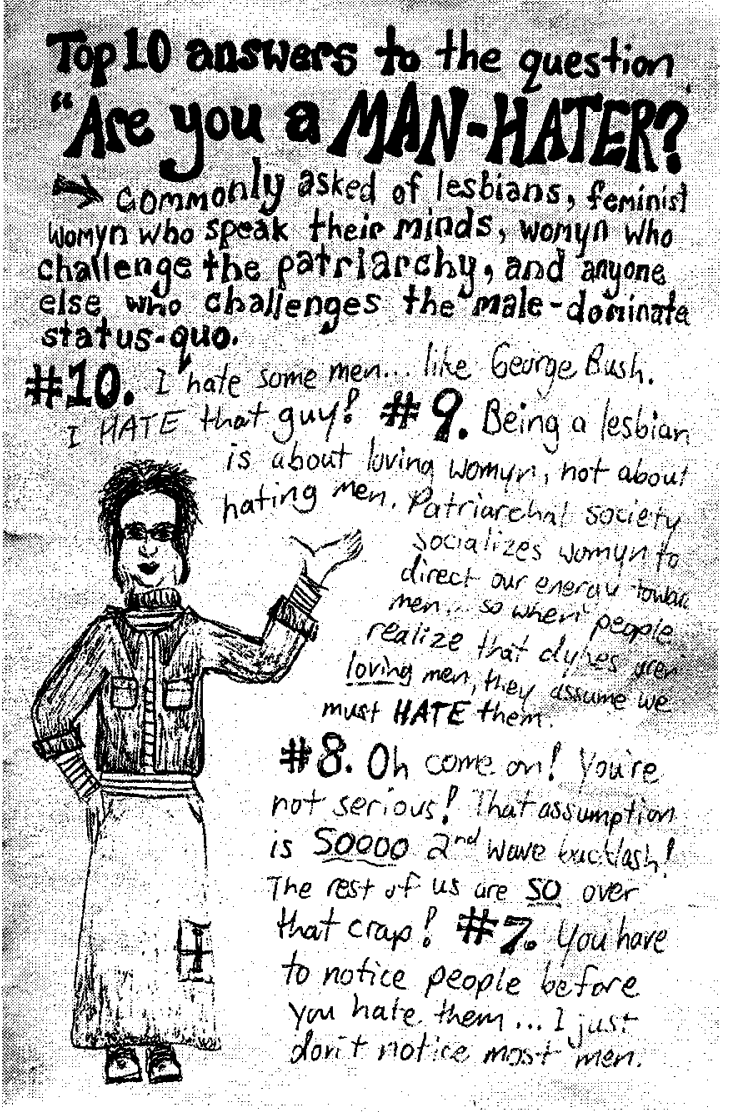

\#6. Are you a woman-hater? Whats the word for the hatred of women? Oh, right. MISOGYNY? What's the word for the hatred of men? Oh, you don t know? I think its something like "misandry." Dont hear that much.. not a very accepted phonomerian I guess. \#5. Awww. that is So sad! louve been totally rain washed by the media backlash against the vomyn's momement. Work on your crifical thinking skills, re check your sour ces, then get back to me. perhaps then we can have a real dialogue. \#4. No, but I hate male pririlege, and abusive men, and the horrible things that many men have. done to womyn, children, other men, the planet. but to soy. $T$ hate all men wouldn't be fair, cause I ove' my Grames, and my dad, and my brother, and Matt, and Adam and Paul. *3. Yes, and I have a gun? (stare menaceingly) Grrer, and.. \#2. Who are you? The "Love Patrol"? I think you rould start with the woman- haters... they re more amerous, Iouder, more belligerent, generally easier

*1. Yes!... and I ve got my REASONS!

Figure 10: from Jess's Slightly More than Sound Bytes 2. The author responds to the backlash against feminism which would label people who work against patriarchy as man-haters. 
impression that "there isn't anything [anyone] can do to further advance the status of women" (122). As such, the mainstream media emphasis on post-feminism presents equity as accomplished, and attempts to discourage individuals from taking on feminist work.

In addition to the hostility third wavers face from anti-feminists, they are also deeply affected by their location in a late-capitalist society (Garrison I 43, I44). For many third wavers, late capitalism is disempowering as they are unable to fulfil social demands for consumption due to poverty, as the media-saturated environment portrays damaging stereotypes of them, and as any resistance they engage in risks commodification. ${ }^{5}$ Third wavers generally belong to marginalised demographics that are denigrated by mainstream cultural products; they largely are unable to follow social pressures to consume products that promise to counter negative stereotypes. When they resist either of these oppressive situations, that resistance is often distorted into a depoliticised cultural product available for mainstream consumption.

Ali Grant notes a factor specific to late-capitalism: the pressure on feminism to de-radicalise. Her research on women's shelters and rape crisis centres - sites of resistance that she notes have become more formalised and institutionalised - found that the groups operating these sites felt tremendous pressure to de-radicalise in order to maintain legitimacy in the eyes of the public and to retain their funding ( $5 \circ$, $53,56,59)$. De-radicalisation involves condemning activities and identities that threaten traditional gendered and heterosexual regimes. Groups have felt forced to demonstrate that they are not "man-hating," "anti-police," lesbian, angry or political $(5 \circ, 56)$. Grant points to the drawbacks that a group looking to challenge gendered systems of power faces in rejecting women who transgress gendered 
norms - removing transgressive women proves the group to be unjust, hinders the services the group can offer and also impedes the "development of radical counterhegemonic identities" $(53,56,59)$.

One of the most significant ways that dominant media and culture work to oppress women and feminists is through the attempted commodification of third wave feminism. ${ }^{6}$ This is not specific to feminism, but is, in fact, common to resistant movements: "the most radical of content [can] be assimilated and thus neutralized if presented within the context of high art or commercial entertainment" (Duncombe, "Walter Benjamin" 67; see also Duncombe, "DIY"). Bhabha also notes this possibility, stating that "sometimes we think we make our most radical stance and it gets totally absorbed" ("Identity" 24). Mainstream cultures work to incorporate or co-opt subcultures in order to nullify the threat that they pose by encouraging the wide adoption of sub-cultural signs. This adoption ensures that the signs lose their original meaning, and the subculture either disappears or "continues on as a neutered, mass-marketed style movement" (Jacques 46 ). Riot grrrls were conscious of this process and worked to circumvent it. In Laura Sister Nobody, a zine maker writes "“c why does usa today, abc, nbc, cbs and every other corporate media fuck want to get a hold of bikini kill and riot grrrl? because theyre not fools - they know somethings happening too- but theyre terrified of it and they want to take it and twist it and package it and spit it out to the masses as the next latest thing in order to kill it" (qtd. in Klein 223). This commodification ensures that productive space is limited to a few producers, who are then mass-produced and distributed, and attempts to limit other marginalised people from producing while ensuring the profit and power of mass-producers and marketers (Schilt, "A Little" I4). Both Frank and Garrison note that this method of containment - "the 
commodification of resistance" - is prevalent in late capitalist societies (Garrison I43; see also Frank 319). Frank goes farther, stating that capitalism "hunger[s]" for counterculture as consumerism moves away from conformity to identity production. He calls this "the genius at the heart of American capitalism," where consumption is reframed as a method "to prove, on the surface at least, that we are rock ' $n$ ' roll rebels, each one of us as rule-breaking and hierarchy-defying as our heroes of the 60s, who now pitch cars, shoes and beer" (319). Capitalism incorporates countercultural practices and products into its system to nullify the threat that countercultures pose, and to further its own goals of profit and control. Hakim Bey suggests that in response, space must be created outside of capitalism. Bey's suggestions follow Bhabha's description of the necessity of third spaces as locations of cultural difference and resistance. Bey's project, which he calls the "temporary autonomous zone," or TAZ consists of fleeting projects that jar spectators into realising the constructed nature of mainstream society. Bey defends the temporary nature of his projects by noting that previous methods of resistance, such as direct confrontations with the state, are not adequate in the face of modern circumstance. Bey contends that the state, as it currently exists, is difficult to fight through direct methods, as the state uses effective surveillance, making resistance challenging, but also because the state is capable of using information to overwhelm citizenry and thus control society. While Bey specifies that temporary autonomous zone work should not be considered the only form of resistance available, he recommends it to encourage uprising while avoiding violence (I I6). By not engaging directly with the state, and by forming, dissolving, and reforming elsewhere, temporary autonomous zone resistance can avoid being crushed or commodified by the state or other powerful structures. In many ways, zines act as temporary 
autonomous zones, with zine makers inserting zines into mainstream society in order to disrupt assumptions about that society, but in a non-confrontational and playful manner.

Jacques describes an example of commodification of third wave feminist resistance: in order to challenge feminine stereotypes and call attention to the oppression of women, riot grrrls wrote terms such as "rape," "shame" and "slut" on their bodies. She notes that while this riot grrrl practice became popular in the early I990s, the mid I990s saw shops flood with tight-fitting t-shirts "emblazoned with sassy, sexy words like 'Tasty,' 'Tart' and 'Maneater'” (49). Jacques takes issue not only with altered sentiment of the words, but also notes that while writing on oneself aligns with the anti-consumer and accessible nature of riot grrrl culture, $t$ shirt purchasing does not. The critique of capitalism inherent in the riot grrrl practise is lost through mass production and marketing. Commodification transformed a resistant practice into a consumer practice (49-50).

In the case of the commodification of riot grrrl practices, mainstream, profitdriven corporations adopted the outward practices of resistance while removing their political edge. The mass-production nature of this commodification also eliminated the challenge that such practices of resistance pose to dominant institutions such as capitalism. When considering resistance, third wave feminists must be wary of these practices, which, while non-violent, can be very effective at suppressing resistance.

\section{Third wave responses to these environments}

In the face of such commodification, third wavers focus on building community outside of capitalist constraints. Third wave feminists, like earlier 
feminist groups, face a number of challenges in building networks and coalitions, including their dispersion over wide geographic spaces. As such, when discussing community, I am speaking of people who imagine themselves as part of a larger group, rather than a group of people who meet physically. In this work, third wavers utilise zines as an invaluable tool for reaching across physical distances while avoiding capitalist structures and the threat of commodification.

Benedict Anderson defines nation as "an imagined political community" - a definition that can be instructive in thinking about third wave feminism (6). Anderson explains that a nation is "imagined" because members will never know or meet most other members: their collectivity exists only in each's imagination (6). Each member, however, is confident of their anonymous and simultaneous belonging to the nation (26). Despite their shared languages and practices, they do not have any expectation of meeting one another (188). While many third wavers meet physically in groups, socially or for activist projects, they are also joined in a larger imagined community. Practices such as zine making and exchange extend physical communities and strengthen the imagination of a larger third wave community.

Anderson finds the root of nationalism in the advent of the printing press. At this point, people became aware of the other people who existed in their "language-field," and also that only those people belonged. Anderson calls these imagined groups of fellow-readers, "in their secular, particular, visible invisibility" the "embryo of the nationally imagined community;" multiples of texts allowed for the imagination of shared experience with strangers (44). McLuhan and Fiore add to Anderson's views on the printing press, stressing that it was the multiplying function of the printing press that created community. They note that with 
individuals sharing the common experience of reading certain texts, the printing press and the multiple copies it allowed "created a public - a reading public" (McLuhan \& Fiore I 22). Feminism, in all its waves, similarly drew on printing technologies to create community in a manner that parallels Anderson and McLuhan and Fiore's nations or "publics"; multiple copies of texts demonstrated to otherwise disparate people their commonalities and the basis for an imagined community.

The motivation for building national community, beyond acknowledging the commonality of language, is the desire to give "meaning to the everyday fatalities of existence (above all death, loss, and servitude)" and to offer redemption from these fatalities (Anderson 36). The motivation for the imagination of third wave feminism as a community is different, of course, but parallels the desire to give meaning. Third wave feminists strive to give meaning to the oppressions they suffer, to find the reasoning for it, and to use this information to confront and challenge these oppressions. They imagine themselves as a community, in order to gain strength and numbers to fight for social justice. Like in Anderson's nations, they have no need to all meet one another in person, but rather communicate, using the latest innovations to the printing press, to further their sense of a shared collectivity and to organise action.

Many participants refer to the community that zines create, and their motivations for creating it. ${ }^{7}$ Some refer to the mutual support for zine making found within the zine community, with participant I stating, "I've never seen an artistic community so free of competitive nature. As a result there is in the zine world an incredible feeling of community and an incredible desire to help each other out, even to the detriment of one's own project." ${ }^{8}$ Others find content in zines that 
reflects their communities that they can't find elsewhere. Participant I 6 creates zines so that "people could find solidarity and community," a desire that participants 2 and I I also finds reflected in zines. In Slightly more than Sound Bytes 3, the author refers to these works as making it "literally... possible for me $\&$ others like me, to survive!" The idea of community that these zine makers foster is one in which zines makers support one another in their creativity and which also gives readers a sense of a larger community with the zine writers and readers.

Feminist community itself is a form of resistance to "the competition that women often feel toward one another in the dominant society" (Duncombe, "Alienated Together" 445). The type of community that third wavers strive to construct matches Bhabha's model of cultural difference, with communities constructed in such a way that they offer members individual liberty, as well as the opportunity for connection. This is accomplished by allowing for flexible identities, coalition building, and sensitivity to power structures.

Community often centres around the belief in a shared identity. Bhabha suggests that any category of identity is not given, but rather constructed ("Third Space” 220). This understanding of identity is reflected in Grant's research on antiviolence activists, who saw themselves as coming together over a "shared sense of political identity" in their alliance against specific power relations, rather than over a shared physical location or biology $(52,53)$. In this case, identities are thought of as tactical positions wherein individuals shift between different identities in order to confront multiple oppressions as they are experienced. This shifting also allows for the construction of coalitions built on "strategically essentialized" identities and positions (Garrison I48). Third wavers use identity the same way they use feminism - strategically and to their own ends. 
By building coalitions in this manner, third wavers forge groups large enough to present a political threat, while also honouring the differences of group members. Ferree and Hess describe these networks as coalitions of groups, organisations or individuals that connect activists, scholars and politicians (xiii, xiv). These networks allow for communication across differences, in a manner that doesn't homogenise differences, and with few material resources. ${ }^{9}$ Compilation zines, in particular, illustrate how coalitions can bring together a variety of views. Viva La Vulva and Status Seekers, for example, present views on women's sexuality and the recent funding cuts to Status of Women Canada, respectively. They bring together women who describe themselves as belonging to various categories of race, sexuality, age, ability, education, economic status and educational background to present their differing views on these central topics. These networks also exist outside of existing, controlled networks created by "big business, big government, and big media" (Gunderloy \& Goldberg I-2).

Zines help third wavers foster this type of community by drawing together disparate individuals and groups. ${ }^{10}$ When asked if they felt a sense of community with other zine makers, twelve participants answered yes, with seven elaborating that they felt a part of a city-wide community, one a nation-wide community and four a community around a group identification. Participant 4 comments: "You really get the sense that we're here to support each other," while participant I elaborates:

as soon as you do a zine, as soon as you put some words (or photos or drawings or anything at all it seems) on paper and make a few copies of it, you're in - you're a part of the scene and welcomed with the same enthusiasm as if you were Hunter Freaking Thompson shilling hand-bound copies of The Rum Diaries.

Participant 16 sees this creation of community as an act of activism in itself. 
Participant I agrees, calling "promoting a sense of community" a revolutionary act. Networks, however, can be difficult to maintain due to the amount of work required of all participants. They can also lack accountability (Ferree \& Hess xxi). Duncombe adds that in networks, such as zines, where writers "privilege personal experience and subjective realities over broader, public concerns" there is a tendency for networks to fragment into "microcommunities" as groups turn inward ("Alienated Together" 446). These potential flaws, however, don't outweigh the benefits that third wavers find in network and coalition building.

A key element of these coalitions is their non-hierarchical nature. Third wavers look to build community with "No Leaders, No Rules, No Permission Asked." " bell hooks suggests that these types of coalitions - ones based in what she calls "mutuality" - are ideal for situations where groups are composed of members with unequal status. hooks' model for coalition building calls for acknowledging the differences within coalitions and networks and working against the power structures these differences bring (Teaching Community 63). Zines allow for collaboration around issues, such as challenging power, while allowing as much difference among participants as those participants desire.

Working to form networks and coalitions also encourage third wavers to expand the definition of what is feminist, or in what issues feminists are involved. Garrison asserts that "feminism is not about fitting into a mold" but rather about moving between "worlds and communities and scenes," building coalitions and acting together across differences (Garrison I60; see also Harris, "Riding” 29). This expansion of third wave feminism often is perceived in opposition to the second wave. Steenbergen, however, asserts that critiques of second wave feminism are "intended to improve the status of women and to move feminism forward 
(“Talkin" 266; see also Austin \& Gregg 90, 91). Pinterics adds that tensions between second and third wave feminists form a dialectic process with the potential to produce stronger and more diverse ideas of what is considered feminism and feminist practice (20). With constant self-reflection, third wave feminists can fashion a feminism that is flexible in its tactics and responsive to its members.

Third wavers also turn this critique back on themselves. By promoting zines as a central element of their theoretical and activist practices, third wave feminists invite individuals and groups who feel misrepresented in third wave feminism to both speak out and influence third wave feminism itself. Frequently, zines published by racialised women, poor women and queer women challenge dominant third wave assumptions (Piano). Additionally, zines are a non-aggressive way to raise others' consciousnesses, as they can be consumed privately, or not at all. They also allow non-group members to educate themselves about marginalised groups without placing extra demands on marginalised groups to educate others. As third wavers critique established and emerging feminisms in order to expand feminism itself, editors of these zines contribute to the evolution and growth of third wave feminism by creating "necessary dialogue among the subculture's participants" and "broadening its appeal to new members" (Piano; see also Bell, "Riding").

Many third wavers describe their cultural products as social spaces or virtual meeting places, which create a space for various feminist projects to develop and take place. ${ }^{12}$ Five participants referred to their zine as a "space," especially with reference to creating a space for marginalised voices. ${ }^{33}$ Zines provide a familiar and safe space in a world where representations of women and other marginalised people are inaccurate and harmful. Participant 16 states that he sees this aspect of zines - that they show "other people that they are not alone" is an integral part of how zines 
build community. Secondly, they provide what Duncombe terms a "free space" where resistance can be formulated (Cultural Resistance 5-6). In these spaces, counter-hegemonic identities, "oppositional ideologies and feminist and political analyses" of oppression can form. ${ }^{14}$ Duncombe adds that because cultural resistance "often speaks in a more familiar and less demanding voice than political dissent" it can act as "a sort of stepping stone into political activity" (Cultural Resistance 6). Since marginalised people have little or no access to traditional community-building spaces, zines allow for a textual one.

In their use of zines as a space, zine makers take advantage of the benefits that Bhabha's idea of third space offers. Their focus on accessibility adheres to Bhabha's contention that cultures don't exist in a naturally occurring hierarchy, and their openness to marginalised topics and non-mainstream forms allow for the cultural negotiation that Bhabha celebrates. Zines also allow for controversial discussions and include marginal understandings of history and society and culture, allowing marginalised people to participate in discussions that would otherwise exclude them.

Additionally, zines act as an example of Bhabha's argument that agency within third space can be used to affect dominant culture and society. Zines organise activism once their writers and readers have formulated their resistance strategies. For example, Slightly More than Sound Bytes 2 describes an anti-violence project conducted by the Sexual Assault Support Centre of Ottawa and encourages readers to participate in it. Status Seekers, raising awareness about the effects of the funding cuts to Status of Women Canada, offers a list of "Ways to Resist," which includes suggestions that encompass political and cultural ways to resist the cuts, in addition to a back cover post card that can be cut out of the zine and mailed to the Prime Minister. Zines Will Change Your Life more generically describes how to organise 
an event, including how to compile and circulate a press release, tips on postering and hosting an event.

In addition to allowing physically disparate people to come together and organise, zines enrich the communities they build. Duncombe asserts that third wavers are trying to build a unique form of community, one that is not built on internal traditions or understandings, but on shared dialogue. This novel type of community is recreated at every point of communication ("Alienated Together" 445; see also Riot Grrrl I79). As such, third wave ideals of embracing difference, selfreflection and non-hierarchy occur naturally in these communities.

\section{Circumventing consumerism}

Another tactic of third wave feminism is to create space outside of capitalism. While critiques of capitalism abound, third wavers focus on critiques of consumerism, and on building systems of non-capitalist interaction. These acts of resistance respond to the overwhelming consumerism of our late-capitalist society, and the threat that consumerism poses to third wavers through acts of commodification. For the most part, third wave work against capitalism manifests through participation in economic forms other than capitalism, such as barter and gifting. ${ }^{15}$ Some third wavers are explicitly against making a profit, while others simply have other priorities, such as getting their zines to as many people as possible. ${ }^{16}$ Those who are against making profit making work to counter consumerism and the overarching consumerism found in other cultural spaces, such as the internet (Piano). They also challenge capitalist ideas that consider "only certain kinds of voices, narratives, and consumer goods fashionable and profitable" (Piano). By challenging the importance of profit, third wavers reveal other possible 
motivations for cultural production, such as resistant or activist goals.

In some cases, third wavers focus on, and work against, corporate consumerism. In discussing the commodification of riot grrrl by the mainstream media, Kathleen Hanna describes the market economy as a force that claims to know what products are good for people, and implies that people's role is to consume these products unquestioningly (I8I). Duncombe states that capitalist democracies justify their existence by "the consent (or consumer purchases) of those [they] govern." As such, he echoes Baudrillard's suggestion that one withdraw her consent by not participating in consumption ("Jean Baudrillard" I00-IOI). Third wavers resist the push to consume by organising anti-consumerism activities, such as clothing swaps and creating their own cultural products, like zines (Mitchell \& Karaian 64).

The zine makers in my sample spoke about their discomfort with consumer culture in their zines and their questionnaires. Participants I, 2 and I 2 state that they see their zines as resisting consumerism, with participant $\mathbf{2} 2$ stating that she sees her zine itself as "a form of activism, in that it allows me to produce, rather than simply consume." Strong Cottonwoods and "Hitch Lifts West" discuss the emptiness of consumer culture, which Electric Maybem 2.3 elaborates on: "This is the plastic age diet. Sweet, quick, immediate, gastronomically boring and colourful-and-fluffy enough to make you beg for more. Is it no wonder we're an addicted country? That I'm a recovering addict at twenty-seven years old? Our culture is founded and traded in addiction, in modern capitalism" (See figure i I on page I I 5 ). Refuel, Viva La Vulva and Slightly More than Sound Bytes 2 also note problems of consumer culture, and encourage people to consider the origins of what they consume, and to choose independent products, or to make things themselves. Three participants, 

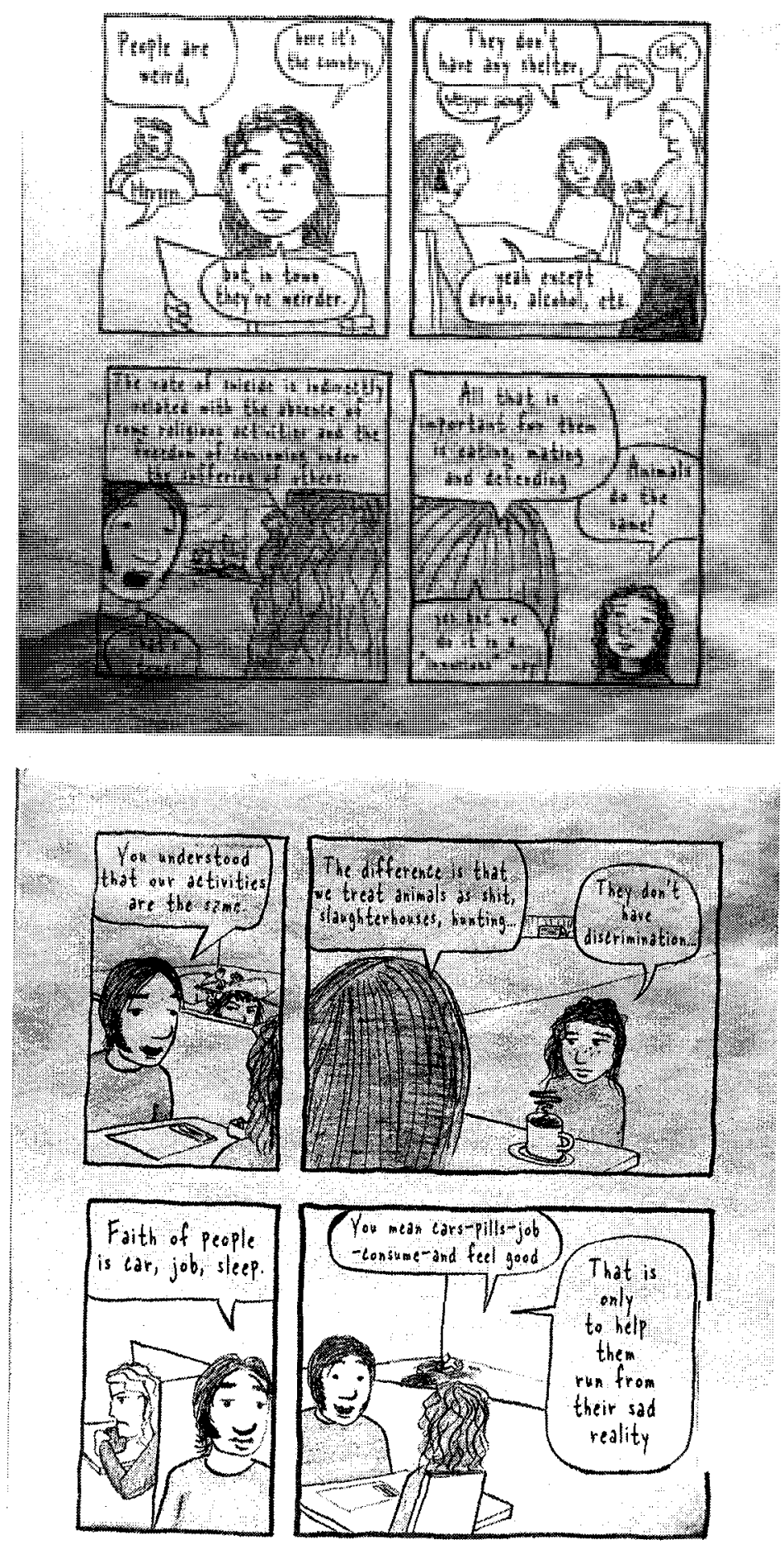

Figure 11: An excerpt from Janardan's "Hitch Lifts West" from Gribeault 3. The protagonists have stopped in at a rest stop on their hitch-hiking trip and discuss the unsatisfying nature of consumer culture. 
when asked about the social or cultural impact of zines, specifically wrote about zines as a space outside of consumerism or capitalism. These participants assert that capitalist structures limit cultural producers, and that by working outside of "the capitalist-commodity-censorship- "product" realm of created works," they have more freedom in what and how they pursue their social goals (participant I4).

The ability of DIY projects to avoid capitalist structures is particularly important for groups defined by low economic status, but also for other marginalised groups, whose members also tend to be impoverished economically. Because DIY cultural products generally don't make profit, and sometimes even lose money, Piano asserts that profit is not the goal of these products. This sentiment is echoed by participant 9, who comments, "Zine makers don't expect to get rich off 'em... but they know they can be heard through them" (ellipsis in original). Participants 3, I 5 and 16 also talk about zines as prioritising the spread of information through zines as a priority. In the introduction to Slightly More than Sound Bytes, the author explains, "Really, this zine is one of my ways of reaching out to people and expressing some things that are important to me. My hope is that it offers a bit of inspiration, laughter, sense of connection or perhaps becomes a catalyst for the self-expression of other young dykes and feminists." Since producers' goals are instead to deliver products or information, they work to design delivery methods that are even "more accessible, cheaper, and participatory" (Piano, see also Brasile 66). This ethic works against the core purpose of capitalist and neo-liberal ideology, allowing marginalised people to participate in cultural production.

In order to encourage more people to take on a producer role, third wavers interrogate the producer / consumer binary. Gunderloy and Goldberg indicate that 
independent cultural producers usually start with the realisation that everyone can be a producer (3). These products blur the binary of producer / consumer, encouraging everyone to consider themselves able to create products and spaces that suit their needs. ${ }^{17}$ Third wave feminists encourage people to become producers both explicitly through the content of their zines, and implicitly, through the form of zines. Because DIY products reflect their production, people consuming these products are also consuming information on how to make these products.

More generally, DIY practices work to deconstruct ideas of expertise, authenticity and aesthetic value. ${ }^{18}$ As such, third wave cultural products are not necessarily about the product itself, but about the empowerment that comes from making the product (Reynolds \& Press 327; Duncombe, "DIY”). For example, Schilt notes that while "Riot Grrrl-associated bands may not have been musically perfect," they encouraged band members and audiences to engage in self-expression, a behaviour that in many ways counters feminine norms ("A Little" I4). Riot Grrrl explains that they "don't wanna assimilate to someone else's (Boy) standards of what is or isn't 'good' music or punk rock or 'good' writing" (179). Participant 3 agrees, saying that zines are about "just doing what you can... rejecting a perfectionist esthetic, and going for it!" Third wave DIY practices value the processes of production over the end product, challenging artistic norms which exclude marginalised people.

In The Medium is the Massage, McLuhan and Fiore discuss professionalism as a construct that accepts the "groundrules" of the surrounding environment. Amateurism, in contrast, is "anti-environmental." As such, amateurism calls for total self-awareness on the part of the individual, and a critical awareness of the environment and its underlying rules. McLuhan and Fiore's work highlights the 
political potential of DIY practices; by engaging with practices in which they are not experts, third wavers can both manipulate products into spreading their political message, but are also more engaged with the production itself. This location of the amateur places third wavers in a powerful position to observe and critique the mainstream culture that frequently oppresses them.

For example, Viva la Vulva works to counter "an over-sexualized / sexually repressive society" which they claim leads to "body image hang-ups, dissatisfaction in bed, lack of knowledge of safe sex, and unhealthy relationships." They go on to provide alternative information about women's sexual satisfaction, women's bodies, menstrual products and history, sexual health, sex toys, DIY porn, sexual abuse, and sexualities. Their discussions are non-expert, and as such they can discuss these issues in myriad non-mainstream ways. Similarly, Slightly More than Sound Bytes 4 discusses how women are socialised not to express anger. Mainstream society, the author states, imprints on us that "Girls don't get angry; The only acceptable way to express your anger is to cry; Forgive and forget; Angry women are crazy; and If you don't have anything nice to say, don't say anything at all." The author then goes on to explain that she feels that women have a lot to be angry about in a society that oppresses them, and that anger is a reasonable reaction to many of the circumstances that women experience. She then discusses appropriate ways of expressing anger, and how to deal with issues that make people angry. The author of this zine interrogates a basic expectation of women's behaviour and points out the gendered differences of society's expectations for people's emotions and reactions. Yoga Moves for Dudes more implicitly critiques mainstream social expectations. By making a zine in which men are encouraged to participate in an activity that is dominated by women (in North America), the author challenges 
social expectations about how men will act and in what activities they will engage. While the zine is dedicated to yoga, it also casually writes about men "slaving over a hot stove (again)" and focusing on their emotions. All of these zines challenge dominant social gendered social expectations in a way rarely seen in mainstream media.

Because DIY practices open up "space for multiple voices," they have the potential to counter racism, sexism and classism within larger society, and also within subcultures. ${ }^{19}$ Many participants agreed with this, with participants 3, 6, I 2, I 3 , I5 and 16 describing zines as a space where marginalised people can express themselves. Participant 2 specifically uses her collaborative zine to provide a forum for marginalised voices. She describes her zine as "giving voice to realities and passions which are absent in the dominant culture." DIY practices also allow for the involvement of economically marginalised individuals; while DIY is, in part, a political project, for many it is also an economic necessity (Mitchell \& Karaian 67). Participant 16 notes that during a period when he was "dirt poor" he made a zine that cost forty cents per issue to photocopy: "I would use whatever random five dollars I could earn and I would make some zines and then I would sell them to my friends for fifty cents a copy to cover costs." Despite being impoverished, he was still able to participate in cultural production. The openness that DIY practices create for anyone to participate complements third wave desires for diverse participation in theorising and activism.

Duncombe asserts that the activity of producing culture is imbued with political meaning. This meaning comes from the social environment, which frames producing as rebellious (Cultural Resistance 7). Four participants saw the production of zines as an inherently political act, with participant 12 elaborating that 
he "consider[s his] zine making a form of activism, in that it allows [him] to produce, rather than simply consume." Producing culture counters the hierarchies that dictate who can produce culture. ${ }^{20}$ Whether or not the end product is political, the act of producing a cultural product, such as a zine, is a political act that resists dominant cultural ideals of production and producers. Third wavers understand production as a political act that can disrupt structures of power. Participants 6, I I, I 2 and 16 describe their zines, or "self-produced resources" as inherently resistant, with participant 2 explaining that he considers "zine making a form of activism, in that it allows [him] to produce, rather than simply consume."

Researchers and zine makers alike refer to the zine form itself as inherently political. Most researchers who write on zines mention an amateur or DIY "feel," though there is variance within this style. ${ }^{2 \mathrm{~T}}$ Klein comments that she has "picked up fanzines that $[\mathrm{she}] \mathrm{ha}[\mathrm{s}]$ found literally impossible to read," while Daniel Brouwer describes the admittedly anomalous Diseased Pariab News as technically proficient, with "professional-grade design and layout" (Brouwer 353; Klein 217). Most zines are produced using photocopying machines, and are made with common copy paper that is folded or stapled. ${ }^{22}$ As such, they tend toward cut-and-paste layout and uneven reproduction (Duncombe, Notes IO-II). Key to their production is that they are easy to produce with whatever tools are available, leading to varied styles that are based on producers' skills, needs and supplies. ${ }^{23}$

The zines in my sample varied from the clean, basic layout of Fun is Free Association to the collage-based Graceful Suicide. While most adhere to the folded and stapled office paper form, some zine makers add personal touches, such as Five Days Ago West and The Dyke-tionnary, which hand bind their zines with yarn, or Slightly More Than Sound Bytes, A Guide to the Mannerly Wooing and Winning of 
the Object of Your Affection, Matilda, Status Seekers and Strong Cottonwoods, which use coloured paper or cardstock. Lickety Split and Gribeault are also halfoffice paper sized, but are oriented sideways. Additionally, Lickety Split has a silkscreened cover. Zine makers also play with the sizes that office paper avails, with Sex and Robots Monthly a full 8.5xi I format, and Electric Maybem 2.3, Matilda Zine: Special Neighbourhood issue, Ghost Pine Zine and Winter Chapter cutting office paper in half and then folding it, making a quarter-page sized zine. Curses! also takes this quarter-page size, but is then bound in clear plastic. The Last Thumbnail Picture Show takes this cut one step further, producing an eighth-size page, which is then bound with a photo index print. Zine-O-Phobia is also an eight-page zine, but it is presented as a single page of $8.5^{\prime X I} \mathrm{I}^{\prime \prime}$ office paper, which the reader must then cut and fold (as per provided instructions) in order to be able to read the zine. (See figure 12 on page I 22-23.) This extensive variety of format and materials in a relatively small sample illustrates how zine makers creatively use the resources and skills available to them. These choices also demonstrate that zine makers don't feel a need to adhere to a given style, and imply that amateur experimentation is encouraged.

Two participants ( 3 and II) mentioned that they learned how to make their zines, in part, from looking at other zines. Whatever the content of a zine, it also "erodes the line between artist and spectator, producer and consumer, challenging the hierarchical division of labor and encouraging everyone to create" (Duncombe, "Walter Benjamin" 68). As such, DIY products like zines encourage and implicitly instruct people on becoming producers. ${ }^{24}$ Walter Benjamin claims that this aspect of independently produced cultural products is what enables their greatest political effect - consumers upon exposure to the product will be induced to also become 

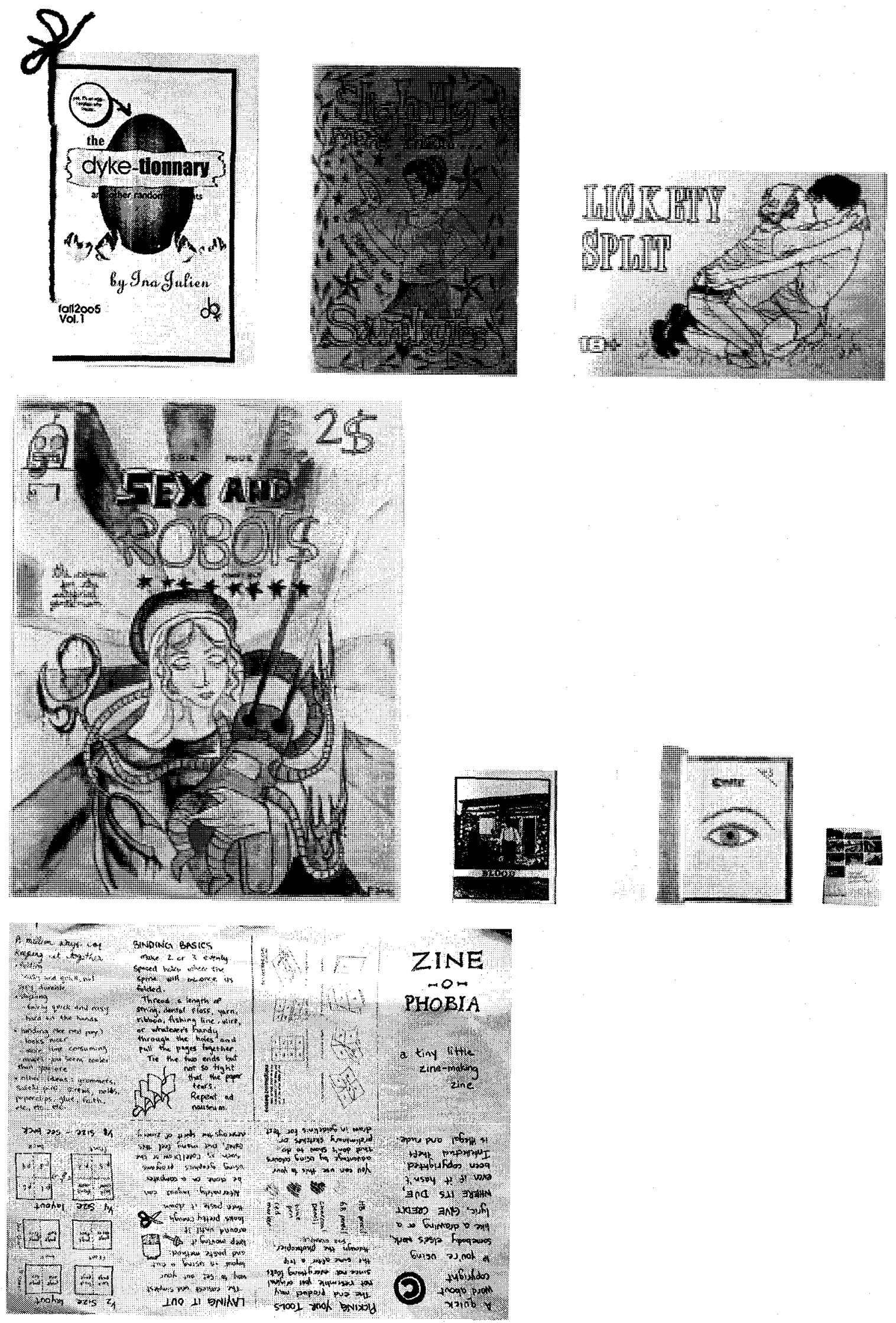
Figure 12: These images show zines at approximately $1 / 3$ their actual size, to demonstrate the wide variance in sizes and formats. They are: The Dyketionnary, Slightly More than Sound Bytes 4, Lickety Split, Sex and Robots Monthly, Ghost Pine Zine, Curses! 3, The Last Thumbnail Picture Show and Zine-O-Phobia. Note also that The Dyke-tionnary is bound with yarn; that Slightly More than Sound Bytes 4 is printed on coloured card stock (it's green); that Lickety Split is printed sideways, also on coloured cardstock and with the image and text silk-screened on; that Sex and Robots Monthly is printed on glossy cardstock in full colour; that Curses! 3 is bound with a clear plastic cover; that The Last Thumbnail Picture Show is bound in a photo index print; and that Zine-O-Phobia must first be bound by the reader before it can be properly read. 
producers, turning them into "collaborators" in either the specific political project or in production in general (Benjamin 78). Participant 3 agrees with this, saying that "their very production is a form of encouragement" - a sentiment that participants I, 5, Is and I6 also mention. Participant s elaborates: "The notion that "anyone can do it" forces you to get involved because there are not excuses not to."

Bhabha notes that producers of cultural products can circumvent normal economic and social controls in order to spread political messages. Because of this opportunity, cultural resistance can be very effective for subversion or transformation of society (Bhabha, "Commitment to Theory" 20; Bhabha, "Translator Translated" 82). Third wavers have noticed this potential of DIY practices for communicating political messages and engaging people in these politics. As such, they have made use of DIY practices in many forms, including zines (Mitchell \& Karaian 67; S. Thompson 62).

One way that zines lead into political activity is by directly challenging mainstream culture and media (Mitchell \& Karaian 67; Piano). Their "nonslick format" itself brings to light the constructed norms of commercial publishing (Garvey 397; see also Sinor 243). A popular zine tactic for challenging mainstream culture, however, is the use of collage and détournement. ${ }^{25}$ (See figure I 3 on page I 25.) Zine makers use mainstream media elements, such as cut-outs from magazines, to "innovatively critique, ridicule, and oppose messages and images disseminated by the mass media." (Kearney 299). Grrrl zines, in particular, use collage and détournement to discuss constructions of femininity in mainstream culture with "writers offer a visual critique of beauty standards and expected behaviour by juxtaposing text and illustrations taken from comics, advertising, teen magazines and 

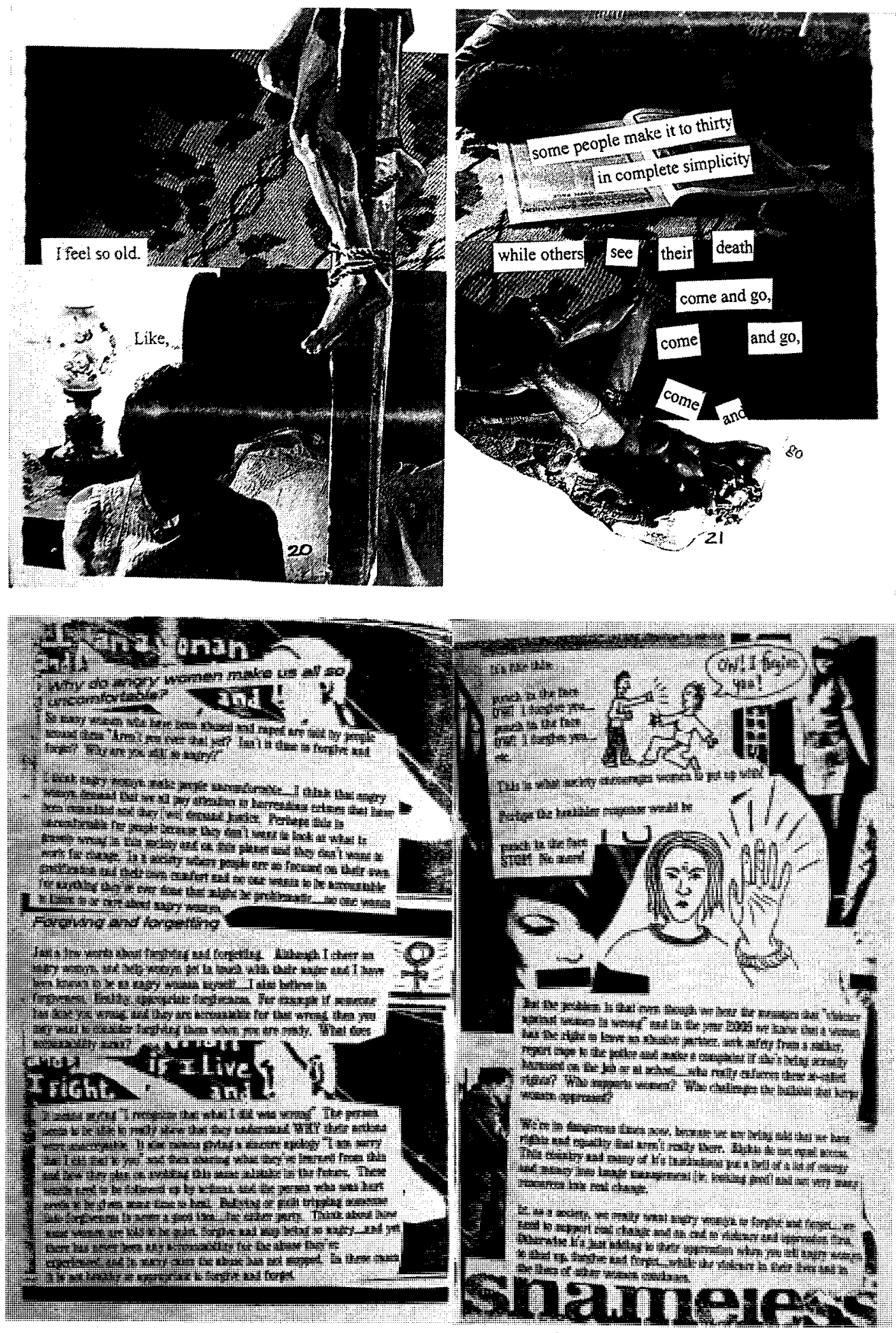

Figure 13: Two collage pieces from Sean Zio's Electric Mayhem 2.3, page 20-21 and Jess's Slightly More than Sound Bytes 4. 
fashion photography. ${ }^{{ }^{26}}$ Sometimes, zine makers include stickers in their zines, to encourage readers to participate in this détournement in their own environments (Vale Vol $I, 4)$. In some cases, zines explicitly critique mainstream media. For example, the author of The Dyke-tionnary explains that she was motivated to make the zine because she "was tired of watching popular mainstream culture, that had never been particularly supportive of queer women, cash in on the new "lesbiancard" every show has pulled out as their last resort to seem taboo or avant-garde, or even just to pull up their ratings." Other zines critique mainstream media less directly - both The Unfortunate Social Incidences that Have Now Been Attributed to Lupix E Vulpius and Other Things and "Marvellous World" in Gribeault 4 show news programs to be vapid and meaningless. (See figure I4 on page I27.) DIY practices also give their media a "tone of intimacy" (Leonard 105). Researchers point to handwritten text and hand-coloured illustrations as features that confer a "human touch" to zines, and frequently make each zine individual. ${ }^{27}$ Participant 2 asserts that "this process-based, handcrafted quality serves to engage the audience by offering cultural souvenirs and shared tokens, deepening the resonance of the journal's communication," suggesting that the form zines take has an impact on the level of communication they can achieve. In addition, contends Marion Leonard, DIY style can "convey a sense of urgency" through features such as uncorrected misspellings, typing and grammatical errors and incorrect pagination (105). The choice to leave errors uncorrected highlights the zine maker's belief in the importance of what she has to say over technical proficiency.

While zines, and other third wave tactics, use what is termed do-it-yourself strategies, my participants suggest that zines are rarely an entirely solitary 


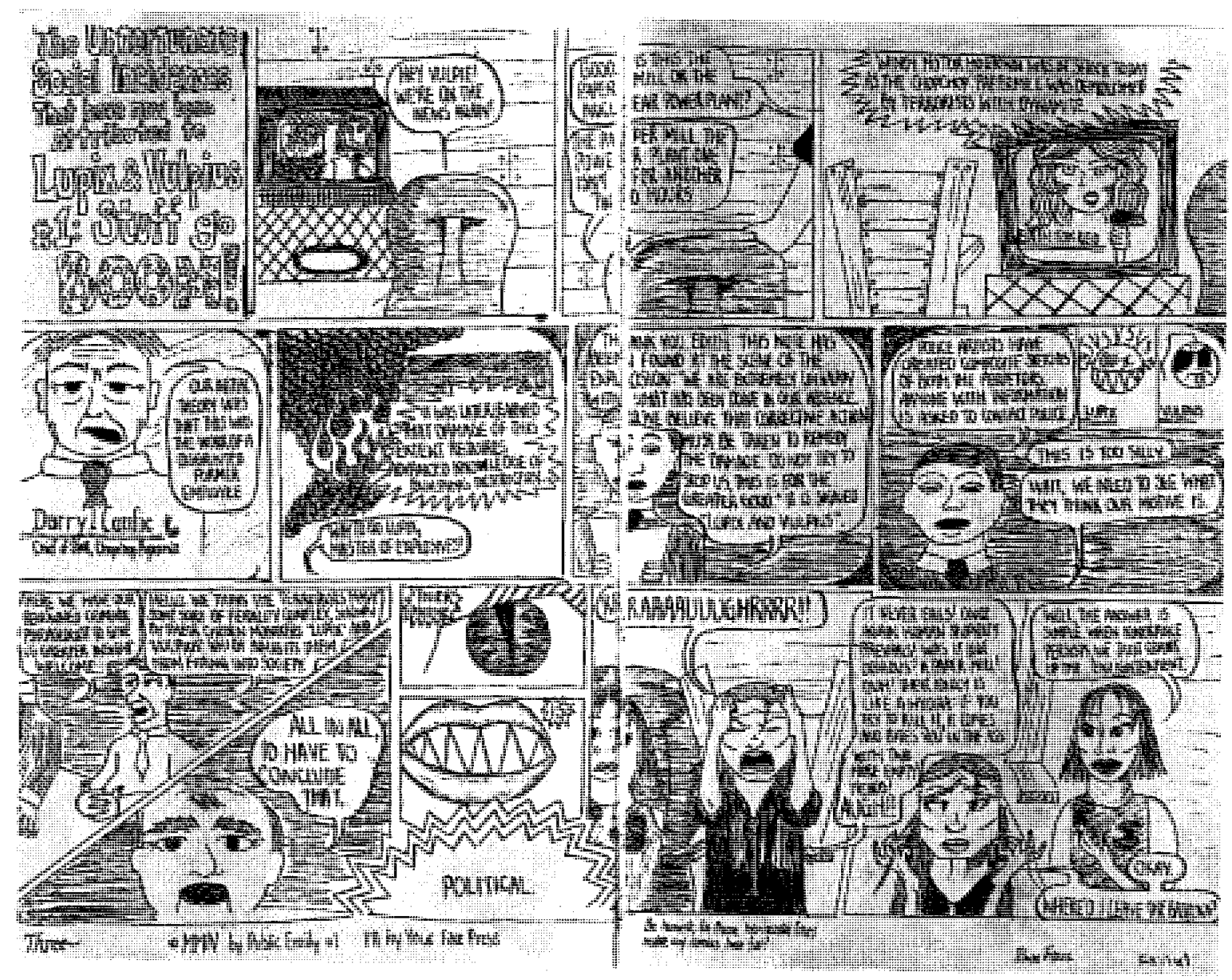

Figure 14: This story, from Emily's The Unfortunate Social Incidences That Have Now Been Attributed to Lupix \& Vulpius and Other Things, page 3-4 shows the mainstream media simplifying an event, while attempting to seem authoritative. 
endeavour. Rather, they might be termed a "do-it-ourselves" type of project. Of my I6 participants, 9 mentioned working on a compilation or group-made zine, despite not being directly asked about this. Of the zines in my sample, eleven zines credited multiple authors. ${ }^{28}$ Many also explicitly thanked people for help with editing and general encouragement. Only six participants claimed to be entirely selftaught, when asked how they acquired their zine-making skills. Of the sixteen participants, three receive no assistance in making their zines, twelve take submissions or have co-writers, nine have production assistance, and six have distribution help. Additionally, eight participants have submitted work to other zines or helped other zine makers with content, and only three have never taught someone any zine making skills. The remaining thirteen who have shared their zinemaking skills have taught a wide variety of skills, with eight teaching layout, four teaching photocopying, and smaller numbers teaching skills such as binding, scanning, collage-making and pagination. Not surprisingly, thirteen zine makers replied that they have also encouraged others to make zines, with five participants teaching or supervising a class or workshop on zine-making. While these numbers come from a very location-specific and small sample of zine makers, their overwhelming responses regarding cross-participation in zine making support the view that zines can be a community building tool, and that DIY projects are not necessarily an insular activity.

This enumeration of skill-sharing and cross participation also highlights the sheer amount of work required to make a zine. ${ }^{29}$ While the zine form appears simplistic, zine creation actually involves a number of specialised skills. In Zines Will Change Your Life, the author's description of different ways to format a zine illustrates this complexity. (See figure is on page I 30 .) Zine makers interact with a 
number of complex and evolving technologies, from photocopiers to graphic design programs. They generally also require hours of writing, graphic creation and editing. For example, in the introduction to Slightly More than Sound Bytes 2, the author says, "“If you are reading this, it means I actually finished the zine I've been working on for...ummmm.... 19 months." In the introductory statement of Zines Will Change Your Life, a zine that goes into specific detail on ways to make a zine, the author states, "I think there's enough info in here to keep you busy for at least ten weeks.”

This work, however, is dismissed in ways that parallel how the work women do traditionally has been dismissed; it is called simplistic, easy, a hobby done in one's spare time using skills naturally acquired, or in the case of zines "girls just mucking around or doing art" (Harris, "Riding" 30; see also Harris, "Not Waving"). The skills that third wave publications demonstrate, and the effort that zine makers put into their work, however, belie these claims. These efforts, which also work outside of capitalist profit structures, indicate the drive and passion that zine makers have in sharing whatever their zines have to offer.

\section{Conclusion}

In this chapter, I argue that zines, through their content and form, encourage feminist community, networks and activism, while managing the threat of latecapitalist commodification. Their roots in DIY practices allow third wavers to actualise their views on inclusiveness and avoid hierarchies, while encouraging constant interrogation of third wave principles and practices. In the face of contemporary pressures, third wave feminists are doing what previous feminists did: they are building community and coalition around issues of social justice; they 


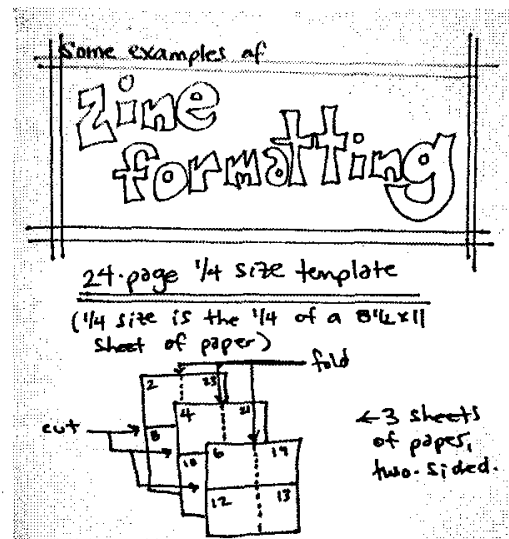

8.page 144 size template

G I sheet of paperitwo-sided.

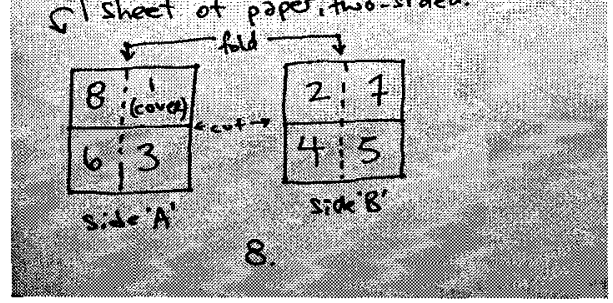

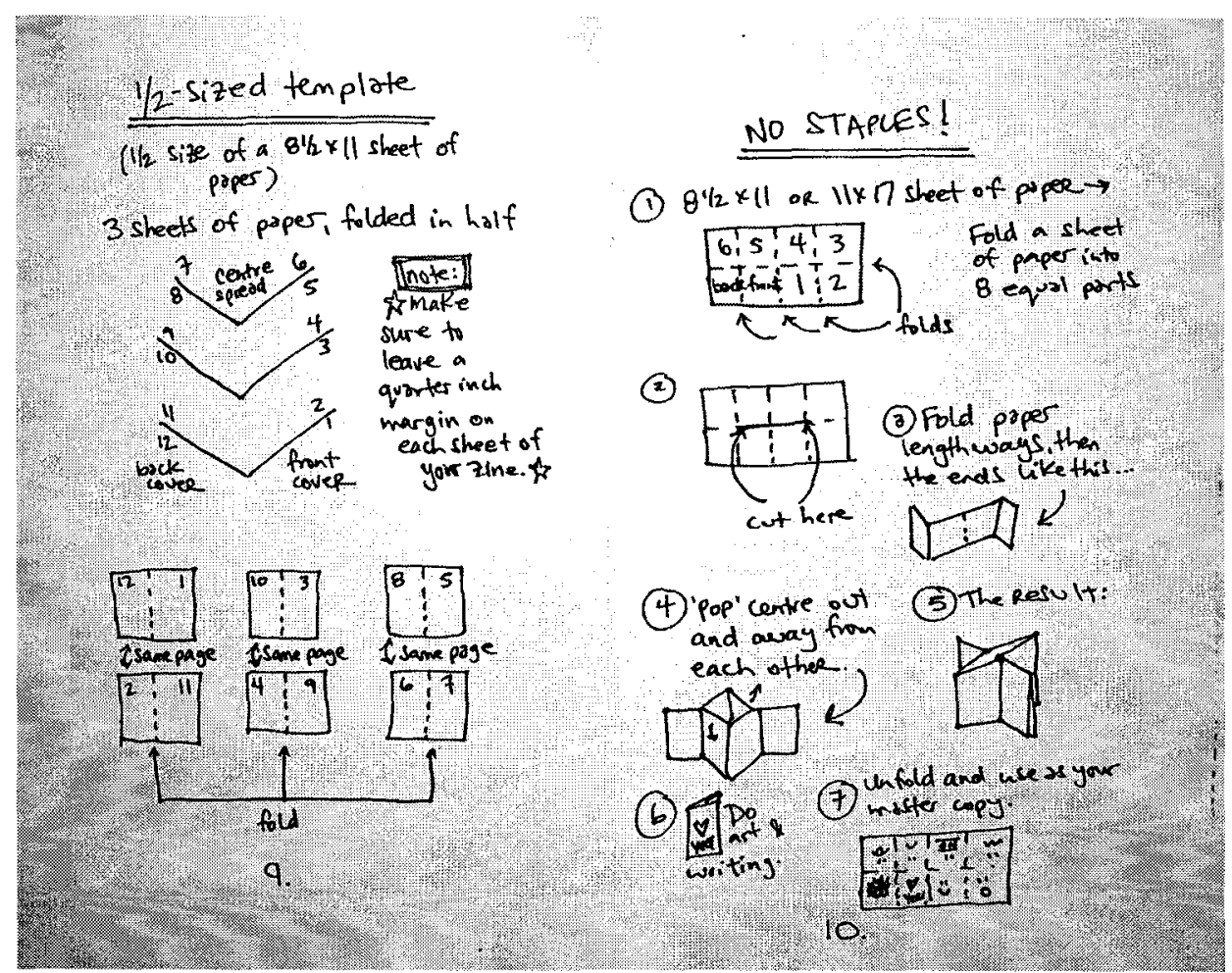

Figure 15: This chapter of Sean Zio's Zines Will Change Your Life, page 8-10 demonstrates a number of zine formats, and how the templates for these formats should look. While photocopying seems an unskilled task, these diagrams indicate that a fair degree of knowledge and skill is required to produce a properly paginated booklet. 
are forging a feminist space across geographic challenges; and they are fighting the overarching forces of oppression. Because of the influence of late-capitalism, and its controlling strategy of commodifying resistance, third wave feminists' strategies in fighting oppressions like patriarchy, racism and homophobia acknowledge the forces of commodification, and subvert it by opting out of capitalist structures.

Next, I consider how these factors play out in the case of one zine maker, and discuss how she frames her publishing endeavours. Finally, I conclude that zines are a valuable political tool, for feminists and other activists. When framed using Bhabha's theory on cultural production, the potential for zines to create resistance space and to effectively challenge power hierarchies becomes evident. 
"See DuBois I49; Johnson 253; Steenbergen, "Feminism" 6, I 2. For example, Ellen DuBois notes that in the first wave of the women's movement, "the conditions of women's lives" such as their dependence on marriage for financial security and the sexual division of labour, which limited their work opportunities and reinforced their dependence on marriage, severely restricted the goals first wave feminists could consider in their call for suffrage and the emancipation of women (I49).

${ }^{2}$ Bell \& Klein xxi; see also Ferree \& Hess viii; Johnson 253; Mitchell \& Karaian 6I.

${ }^{3}$ Steenbergen, "Talkin" 266; see also Harris, "Not Waving"; Steenbergen, "Feminism" 8-9.

${ }^{4}$ Steenbergen, "Feminism" I 2; see also Garrison I44; Steenbergen, "Talkin"” $263-64$. 'Additionally, Brasile points out that many third wavers can't participate in the traditional politics of their society, as they can't vote due to age restrictions $(65)$. ${ }^{6}$ Mitchell \& Karaian 67; see also Collins 74; Driscoll i77; Harris, "Not Waving"; Harris, "Riding" 30.

${ }^{7}$ In their questionnaires, participants I, I I, I 2, I 5 and I6 assert that zines create community. Participant 16 , in particular, states that he creates zines with the explicit intention of "community building."

${ }^{8}$ Participant 4 also refers to how members of the zine making community support one another in their work.

"See Duncombe, "Alienated Together" 435; Ferree \& Hess xv; Garrison I45, I60; Harris, "Riding" 29.

${ }^{10}$ See Duncombe, "Alienated Together" 428, 435, 446; Green \& Taormino xiv.

II Duncombe, "Alienated Together" 445; see also Ferree \& Hess xiii; Harris, "Not Waving"; Harris, "Riding” 28; Riot Grrrl 179.

${ }^{12}$ See Bell, "Riding"; Duncombe, "Alienated Together" 430, 435, 447; Ferris 52; Garrison I 59; Harris, "Not Waving"; Mitchell \& Karaian 67; Samek 139.

${ }_{13}$ The following participants referred to their zine as a space for marginalised voices: $2,6,13,14,16$

${ }^{14}$ Samek I 39; see also Duncombe, "Alienated Together" 430, 447; Duncombe, Cultural Resistance 5-6; Duncombe, "Subcultures" I35; Grant 54, 55; Mitchell \& Karaian 67.

${ }^{15}$ See Brasile 66; Pinterics 17. Participant I 4 also notes that zines are a part of a gift culture, which allows zine makers more freedom in creating what they want, and in easily distributing those products.

${ }^{16}$ For examples of those explicitly against profit, see Duncombe, "DIY"; Piano; Riot Grrrl I 80. For examples of those incidentally against profit, see Brasile 66; Ferris 54; Green \& Taormino xiii; Piano.

${ }^{17}$ See Bell, "Women-Produced" 59; Benjamin 72; Duncombe, "Alienated Together" 446; Duncombe, "DIY"; Duncombe, "Walter Benjamin" 68.

${ }^{\mathrm{r} 8}$ See Davis 316; Klein 216; Reynolds \& Press 324.

${ }^{19}$ See Austin and Gregg 82; Davis 316; Garvey 367; Piano.

${ }^{20}$ Duncombe, "Walter Benjamin" 68; see also Bell, "Riding"; Hanna r 8I.

${ }^{21}$ Sinor 243; see also Brouwer 352, 353; Duncombe, "DIY"; Eichhorn 577; Guzzetti \& Gamboa 4I 8; Klein 217; Long 403; Romanesko; Schulman in Long 402; ScottDixon, "Ezines". 
${ }^{22}$ See Austin \& Gregg 82; Bailey \& Michel; Duncombe, "Alienated Together" 427, Notes I0-I I; Garvey 397; Green \& Taormino xi; Mitchell \& Karaian 66; Pinterics 17. ${ }^{23}$ See Austin \& Gregg 82; Duncombe, Notes I I; Green \& Taormino xi; Pinterics 17. ${ }^{24}$ See Bell, "Riding"; Benjamin 78; Green \& Taormino xiii.

${ }^{25}$ See Duncombe, "Alienated Together" 427; Duncombe, "DIY"; Duncombe, Notes I0; Garvey 397; Green \& Taormino xi; Leonard 105. Détournement is a French word meaning "diversion, deflection, turning aside from the normal course or purpose (often with an illicit connotation)" (Knabb 37I). In this case, however, it refers to "the reuse of preexisiting artistic elements in a new ensemble" with each separate element excised from its normative context, thus losing its original sense, and juxtaposed with new elements in a meaningful ensemble ("Detournement" 55; $\mathrm{McDonough}$ 5). The practice of détournement highlights Bhabha's contention that culture is created in the space between words and objects, and agrees that while there is much power in determining that space, that no cultures created there are inherently superior to any others ("Commitment to Theory" $36-38$ ). While situationist détournement included the détourning of literature and architecture, the détournement that occurs in zines parallels more the situationist détourning of visual art. Of particular note is the situationist détourning of comic strips, with new text inserted in speech bubbles, and the détourning of advertising billboards "by pasting over pre-prepared placards" (Plant 86-87; Viénet 214). For more on détournement, see Guy Debord and Gil J. Wolman's "Methods of Detournement," Sadie Plant's The Most Radical Gesture, especially pages 86-89 and Tom McDonough's "My Beautiful Language of My Century."

${ }^{26}$ Leonard ros; see also Collins 83; Richardson f.6 qtd. in Scott-Dixon, "Ezines"; Kearney 300-0I.

${ }^{27}$ See Bailey \& Michel; Knobel \& Lankshear; Leonard io5; Vale Vol I, 5. ${ }^{28}$ The following zines have contributions from more than one author: Electric Mayhem 2.3, Matilda Zine, Viva la Vulva, Refuel, A Guide to the Mannerly Wooing and Winning of the Object of Your Affection, The Miss G Home for Wayward Jokes, Gribeault 3, Gribeault 4, Lickety Split, Status Seekers, Sex and Robots Monthly.

${ }^{29}$ For discussion of the "tremendous labour" involved in zine making, see Collins 86. 


\section{Conclusion}

After receiving a zine from a friend, then making contributions to her friend's zine, Paula Belina started publishing her own zine, Streeteaters. Belina sold her zines at Ravenswing Craft and Zine Fair 2007, in addition to holding a free workshop on block printing and performing her spoken word poetry. Her answers to my questionnaire discuss many of the themes I highlight with this thesis. I will discuss briefly Belina's zines and questionnaire, before drawing my conclusions about the potential of zines for activist work.

Belina was motivated first by her desire to "gather together" the work of "many artists and writers whose work [she] loved," and then by the positive response she received from her readers. After 6 years and 39 issues, she finished work on this anthology zine to move on to other projects, such as a new series Fun is Free (Association), which "collects all sorts of surrealist \& acting / playing games that people can play to engage themselves in the moment $\&$ outside of consumercapitalist realities," and Refuel, a vegan recipe zine. She says that she feels connected to her local zine community; she teaches a number of people zine-making skills, such as how to use a photocopier and to collage, she sends out submissions to other zines and she holds free workshops on writing and political print making. She also reads zines from across Canada and the United States, though mostly from Montreal, Halifax, Ottawa and Vancouver. Zines, she states, "give people a space to put their work and validate each other outside of forums of institutionalized learning and employment" and are "intimately connected to the zine maker." Belina's initial interaction with zines, along with her ongoing connections to her zine community, demonstrates the strength and potential of zines to build communities and coalitions that can be both local and international, politicise domestic and leisure 
activities, and which invite the participation of marginalised people.

Belina draws on previous activist publishing in her own work. In Stamp Carvings by Paula Belina, she pairs some of her stamps with the photographs and paintings that inspired them (see figure 16 on page 136). In Block Traffic! Block Prints, a zine she created to accompany a block printing workshop, Belina gives a brief biography of six block print artists who have created political art on topics including hunger, poverty, disarmament, fascism, labour issues, capitalism and racism. While these artists cover a variety of topics, they share a determination to resist oppressive forces in whatever context they find themselves. By considering these artists and the effect of their work, the content of Belina's work draws on previous forms and styles of resistance publishing through block printing, while the form of her work, zines, draws on the history of resistance publishing, such as second-wave feminist newspapers and riot grrrl zines.

Zine makers counter oppressive social expectations, and mainstream media that reinforce them, through the use and celebration of DIY practices. Belina states: "accessibility is huge for me - zines are part of gifting, they are part of a great resource of D.I.Y. learning (how to cook, how to garden etc.) they are selfempowering and they are an antidepressant, anti-alienating force for me." She then transcribes The Why Cheap Art Manifesto on the back of the questionnaire (see figure 17 for a reproduction of the original pamphlet, on page 137 ). Belina's association between the work she does in her zines and The Why Cheap Art? Manifesto demonstrates her awareness of the limitations that mainstream media and commodification place on communication for marginalised people and her refusal to accept these restrictions. 


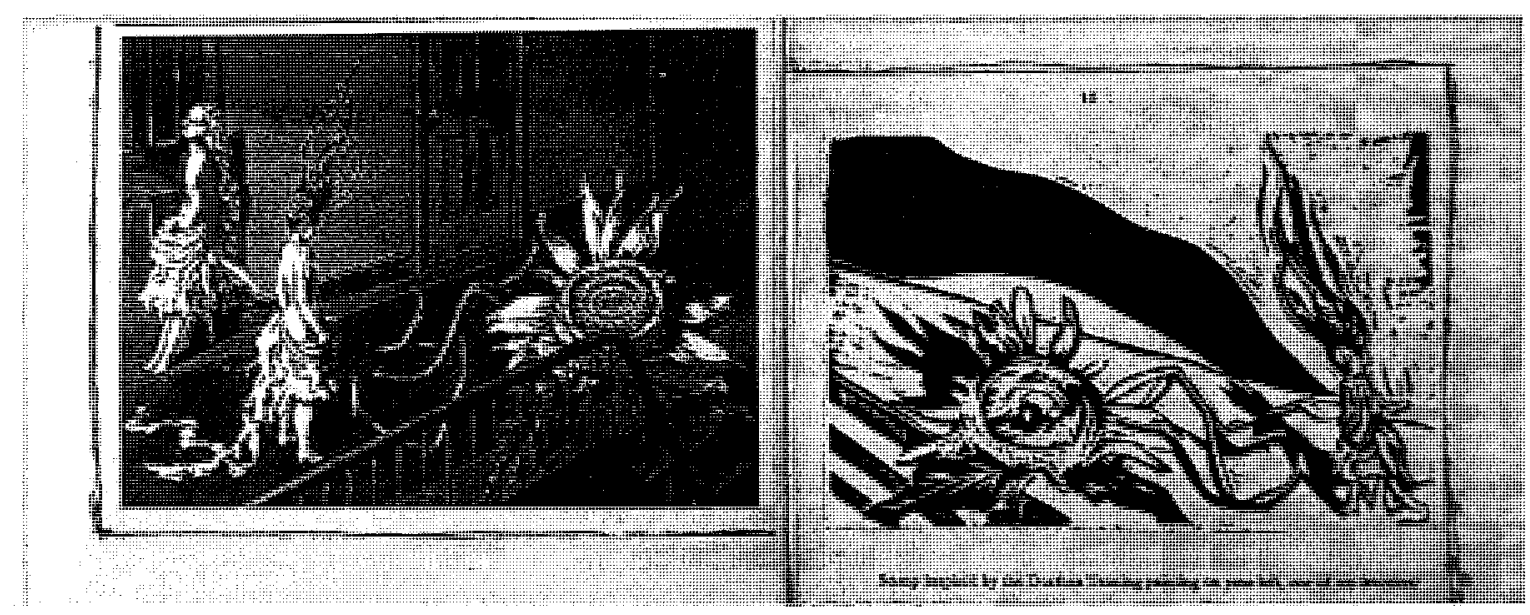

Figure 16: In Stamp Carvings by Paula Belina, Paula Belina pairs her block print (on right) with the painting that inspired it (on left). In doing so, she draws connections between her work and the resistant and political art that chronologically precedes it. 


\section{the WHYCHEAPART? manitesto}

PEOPLE have been THINKING too long that

ART is a PRIVILECE of the MUSEUMS \& the

RICH. ART IS NOT BUSINESS !

It does not belong to banks \& fancy investors

ART IS FOOD. You cant EAT it BUT it FEEDS

you. ART has to be CHEAP \& available to

EVERYBODY. It peeds to be EVERYWHERE

because it is the INSIDE of the

WORLD.

AnT 800THixs PADI:

Art wakes up sleepers !

ART ITGHTS AGAINST WAR \& STUPIDITY I

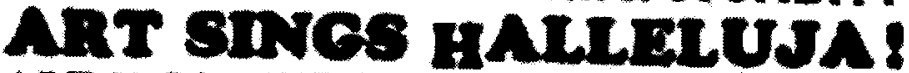

ART IS FOR KITCHENS I

ART IS LIKE GOOD BREAD!

Art is inceraen troese

Art is like white clouds in blue sky 1
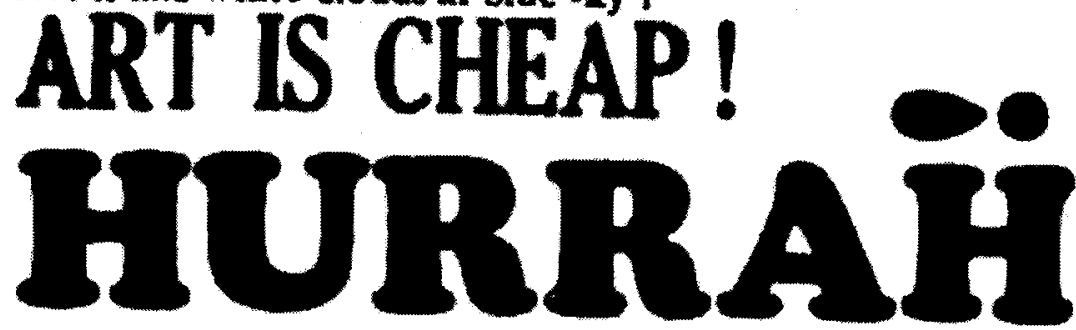

Bread \& Puppet Glover, Vermont 1984

Figure 17: The Why Cheap Art? Manifesto was published in 1984 by the Bread and Puppet Theatre group. According to their website, the Bread and Puppet Theatre group are a puppet theatre group in that formed in New York in 1962, and are now based in Vermont. They are a non-profit self-supporting theatre group that performs theatre shows, engages in political protests, and publishes posters and literature. They launched the Cheap Art movement in 1982 in response to the appropriation of art by the corporate sector. Their home page states: "Cheap Art hopes to reestablish the appreciation of artistic creation by making it available to a wider audience and inspire anyone to revel in an art making process that is not subject to academic approval or curatorial acceptance" (www.breadandpuppet.org). 
While The Why Cheap Art Manifesto demands that art be made available to everyone, Belina, by focusing on DIY practices, insinuates that art must also be available for everyone to create as well as to consume. While zines can perform the practical task of teaching one to cook or garden, they also inherently work to empower their readers to become creators. The Why Cheap Art Manifesto explains that art, such as Belina's zines, influences people in a number of ways - not only is art "like good bread" and "like green trees," it also "wakes up sleepers" and "fights against war \& stupidity." These creations may act as comfort to their creators, but they are also inherently political.

Belina's zines are also explicitly political. Refuel, for example, advocates vegan-ism. While it is a vegan recipe zine, it also contains tips on how to buy a second-hand bike, a recommendation for a new zine on yeast infections, comics about being vegan and political awareness in general, meditations / prayers / rituals that different cultures take part in before eating. In these additional pieces, Belina brings in other perspectives, politicises the recipes and choices one makes in eating, questions consumer behaviour around food (purchasing, eating) and talks about the community she finds in eating and cooking.

Belina also challenges the standardised way that recipes are published, and the delineation between the art and work of cooking, and the art of creative writing and the craft of recipe creating. For example, her recipes are titled with names like "Oh my God borscht is so fuckingamazing" and "Vegans rock breakfast." Her recipe for "Paula's "creamy" pasta" counters recipe-writing standards (see figure I 8 on page 139). By neglecting to include the precise measurements found in most cookbooks, Belina's method of writing allows the cook latitude in creating something of their own, while also making the practice of this recipe a poetry 


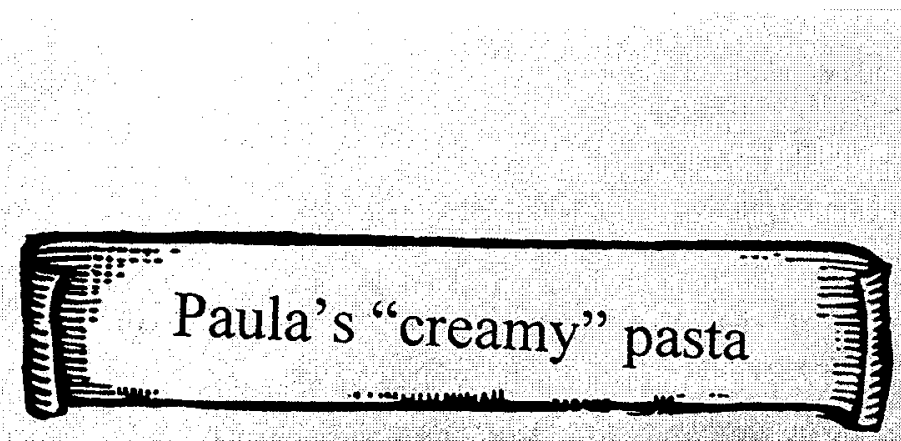

(also called "avocado \& garlic have a pasta wedding, \& you're invited!" - foretold in a quick, hurried manner:)

Pasta-cook it, put in bowl, yeah, you know you've done it before, anyway, c-section the pit out of an avocado and eggcrack that lovely, green sucker in there, y'know, mashed a little, rain down some raw chopped garlic, some sesame salad dressing, some sesame seeds, some sunflower seeds, throw some sprouts in there, friend! Stir that baby up, if you want this style to work better, you may want to blend the avocado and garlic together before headin' out on the road to vegan friendly "creaminess"!

Figure 18: From Refuel, page 6, Paula Belina's pasta recipe doesn't follow recipe-writing conventions. 
reading with rhythm and light-heartedness that highlight the playfulness and art possible in the practice of cooking, rather than the strict adherence to authoritative instructions that can make the practice a chore, or a chance for failure. This is an example of the empowerment that Belina talks about - her zine both demonstrates why one might wish to choose a vegan diet and how one can go about this, while also encouraging creativity in her readers.

Belina highlights the potential of this space to avoid the censorship inherent in capitalist cultural production, stating that zines "live outside of the capitalistcommodity-censorship-"product" realm of created works." In her response to the questionnaire, Belina draws a number of connections between accessibility of cultural products, DIY practices, commodification and capitalism. She feels that her DIY cultural work, including zine making and holding free workshops, helps her and others to counter oppression. Belina's zine Refuel is a black and white zine photocopied on both sides of 6 pieces of office paper, folded in half and stapled. While the cost of photocopying alone likely eats up half of what the zine sells for, Belina sells it for \$2. The labour and creativity that Belina puts into the zine does not figure into the price of the zine - her labour and creativity are a gift. Through DIY practices such as these, Belina avoids negative effects of consumerism, such as consumerism's ability to counter resistance, to discourage production and to reinforce oppression through limiting marginalised people's participation in cultural production.

Belina's work illustrates the potential of a DIY ethic and its realisation in zines. Her emphasis on accessible work is demonstrated in her willingness to share and teach; she empowers other people to become creators and producers in order to circumvent the censorship inherent in capitalist cultural production. Her actions 
build community and coalitions, and create an inclusive space for activism. This space creates a venue for marginalised voices and platform for cultural and political activism. Next, I will conclude that when zines such as Belina's are framed with Bhabha's theory of cultural resistance, they provide a crucial site of resistance for feminists and other activists.

In this thesis, I argue that zines are an important site of resistance for thirdwave feminists and other activists; they effectively counter and challenge contemporary oppressions in both their content and form. Marginalised voices, like those in zines, are threatened by dominant structures that would suppress them. Like previous feminist publishers, though, zine makers develop a form that circumvents that oppression. In this case, zines avoid the commodification that mainstream media uses to negate resistance narratives. They create a non-physical space for marginalised resistance to develop according to third-wave principles of inclusiveness and non-hierarchy.

While zines may seem like an entirely new form of resistance, they bear many striking similarities to previous forms of feminist publishing. While feminists from different waves have faced varied oppressions and responded accordingly, my examination of the contexts within which these feminists resisted indicate continuities and parallels between the waves. Feminists in the first, second and third waves have sought to overcome barriers to feminist discourse, whether they be geographic distance, mainstream media stereotypes or mainstream cultural insistence on a lack of need for feminism. Feminists from all three waves take advantage of the printing technologies available to them to create works that reach out to other marginalised people, build communities and coalitions, disseminate information and demand a voice for marginalised people in mainstream culture and media. Feminists 
have long used the creation of cultural products, including publications, as a practice of resistance. While these publications may seem different in form and content, they share feminist goals and aspirations, and determination to fight oppression in whatever form it takes.

Zines are inherently political - in a society dominated by capitalism, they are part of a gifting and barter system. In a culture dominated by mainstream media that produce an overwhelming amount of media that adhere to extremely strict representations of different groups, zines publish different, complex (unprofitable) perspectives. In a society where identity is dictated by consumer patterns, and which alienates individuals, zines build communities between readers and writers, and blur the lines between the two. And in a culture where resistance itself is commodified, zines work to circumvent this negating force. Zines can seem like a personal project with limited scope and reach. But when zines are framed, as Kelley suggests, as a valid, though unorganised and marginal, form of resistance, the activism taking place in zines is undeniable. Zines are the site of vibrant activism on many fronts, but hold particular potential for marginalised people and groups, like feminists.

Bhabha's framework for cultural difference explains the vast potential of cultural resistance, such as zines. His conception of third space as a space for negotiation between cultures, as an alternative to demanding homogeneity or unity within groups, speaks to third wave goals of inclusiveness. When cultures, or in this case, groups of feminists aren't pressured to present a unified front in order to achieve legitimacy, accurate and open dialogue about and between people with complex and intersecting group identities can occur. Marginalised people and groups are able to participate fully. When cultural or political groups are seen as 
constructed, rather than naturally occurring, the lived realties of those who belong to multiple groups can be acknowledged. Bhabha contends that his model allows for self-definition and for groups to act as authorities on their own cultures, which is a key demand of third wavers. Zines seem to prove Bhabha's theory - they act in third spaces, welcoming marginalised voices and allowing for cultural negotiation without demanding homogeneity. They also create space for marginalised people to act as authorities on their own lives.

Bhabha frames the cultural products of third space as political and resistant. Bhabha contends that when alternative narratives are presented, even if they are presented by marginalised people in marginal spaces, they unsettle the concept that the dominant narrative is true, and present it as merely one of many versions. As such, the power hierarchies on which dominant groups rely to justify their power are threatened. Such narratives work outside of the third space in which they were created in ways that the dominant culture cannot contextualise within its hierarchy. In effect, they create space for negotiation over cultural authority. This type of resistance precisely fills the needs of third wave feminists. Third wavers don't look to have dominant groups "accept" marginalised people. Instead, they look to break down the hierarchies that allow one group to decide whether or not to "accept" another. My study demonstrated that zines are a medium for third wavers to present these alternative narratives that challenge power hierarchies. They are also a form that dominant groups find difficult to contextualise into the hierarchy, making them an especially powerful form of resistance. Bhabha's theory explains why zines are more than individual projects with limited influence. As a whole, they have the potential to unsettle the hierarchies that underpin many oppressions.

I have shown how zines are part of a continuum of resistance feminist 
publishing, and explained their potential as part of an alternative politics. While they differ from previous types of resistance, this is largely due to the changes in the nature of the oppressions they challenge. My sample of zine makers in the Ottawa area demonstrates that zines are a critical example of effective resistance. But my sample was necessarily small and local. Further research needs to be done in other parts of the country. In particular, zines might have a different presence in northern or rural Canada, where tools like photocopiers might be less accessible. Zines have also been critiqued as a form of cultural resistance in which mainly white people engage. While riot grrrl, and the punk movement from which it grew, were dominated by white people, zines have since moved away from these punk roots, and racialised people, as well as other marginalised people, have certainly taken them up. The evidence of racialised people making zines, however, is as anecdotal as the assertion that mostly white people make them. Research is needed to determine who is making zines, internationally and in Canada. If they are only being used in certain places or by certain people, further study of what other types of cultural resistance feminists and activists deploy and how these forms compare or interact with zines and zine makers would be instructive.

Zines are a work in progress and are, therefore, difficult to study. The main challenge to a full exploration of zines is that they consist of many independent elements. In this, zines closely mirror second-wave consciousness-raising groups, which worked individually at a small level to make small changes, but when taken as a whole, worked to politicise women and bring attention to women's issues. Though this feature of zines makes them challenging to study, it is a necessary feature, as their lack of organised hierarchy and adherence to capitalism and consumerism prevent dominant forces from commodifying them into de-politised 
consumer products. While zines are a relatively new phenomenon, especially in their post-riot grrrl form, a thorough study of who zine reach and their effect on communities could show more clearly emergent possibilities for resistance, and their potential effect on larger society.

Additionally, I argued that people who do not identify as feminist still are engaged with feminist goals, as evidenced through their zines. Third-wave work demonstrates a commitment to anti-oppression and social justice, and a reluctance to take on or impose labels. In third wave, it seems, you can do feminist work (and by feminist work they mean anti-oppression work) without calling yourself feminist. It has yet to be determined what this realignment from a focus on women to one on gender complicated by myriad other issues, or on social justice in general, means for feminism as a movement. Does feminism lose strength and focus by taking on issues other than gender, or does it gain members and momentum, and even credibility, from attending to non-gendered and intersecting oppressions? Research on how these questions play out in third-wave and social justice forums, such as zines, could provide more concrete answers to these concerns.

As forms of resistance evolve to address new and continuing forms of oppression, they can be difficult to define according to previous standards. Thirdwave activism asks that we open ourselves to new forms and manners of resistance. Zines are only one example of this type of resistance, but their richness both in content and as a form indicates a third-wave movement rich with complex ideas of resistance and activism. They are a telling indicator of the third wave; as Belina asserts, “zines are no-bullshit.” 
Appendix I: List of Second-Wave Feminist Newspapers

Broadside I.I (May 1979)

Broadside 10.5 (August / September 1989)

Cayenne I (November / December 1984)

Cayenne 2

Cayenne 3

Cayenne 4

Common Ground I I.I (February I992)

Common Ground I I.2 (April 1992)

Khush Khayal I.I (February 1989)

Khush Khayal I.2 (May 1989)

Khush Khayal I.3 (October 1989) misprinted as May 1989

Khush Khayal I.4

Khush Khayal 2.4

Lesbian / Lesbienne I (August 1979 / December 1980)

Lesbian / Lesbienne 2 (October 1981)

Lesbian / Lesbienne I.4 (March) special issue March $27^{\text {th }}$ Day of Action against the

Right

Lesbian Perspective (March 1977)

Lesbian Perspective (July 1978)

Lesbian Perspective (September 1979)

Lesbian Perspective / Lavender Sheets (April 1980)

Lesbian Perspective (Summer 1980)

Long Time Coming 2.3 (January 1975)

Long Time Coming 2.4 (March 1975)

Long Time Coming 2.6 (May 1975)

Long Time Coming (January I975) special issue "Myth of Madness"

The Northern Woman (June 1973)

The Northern Woman 4 (September 1973)

The Northern Woman Io (June 1974)

The Northern Woman I3 (September 1974)

The Northern Woman I 2.I (July 1989)

The Other Woman I.I (May / June 1972)

The Other Woman 1.2

The Other Woman / Bellyfull / Velvet Fist (Winter 1972)

The Other Woman 4.4

The Pedestal I.I (Fall I969)

The Pedestal 5.I (1973)

Rebel Girl's Rag 2.I (November / December 1987)

Rebel Girl's Rag 6.2 (May / June I992)

Upstream 3.I (October I978)

Upstream 2.3 (April 1978

The Womanist (September / October 1988)

The Womanist (December I 988 / January 1989)

The Womanist (February / March 1989)

The Womanist 4.2 (Fall 1993) 
Appendix 2: List of Zines

Apt. s 2, by Sean Zio

Beautiful Mess o, by Sarala B.

Block Traffic! Block Prints, by Paula Belina

Curses 2, author unlisted

Curses 3, author unlisted

Curses 4, author unlisted

The Dyke-tionnary I, by Ina Julien

Electric Mayhem 2.3, by Sean Zio

Electric Maybem 3, by Sean Zio

Five Days Ago West, by Jon Sookocheff

Fun is Free (Association) 2, by Paula Belina

Ghost Pine Zine: Blood, by Jeff

A Guide to the Mannerly Wooing and Winning of the Object of Your Affection, by

Ms. Matilda Manners and Ms. Edwina Etiquette

Graceful Suicide o, by Adrian Fynch

Graceful Suicide 5, by Adrian Fynch

"Hitch Lifts West" in Gribeault 3, by Janardan

"Hitch Lifts West" in Gribeault 4, by Janardan

"Hitch Lifts West (A Year After)" in Gribeault 4, by Janardan

I Miss You, by Paula Belina

Kissoff Zine I I, by Chris Kiss

The Last Thumbnail Picture Show, by Adam Thomlison

Lickety Split, by Amber Goodwyn

"Marvelous World" in Gribeault 4, by Janardan

Matilda, by Jennifer

Matilda Zine: Special Neighborbood Issue, by Jennifer

The Miss G. Home for Wayward Jokes, by Yolumei

ReFuel: Veggie Recipes and Food for Thought, by Paula and Erica

Sewing the Seeds of Life, by Scott Gordon Towson

Sex and Robots Monthly 4 , author unlisted

Slightly More than Sound Bytes 2, by Jess

Slightly More than Sound Bytes 3, by Jess C.

Slightly More than Sound Bytes 4, by Jess

Stamp Carvings by Paula Belina, by Paula Belina

Status Seekers, by Rose and Anna

This is What She Said, by Megan Butcher

Travelling the Republic of Heaven, by Zio

The Trophy Wife, by Emily Armstrong

Underwater Cigarettes, author unlisted

The Unfortunate Social Incidences that Have Now Been Attributed to Lupix and

Vulpius and Other Things I, by Emily

Viva La Vulva, by The Clit Liberation Front

"What I Should Have Done" in Gribeault 4, by Kate Aley

Winter Chapter, by Amber Goodwyn

Yoga Moves for Dudes I, by J.G. Sookocheff

Zine-O-Phobia, author unlisted

Zines will Chang Your Life, by Sean Zio 
Appendix 3: Questionnaire

\section{Questionnaire}

This is a research study examining the role of zines in activism. I am considering how zines challenge aspects of Canadian culture and society. I am looking both at activist and non-activist zines. I am particularly interested in networks among zine creators, and if or how zine creators support each other's work.

Please contact me at any time if you have questions or concerns about the questionnaire or your participation. Please forward this questionnaire or my contact information to anyone else you think may be interested in participating. Please select the level of anonymity that you will allow for the final research project:

- The researcher may refer to me by my real full name.

- The researcher may refer to me by my real first name.

- The researcher may refer to me by the name I publish under.

- The researcher may refer to me as the author of the title of my zine.

- I want my answers to this questionnaire to be anonymous.

I. When did you first see or hear about a zine? Please describe this experience in detail.

2. When did you first produce your first zine?

3. How many zines and issues of each zine have you since produced?

4. What made you decide to make your own zine?

5. Who taught you the skills you use to make your zine?

6. Who encouraged you to make your zine?

7. What elements do other people participate in, or do you make your entire zine yourself?

8. Do you work on other people's zines? If so, which zines? What type of work or contribution do you do?

9. Have you encouraged others to make a zine? If so, how?

Io. Have you taught anyone the skills they need to make a zine? If so, what skills?

I I. Do you feel a sense of community with other zine producers in Ottawa, Canada, North America, worldwide? If so, please describe this community, and the networks it involves.

I 2. Where are your zines available?

13. Where do you send your zines?

I4. Where do you read zines from?

I 5 . What determines if you are interested in reading a zine? What types of zines or topics covered in zines are you particularly interested in reading?

I6. Do you consider yourself to be a feminist? If so, please define what feminist means to you.

17. Do you participate in feminist activism? If so, what types of activism? If not, do you participate in non-feminist activism? If so, what types of activism?

18. Do you see your zine as an element of feminist or non-feminist activism? If so, what role does your zine play in your activism?

19. Do you try to fulfil any larger social goals through zine publishing? If so, what goals?

20. What political, social or cultural impact do you think zines make? 


\section{Works Cited}

Adamson, Nancy, Linda Briskin and Margaret McPhail. Feminist Organizing for Change: The Contemporary Women's Movement in Canada. Toronto: Oxford University Press, I988.

Ahn, Christina. "Not Post-Feminism." Turbo Chicks: Talking Young Feminisms. Ed. Allyson Mitchell, Lisa Bryn Rundle and Lara Karaian. Toronto: Sumach Press, 2002. I I9-I 24.

Alcantara-Tan, Sabrina Margarita. “The Herstory of Bamboo Girl Zine.” Pinay Power: Peminist Critical Theory: Theorizing the Filipinal American Experience. Ed. Melinda L. de Jesús. New York; London: Routledge, 2005. 34I-349.

Andersen, Margaret L. Thinking About Women: Sociological Perspectives on Sex and Gender. 4th ed. Boston: Allyn and Bacon, 1997.

Andersen, Robin. "The Thrill is Gone: Advertising, Gender Representation, and the Loss of Desire." Sex and Money: Feminism and Political Economy in the Media. Eds. Eileen R. Meehan and Ellen Riordan. Minneapolis: University of Minnesota Press, 2002. 223-239.

Anderson, Benedict. Imagined Communities: Reflections on the Origin and Spread of Nationalism. $2^{\text {nd }}$ ed. London: Verso, I991.

Armstrong, David. A Trumpet to Arms: Alternative Media in America. Los Angeles: J.P. Tarcher, I98I.

Armstrong, Jayne. "Internet Forms and E-Zines." The Cyberspace Handbook. Ed. Jason Whittaker. London: Routledge, 2004. I7 I-I 88.

Armstrong, Jayne. "Web Grrrls, Guerrilla Tactics: Young Feminisms on the Web." Web.Studies. Ed. David Gauntlett and Ross Horsley. ${ }^{\text {nd }}$ ed. London: Edward Arnold, 2004. 92-102.

Arnould, Eric J. and Linda L. Price. "Authenticating Acts and Authoritative Performances: The Questing for Self and Community." The Why of Consumption: Contemporary Perspectives on Consumer Motives, Goals, and Desires. Ed. S. Ratneshwar, David Glen Mick and Cynthia Huffman. London: Routledge, 2000. I40-163.

Arthur, Nicole. "Rock Women.” Alt.Culture: An A-to-Z Guide to the 'gos Underground, Online, and Over-the-Counter. Ed. Nathaniel Wice and Steven Daly. New York: HarperCollins, 1995. 208-209.

Auletta, Ken. "Fourteen Truisms for the Communications Revolution." Media Studies Journal I0.2-3 (1996): 29-38. 
Austin, S. Bryn and Pam Gregg. “A Freak Among Freaks: The 'Zine Scene.” Sisters, Sexperts, Queers: Beyond the Lesbian Nation. Ed. Arlene Stein. New York: Plume, 1993. 8I-95.

Bacchi, Carol Lee. Liberation Deferred? The Ideas of the English-Canadian

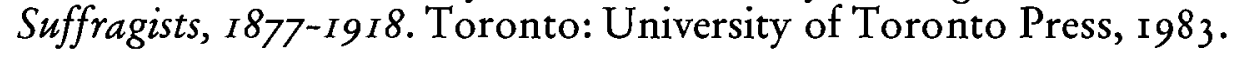

Bacon-Smith, Camille. Enterprising Women: Television Fandom and the Creation of Popular Myth. Philadelphia: University of Pennsylvania Press, 1992.

Bail, Kathy. DIY Feminism. NSW: Allen \& Unwin Australia, 1996.

Bailey, Steve and Anita Michel. "The Photocopied Self: Perzines, Self-Construction, and the Postmodern Identity Crisis." Reconstruction: Studies in Contemporary Culture 4.2 (2004): N. pag. 6 December 2007. $<$ http://reconstruction.eserver.org/042/bailey.htm>.

Barber, Benjamin R. Jihad vs. McWorld: How Globalism and Tribalism are Reshaping the World. New York: Times Books, 1995.

Baudrillard, Jean. "The System of Objects." Jean Baudrillard: Selected Writings. Trans. Jacques Mourrain. Ed. Mark Poster. Cambridge: Polity, I988. I3-3 I. Trans. of Le Système des Objets. Paris: Gallimard, I968.

Baudrillard, Jean. "Consumer Society." Jean Baudrillard: Selected Writings. Trans. Jacques Mourrain. Ed. Mark Poster. Cambridge: Polity, 1988. 32-59. Trans. of La Société de Consommation: Ses Mythes, ses Structures. Paris: Gallimard, I970.

Baudrillard, Jean. "The Masses: The Implosion of the Social in the Media." Cultural Resistance Reader. Ed. Stephen Duncombe. London: Verso, 2002. I00-I I 2.

Baumgardner, Jennifer and Amy Richards. Manifesta: Young Women, Feminism, and the Future. New York: Farrar, Straus and Giroux, 2000.

Baxandall, Rosalyn and Linda Gordon. Introduction. Dear Sisters: Dispatches from the Women's Liberation Movement. Ed. Rosalyn Baxandall and Linda Gordon. New York: Basic Books, 2000. I-18.

Beer, Amy. "Periodical Pleasures: Magazines for U.S. Latinas." Sex and Money: Feminism and Political Economy in the Media. Ed. Eileen R. Meehan and Ellen Riordan. Minneapolis: University of Minnesota Press, 2002. I64-I 80.

Bell, Brandi Leigh-Ann. "Women-Produced Zines: Moving into the Mainstream. Canadian Woman Studies 20.4/21.I (2001). 56-60.

Bell, Brandi Leigh-Ann. "Riding the Third Wave: Women-Produced Zines and Feminisms.” Resources for Feminist Research 29.3/4 (2002): 187-198. 
Bell, Diane and Renate Klein. "Foreword - Beware: Radical Feminists Speak, Read, Write, Organise, Enjoy Life, and Never Forget." Radically Speaking: Feminism Reclaimed. Ed. Diane Bell and Renate Klein. London: Zed Books, 1996. xvii-xxx.

Benjamin, Walter. "The Author as Producer." Cultural Resistance Reader. Ed. Stephen Duncombe. London: Verso, 2002.67-8I.

Bey, Hakim. "TAZ: The Temporary Autonomous Zone." Cultural Resistance Reader. Ed. Stephen Duncombe. London: Verso, 2002. I I 3-I I7.

Bhabha, Homi K. "The Commitment to Theory." The Location of Culture. London: Routledge, 1994. 19-39.

Bhabha, Homi K. "Dissemination: Time, Narrative and the Margins of the Modern Nation." The Location of Culture. London: Routledge, I994. I39-I70

Bhabha, Homi K. Public discussion with Jamelie Hassan and Monika Kin Gagnon. "Identity and Cultural Displacement." Art Gallery of Ontario, Toronto. 5 April I995. Aldin's Gift. Ed. Jamelie Hassan. North York: Art Gallery of York University; Windsor: Art Gallery of Windsor, 1996. 10-28.

Bhabha, Homi K. Interview with Jonathan Rutherford. "The Third Space: Interview with Homi Bhabha.” Identity: Community, Culture, Difference. London: Lawrence and Wishart, 1990. 207-221.

Bhabha, Homi K. Interview with W.J.T. Mitchell. "Translator Translated." Artforum 33.7 (1995): 80-83, I IO, I I 4, I I 8-I9.

Bloomberg, Kristin Mapel. "Cultural Critique and Consciousness Raising: Clara Bewick Colby's Woman's Tribune and Late-Nineteenth-Century Radical Feminism." Women in Print: Essays on the Print Culture of American Women from the Nineteenth and Twentieth Centuries. Ed. James P. Danky and Wayne A. Wiegand. Madison: University of Wisconsin Press, 2006. 27-63.

Brasile, Monica. "From Riot Grrrl to Mamagirl in Omaha, Nebraska." Canadian Woman Studies 20.4/21.I (200I). 63-68.

Brouwer, Daniel C. "Counterpublicity and Corporeality in HIV/AIDS Zines." Critical Studies in Media Communication 22.5 (2005): 35 I-37I.

Calixte, Shana L., Jennifer L. Johnson and J. Maki Motapanyane. "Liberal, Socialist, and Radical Feminism: An Introduction to Three Theories about Women's Oppression and Social Change." Feminist Issues: Race, Class, and Sexuality. Ed. Nancy Mandell. $4^{\text {th }}$ ed. Toronto: Pearson Prentice Hall, 2005. I-34.

Chidgey, Red. "The Resisting Subject: Per-Zines as Life Story Data." University of Sussex Journal of Contemporary History Io (2006): I-I 3 . 
Cleverdon, Catherine L. The Woman Suffrage Movement in Canada. Toronto: University of Toronto Press, 1974.

Collins, Dana. “'No Experts: Guaranteed!': Do-It-Yourself Sex Radicalism and the Production of the Lesbian Sex Zine 'Brat Attack.'” Signs 25.I (I 999): 65-89.

Crean, Susan. "Post-Feminism and Power Dressing: Who Says the Women's Movement Has Run out of Steam?" Twist and Shout: A Decade of Feminist Writing in This Magazine. Ed. Susan Crean. Toronto: Second Story Press, 1992. I 23-I33.

Curran, James. "Global Journalism: A Case Study of the Internet." Contesting Media Power: Alternate Media in a Networked World. Ed. Nick Couldry and James Curran. Oxford: Rowman \& Littlefield, 2003. 227-24I.

Davis, Heather. "Screaming as Loud as the Boys: Women in Punktopia." Turbo Chicks: Talking Young Feminisms. Ed. Allyson Mitchell, Lisa Bryn Rundle and Lara Karaian. Toronto: Sumach Press, 2002. 3 I 5-323.

Debord, Guy and Gil J. Wolman. "Methods of Detournement." Les Levres Nues 6 (September 1955). Rpt. in Situationist International Anthology. Ed. and trans. Ken Knabb. California: Bureau of Public Secrets, i 98 r. 8-I 4.

De Moor, Katrien. "Diseased Pariahs and Difficult Patients: Humour and Sick Role Subversions in Queer HIV/AIDS Narratives." Cultural Studies 19.6 (2005): 737-754.

"Detournement as Negation and Prelude." Internationale Situationniste 3 (December 1959). Rpt. in Situationist International Anthology. Ed. and trans. Ken Knabb. California: Bureau of Public Secrets, 198 I. 55-56.

Diaz, Angeli R. "Postcolonial Theory and the Third Wave Agenda." Women and Language 26.I (2003): 10-I7.

Downey, John and Natalie Fenton. "New Media, Counter Publicity and the Public Sphere." New Media and Society 5 (2003): I 85-202.

Downing, John and Rob Fasano, Patricia A. Friedland, Michael F. McCullough, Terry Mizrahi and Jeremy J. Shapiro. "Computers for Social Change: Introduction." Computers for Social Change and Community Organizing. Ed. John Downing, Rob Fasano, Patricia A. Friedland, Michael F. McCullough, Terry Mizrahi and Jeremy J. Shapiro. New York: Haworth, I99I. I-8.

Dreifus, Claudia. Woman's Fate: Raps from a Feminist Consciousness-Raising Group. New York: Bantam, 1973.

Driscoll, Catherine. "Girl Culture, Revenge and Global Capitalism: Cybergirls, Riot Grrls, Spice Girls." Australian Feminist Studies I 4.29 (1999): 173 -193. 
DuBois, Ellen. "The Nineteenth-Century Woman Suffrage Movement and the Analysis of Women's Oppression." Capitalist Patriarchy and the Case for Socialist Feminism. Ed. Zillah R. Eisenstein. New York: Monthly Review Press, I979. I $37^{-1} 50$.

Duncombe, Stephen. Introduction. Cultural Resistance Reader. Ed. Stephen Duncombe. London: Verso, 2002. I-16.

Duncombe, Stephen. "DIY Nike Style: Zines and the Corporate World." Z Magazine: A Political Monthly. December 1999. 6 December 2007. <www.zmag.org/ZMag/articles/deci 999duncombe.htm>.

Duncombe, Stephen. Introduction. "Jean Baudrillard, 'The Masses: The Implosion of the Social in the Media." Cultural Resistance Reader. Ed. Stephen Duncombe. London: Verso, 2002. I00-IOI.

Duncombe, Stephen. "Let's All Be Alienated Together: Zines and the Making of Underground Community." Generations of Youth: Youth Cultures and History in Twentieth-Century America. Ed. Joe Austin and Michael Nevin Willard. New York: New York University Press, I998. 427-452.

Duncombe, Stephen. Introduction. "Mixing Pop and Politics." Cultural Resistance Reader. Ed. Stephen Duncombe. London: Verso, 2002. 333.

Duncombe, Stephen. Notes from Underground: Zines and the Politics of Alternative Culture. London: Verso, 1997.

Duncombe, Stephen. Introduction. "Subcultures and Primitive Rebels." Cultural Resistance Reader. Ed. Stephen Duncombe. London: Verso, 2002. I 35 .

Duncombe, Stephen. Introduction. "Walter Benjamin, 'The Author as Producer."” Cultural Resistance Reader. Ed. Stephen Duncombe. London: Verso, 2002. 67-68.

Duncombe, Stephen. Introduction. “A Woman's Place.” Cultural Resistance Reader. Ed. Stephen Duncombe. London: Verso, 2002. 240.

Dworkin, Andrea. "Dworkin on Dworkin." Radically Speaking: Feminism Reclaimed.Ed. Diane Bell and Renate Klein. London: Zed Books, 1996. 203217.

Eichhorn, Kate. "Sites Unseen: Ethnographic Research in a Textual Community." Qualitative Studies in Education I4.4 (2002): 565-578.

Featherstone, Mike. Consumer Culture and Postmodernism. London: Sage, I99I.

Fejes, Fred. "Advertising and the Political Economy of Lesbian / Gay Identity." Sex and Money: Feminism and Political Economy in the Media. Eds. Eileen R. 
Meehan and Ellen Riordan. Minneapolis: University of Minnesota Press, 2002. 196-208.

Ferris, Melanie A. "Resisting Mainstream Media: Girls and the Act of Making Zines." Canadian Woman Studies 20/21.4/I (200I): 5I-55.

Ferree, Myra Marx and Beth B. Hess. Controversy and Coalition: The New Feminist Movement across Three Decades of Change. $3^{\text {rd }}$ ed. New York: Routledge, 2000.

Firat, A. Fuat and Nikhilesh Dholakia. Consuming People: From Political Economy to Theatres of Consumption. London: Routledge, 1998.

Fleras, Augie. "Please Adjust Your Set': Media and Minorities in a Multicultural Society." Communications in Canadian Society. Ed. B. D. Singer. $4^{\text {th }}$ ed. Scarborough: Nelson, 1995.

Flexner, Eleanor and Ellen Fitzpatrick. Century of Struggle: The Woman's Rights Movement in the United States. Enlarged ed. Cambridge: Belknap Press, 1959.

Frank, Thomas. "Why Johnny Can't Dissent." Cultural Resistance Reader. Ed. Stephen Duncombe. London: Verso, 2002. 316-326.

Friese, Susanne. Self-Concept and Identity in a Consumer Society: Aspects of Symbolic Product Meaning. Marburg: Tectum Verlag, 2000.

Gabriel, Yiannis and Tim Lang. The Unmanageable Consumer. ${ }^{\text {nd }}$ ed. London: Sage, 2006.

Ganley, Gladys D. The Exploding Political Power of Personal Media. Norwood: Ablex, 1992.

Garvey, Ellen Gruber. "Out of the Mainstream and into the Streets: Small Press Magazines, the Underground Press, Zines, and Artists' Books." Perspectives on American Book History: Artifacts and Commentary. Ed. Scott E. Casper, Joanne D. Chaison and Jeffrey D. Groves. Amherst: University of Massachusetts Press, 2002. 367-402.

Garrison, Ednie Kaeh. "U.S. Feminism - Grrrl Style! Youth (Sub)Cultures and the Technologies of the Third Wave." Feminist Studies 26.I (2000): I $4 \mathrm{I}-\mathrm{I} 72$.

Gillis, Stacy and Rebecca Munford. "Genealogies and Generations: The Politics and Praxis of Third Wave Feminism." Women's History Review I 3.2 (2004): 165I 82.

Gillett, James. "Media Activism and Internet Use by People with HIV/AIDS." Sociology of Health and Illness 25.6 (2003): 608-624. 
Glickman, Rose L. Daughters of Feminists. New York: St. Martin’s Press, 1993.

Grant, Ali. "Unwomanly Acts: Struggling over Sites of Resistance." New Frontiers of Space, Bodies and Gender. Ed. Rosa Ainley. London: Routledge, I998. 506I.

Graydon, Shari. "The Portrayal of Women in Media: The Good, the Bad, and the Beautiful." Communications in Canadian Society. Ed. Benjamin D. Singer. $4^{\text {th }}$ ed. Scarborough: Nelson Canada, I995. I43-17I.

Green, Karen and Tristan Taormino. Introduction. A Girl's Guide to Taking Over the World: Writings from the Girl Zine Revolution. Ed. Karen Green and Tristan Taormino. New York: St. Martin’s Griffin, I997 xi-xiv.

Gunderloy, Mike and Janice Cari Goldberg. The World of Zines: A Guide to the Independent Magazine Revolution. New York: Penguin, 1992.

Guzzetti, Barbara J and Margaret Gamboa. "Zines for Social Justice: Adolescent Girls Writing on Their Own." Reading Research Quarterly 39.4 (2004):408436.

Hackett, Robert, Richard Pinet and Myles Ruggles. "News for Whom? Hegemony and Monopoly Versus Democracy in Canadian Media." Seeing Ourselves: Media Power and Policy in Canada. Ed. Helen Holmes and David Taras. $2^{\text {nd }}$ ed. Toronto: Harcourt Brace, 1996. 257-272.

Hanna, Kathleen. Interview with Daniel Sinker. Punk Planet. Rpt. In Cultural Resistance Reader. Ed. Stephen Duncombe. London: Verso, 2002. I80-182.

Harris, Anita. "Not Waving or Drowning: Young Women, Feminism, and the Limits of the Next Wave Debate." Outskirts: Feminism Along the Edge 8 (200I): N. pag. 9 April 2008 <http://www.chloe.uwa.edu.au/outskirts/archive/volume8/harris>.

Harris, Anita. "Riding my Own Tidal Wave: Young Women's Feminist Work." Canadian Woman Studies 20/21.4/I (2001): 27-3I.

Heywood, Leslie and Jennifer Drake. Introduction. Third Wave Agenda: Being Feminist, Doing Feminism. Ed. Leslie Heywood and Jennifer Drake. Minneapolis: University of Minnesota Press, 1997. I-20.

Hogan, Rebecca. "Engendered Autobiographies: The Diary as a Ferminine Form.” Prose Studies: History, Theory, Criticism. I4.2 (1991): 95 -107.

Hole, Judith and Ellen Levine. Rebirth of Feminism. New York: Quadrangle, I97I. hooks, bell. Killing Rage: Ending Racism. New York: H. Holt, I995. hooks, bell. Teaching Community: A Pedagogy of Hope. New York: Routledge, 
2003 .

Howley, Kevin. “A Poverty of Voices.” Journalism 4.3 (2003): 273-292.

"The Importance of Media Education.” Media Awareness Network. 26 April 2008. $<$ http://www.mediaawareness.ca/english/issues/stereotyping/aboriginal_people/aboriginal_educ ation.cfm>.

Jacques, Alison. "You Can Run But You Can't Hide: The Incorporation of Riot Grrrl into Mainstream Culture." Canadian Woman Studies 20.4/2 I.I (200I): $46-50$.

Jerry, E. Claire. “The Role of Newspapers in the Nineteenth-Century Woman's Movement." A Voice of Their Own: The Woman Suffrage Press, I840-1910. Ed. Martha M. Solomon. Tuscaloosa: University of Alabama Press, I99 I. I729.

Johnson, Miriam. “Innocence Upstaged.” Turbo Chicks: Talking Young Feminisms. Ed. Allyson Mitchell, Lisa Bryn Rundle and Lara Karaian. Toronto: Sumach Press, 2002. 252-255.

Kearney, Mary Celeste. "Producing Girls: Rethinking the Study of Female Youth Culture." Delinquents and Debutantes: Twentieth-Century American Girls' Cultures. Ed. Sherrie A. Inness. New York: New York University Press, I 998. 285-3 Io.

Kelley, Robin D.G. “Race Rebels.” Cultural Resistance Reader. Ed. Stephen Duncombe. London: Verso, 2002. 96-98.

Kerr, Kandace. “Early Feminist Journalists.” Kinesis I I (1984): I I.

Kim, Marlene. "Poor Women Survey Poor Women: Feminist Perspectives in Survey Research.” Feminist Economics 3.2 (1997): 99-1 I7.

Klein, Melissa. "Duality and Redefinition: Young Feminism and the Alternative Music Community." Third Wave Agenda: Being Feminist, Doing Feminism. Ed. Leslie Heywood and Jennifer Drake. Minneapolis: University of Minnesota Press, I997. 207-225.

Knabb, Ken. Translator's Notes. Situationist International Anthology. Ed. and trans. Ken Knabb. California: Bureau of Public Secrets, I 981. 371-377.

Knobel, Michele and Colin Lankshear. "Cut, Paste, Publish: The Production and Consumption of Zines.” State of the Art Conference. Athens, Georgia. 25-28 January 200I. N. Pag.

Kramer, Felix. "Warm Hearts/Cold Type: Desktop Publishing Arrives.” Computers for Social Change and Community Organizing. Ed. John Downing, Rob 
Fasano, Patricia A. Friedland, Michael F. McCullough, Terry Mizrahi and Jeremy J. Shapiro. New York: Haworth, I99I. I I9-I 27.

Leonard, Marion. "Paper Planes: Travelling the New Grrrl Geographies." Cool Places: Geographies of Youth Cultures. Ed. Tracey Skelton and Gill Valentine. London: Routledge, I998. I0I-I I9.

Letherby, Gayle and Dawn Zdrwodowski. “'Dear Researcher' The Use of correspondence as a Method within Feminist Qualitative Research." Gender E Society 9.5 (1995): 576-593.

Licona, Adela C. “(B)orderlands' Rhetorics and Representations: The Transformative Potential of Feminist Third-Space Scholarships and Zines." NWSA Journal I7.2 (2005): 104-I 29.

Long, Thomas L. "Plague of Pariahs: AIDS 'Zines and the Rhetoric of Transgression." Journal of Communication Inquiry 24.2 (2000): 40I-4I I.

Lunt, Peter. "Psychological Approaches to Consumption: Varieties of Research Past, Present and Future." Acknowledging Consumption: A Review of New Studies. Ed. Daniel Miller. London: Routledge, I995. 238-263.

Mahood, Sally. "The Women's Suffrage Movement in Canada and Saskatchewan." Women Unite! An Anthology of the Canadian Women's Movement.

Toronto: Canadian Women's Educational Press, 1972. 22-27.

"Male Authority in the Media." Media Awareness Network. 26 April 2008. <http://www.mediaawareness.ca/english/issues/stereotyping/men_and_masculinity/masculinity _authority.cfm>.

McChesney, Robert W. "The Communication Revolution: The Market and the Prospect for Democracy." Democratizing Communication? Comparative Perspectives on Information and Power. Ed. Mashoed Bailie and Dwayne Winseck. Cresskill: Hampton, I997. 57-78.

McCullough, Michael F. "Democratic Questions for the Computer Age." Computers for Social Change and Community Organizing. Ed. John Downing, Rob Fasano, Patricia A. Friedland, Michael F. McCullough, Terry Mizrahi and Jeremy J. Shapiro. New York: Haworth, 199I. 9-I 8.

McDonough, Tom. "My Beautiful Language of My Century": Reinventing the Language of Contestation in Postwar France, 1945-1968. Cambridge: MIT Press, 2007.

McLuhan, Marhsall. The Mechanical Bride: Folklore of Industrial Man. I951. Corte Madera: Gingko Press, 2002.

McLuhan, Marshal and Quentin Fiore. The Medium is the Massage: An Inventory of 
Effects. New York: Bantam, 1967.

Mitchell, Allyson and Lara Karaian. "Third Wave Feminisms." Feminist Issues: Race, Class, and Sexuality. Ed. Nancy Mandell. $4^{\text {th }}$ ed. Toronto: Pearson Prentice Hall, 2005. 58-82.

Norris, Pippa. Digital Divide: Civic Engagement, Information Poverty, and the Internet Worldwide. Cambridge: Cambridge UP, $200 \mathrm{I}$.

Oliphant, Tami. "The Invisibility of the Alternative Press." Library Juice 5.I (2002) < http://www.libr.org/Juice/issues/vols/LJ_s.r.sup.html>.

Orr, Catherine M. "Charting the Currents of the Third Wave." Hypatia I2.3 (1997): 29-46.

Osler, Andrew M. "The Evolution of a National Press Policy: Ownership and Social Control in the I990s." Communications in Canadian Society. Ed. Benjamin D. Singer. $4^{\text {th }}$ ed. Scarborough: Nelson, I995. 29I-3 IO.

Passet, Joanne E. "Power through Print: Lois Waisbrooker and Grassroots Feminism." Women in Print: Essays on the Print Culture of American Women from the Nineteenth and Twentieth Centuries. Ed. James P. Danky and Wayne A. Wiegand. Madison: University of Wisconson Press, 2006. 229-250.

Piano, Doreen. "Congregating Women: Reading $3^{\text {rd }}$ Wave Feminist Practices in Subcultural Production." Rhizomes 4 (Spring 2002). 6 December 2007. < http://www.rhizomes.net/issue4/piano.html>. N. pag.

Piercy, Marge and Jane Freeman. Getting Together: How to Start a ConsciousnessRaising Group. Cape Cod: Cape Cod Women's Liberation, I972. 6 December 2007. $<$ http://research.umbc.edu/ korenman/wmst/crguide2.html>. N. pag.

Pinterics, Natasha. "Riding the Feminist Waves: In with the Third?" Canadian Woman Studies 20.4/2I.I (200I): I 5-2I.

Plant, Sadie. The Most Radical Gesture: The Situationist International in a Postmodern Age. London: Routledge, 1992.

Pooler, Jim. Why We Shop: Emotional Rewards and Retail Strategies. Westport: Praeger, 2003.

Pozner, Jennifer L. “The 'Big Lie': False Feminist Death Syndrome, Profit, and the Media." Catching a Wave: Reclaiming Feminism for the $2 I^{\text {st }}$ Century. Ed. Rory Dicker and Alison Piepmeir. Boston: Northeastern University Press, 2003. 31-56.

"Preamble to Aphra" Aphra I. I969. Rpt. in Ellen Gruber Garvey. "Out of the Mainstream and into the Streets: Small Press Magazines, the Underground 
Press, Zines, and Artists' Books.” Perspecitves on American Book History: Artifacts and Commentary. Ed. Scott E. Casper, Joanne D. Chaison and Jeffrey D. Groves. Amherst: University of Massachusetts Press, 2002. 367402.

Rauch, Jennifer. "Hands-On Communication: Zine Circulation Rituals and the Interactive Limitations of Web Self-Publishing." Popular Communication 2.3 (2004): I $53-169$.

Ray, Janet. Towards Women's Rights. Toronto: Grolier, I98I.

Reinharz, Shulamit and Lynn Davidman. Feminist Methods in Social Research. Oxford: Oxford University Press, 1992.

Reynolds, Simon and Joy Press. The Sex Revolts: Gender, Rebellion, and Rock ' $n$ ' Roll. Cambridge: Harvard University Press, I995.

Ritzer, George. Explorations in the Sociology of Consumption: Fast Food, Credit Cards and Casinos, London: Sage, 200I.

Riordan, Ellen and Eileen R. Meehan. Introduction. Sex and Money: Feminism and Political Economy in the Media. Minneapolis: University of Minnesota Press, 2002.

Riot Grrrl. "Riot Grrrl is..." Cultural Resistance Reader. Ed. Stephen Duncombe. London: Verso, 2002. I78-I79.

Robbins, Trina. From Girls to Grrrlz: A History of Women's Comics from Teens to Zines. San Francisco, California: Chronicle Books, 1999.

Robinson, Gertrude J. and Armande Saint-Jean. "From Flora to Kim: Thirty Years of Representation of Canadian Women Politicians." Seeing Ourselves: Media Power and Policy in Canada. Ed. Helen Holmes and David Taras. ${ }^{\text {nd }}$ ed. Toronto: Harcourt Brace, 1996. 23-36.

Romanesko, Jim. "Fanzines Explained.” American Journalism Review. 1995. N. pag.

Ross, Karen. "Selling Women (Down the River): Gendered Relations and Political Economy of Broadcast News." Sex E Money: Feminism and Political Economy in the Media. Ed. Eileen R. Meehan and Ellen Riordan. Minneapolis: University of Minnesota Press, 2002. I I 2-I 29.

Roth, Lorna. "Northern Voices and Mediating Structures: First People's Television Broadcasting North of 60." Seeing Ourselves: Media Power and Policy in Canada. Ed. Helen Holmes and David Taras. $2^{\text {nd }}$ ed. Toronto: Harcourt Brace, I996. I73-I9I.

Sadlier, Rosemary. Mary Ann Shadd: Publisher, Editor, Teacher, Lawyer, Suffragette. Toronto: Umbrella Press, I995. 
Samek, Toni. "Unbossed and Unbought: Booklegger Press, the First WomenOwned American Library Publisher." Women in Print: Essays on the Print Culture of American Women from the Nineteenth and Twentieth Centuries. Ed James P. Danky and Wayne A. Wiegand. Madison: University of Wisconsin Press, 2006. I 26- I 55.

Schilt, Kristen. "I'll Resist with Every Inch and Every Breath": Girls and Zine Making as a Form of Resistance." Youth and Society 35 (2003): 7 I-97.

Schilt, Kristen. "'A Little Too Ironic': The Appropriation and Packaging of Riot Grrrl Politics by Mainstream Female Musicians." Popular Music and Society 26.I (2007): 5-I6.

Scott-Dixon, Krista. "Ezines and Feminist Activism: Building a Community." Resources for Feminist Research 27.I/2 (I999): I $27-132$.

Scott-Dixon, Krista. "The All-Girl On-Line Revolution." Herizons I 5.I (200I): 2426.

Sinha, Nikhil and Allucquére Rosanne Stone. "Computers and Communication." Questioning the Media. John Downing, Ali Mohammadi and Annabelle sreberny-Mohammadi, Eds. Thousand Oaks: Sage, r995.

Sinor, Jennifer. "Another form of Crying: Girls Zines as Life Writing." Prose Studies 26.I-2 (2003): 240-264.

Smith, Matthew J. "Strands in the Web: Community-Building Strategies in Online Fanzines." Journal of Popular Culture 33.2 (1999): 87-99.

Solomon, Martha M. "The Role of the Suffrage Press in the Women's Rights Movement." A Voice of Their Own: The Woman Suffrage Press, I840-19I0. Ed. Martha M. Solomon. Tuscaloosa: University of Alabama Press, I 99I. II6.

Solomon, Michael R, Judith L. Zaichkowsky and Rosemary Polegato. Consumer Behaviour: Buying, Having and Being. Toronto: Prentice Hall, 2002.

Spencer, Amy. DIY: The Rise of Lo-Fi Culture. London: Marion Boyars Publishers, 2005.

Steenbergen, Candis. "Feminism and Young Women: Alive and Well and Still Kicking." Canadian Woman Studies 20/21.4/I (200I): 6-1 4.

Steenbergen, Candis. “Talkin' 'Bout Whose Generation?!” Turbo Chicks: Talking Young Feminisms. Ed. Allyson Mitchell, Lisa Bryn Rundle and Lara Karaian. Toronto: Sumach, 2001. 256-272.

Stokes, Ashli Quesinberry. “Constituting Southern Feminists: Women’s Liberation 
Newsletters in the South." Soutbern Communication Journal 70.2 (2005): 91I08.

Taras, David. Power \& Betrayal in the Canadian Media. Peterborough, Ontario: Broadview Press, 1999.

Taras, David. "Swimming Against the Current: American Mass Entertainment and Canadian Identity." Canada and the United States: Differences that Count. Ed. David M. Thomas. $2^{\text {nd }}$ ed. Peterborough: Broadview Press, 2000. 192208.

Thompson, Craig J. "Postmodern Consumer Goals Made Easy!!!!” The Why of Consumption: Contemporary Perspectives on Consumer Motives, Goals, and Desires. Ed. S. Ratneshwar, David Glen Mick and Cynthia Huffman. London: Routledge, 2000. I 20-I 39.

Thompson, Craig J. and Tambyah Siok Kuan. "Special Session Summary of "Rethinking Theories of "Consumer Culture" Through Postmodern Analyses of Consumption and the Production of Hybrid Cultural Forms."” Advances in Consumer Research 25 (1998): 58-59.

Thompson, Stacy. Punk Productions: Unfinished Business. Albany: State University of New York Press, 2004.

Tuchman, Gaye. "Women's Depiction by the Mass Media." Signs 4.3 (1979): 528542.

Vale, V. Introduction. Zines! Volume I. By Vale. Ed. V. Vale. San Francisco: V / Search, $1996.4-5$.

Veblen, Thorstein. The Theory of the Leisure Class: An Economic Study of Institutions. I899. New York: Augustus M Kelley, I965.

Viénet, René. "The Situationists and the New Forms of Action Against Politics and Art." Internationale Situationniste I I (October 1967). Rpt in Situationist International Anthology. Ed. and trans. Ken Knabb. California: Bureau of Public Secrets, I981. 213-216.

Villacorta, Claire. "Where's the Riot? Girl Zinesters and Girl Scenesters in the Philippines." Sapling Thoughts 4 (2001): N. pag.

Vipond, Mary. Listening In: The First Decade of Canadian Broadcasting, 19221932. Montreal; Kingston: McGill-Queen's UP, 1992.

Vipond, Mary. The Mass Media in Canada. $2^{\text {nd }}$ ed. Toronto: James Lorimer \& Company, 1992.

Vipond, Mary. The Mass Media in Canada. 3 rd ed. Toronto: James Lorimer \& Company, 2000. 
Walcott, Rinaldo. "'Who is She and What is She to You?': Mary Ann Shadd Cary and the (Im)possibility of Black/Canadian Studies." Rude. Ed. Rinaldo Walcott. Toronto: Insomniac Press, 2000. 27-47.

Wald, Gayle. "Just a Girl? Rock Music, Feminism, and the Cultural Construction of Female Youth." Signs 23.3 (1998): 58 5-6ro.

Warde, Allen. Consumption, Food and Taste: Culinary Antinomies and Commodity Culture. London: Sage, 1997.

Weinstein, Matthew. "Randomized Design and the Myth of Certain Knowledge: Guinea Pig Narratives and Cultural Critique." Qualitative Inquiry I0.2 (2004): 246-260.

Wertham, Fredric. The World of Fanzines: A Special Form of Communication. Carbondale; Edwardsville: Southern Illinois University Press, 1973.

Wieloch, Neil. "Collective Mobilization and Identity From the Underground: The Deployment of 'Oppositional Capital' in the Harm Reduction Movement." The Sociological Quarterly 43.I (2002): 45-72.

Willis, Ellen. "Radical Feminism and Feminist Radicalism." Social Text 9/10 (1984): 9I-II 8 .

Winter, James. Democracy's Oxygen: How Corporations Control the Neres. Montreal: Black Rose Books, 1997. 